\title{
DATA PACKET FOR THE FRIT 202-A11 - SB3 GLASS SYSTEM: A Candidate for the Cold Crucible Induction Melter (CCIM) Demonstration
}

D.K. Peeler

K.M. Fox

T.B. Edwards

D.R. Best

I.A. Reamer

R.J. Workman

June 2007

Process Science and Engineering Section Savannah River National Laboratory Aiken, SC 29808 
WSRC-STI-2007-00302

Revision 0

\section{DISCLAIMER}

This report was prepared by Washington Savannah River Company (WSRC) for the United States Department of Energy under Contract No. DE-AC09-96SR18500 and is an account of work performed under that contract. Neither the United States Department of Energy, nor WSRC, nor any of their employees makes any warranty, expressed or implied, or assumes any legal liability or responsibility for the accuracy, completeness, or usefulness, of any information, apparatus, or product or process disclosed herein or represents that its use will not infringe privately owned rights. Reference herein to any specific commercial product, process, or service by trademark, name, manufacturer or otherwise does not necessarily constitute or imply endorsement, recommendation, or favoring of same by WSRC or by the United States Government or any agency thereof. The views and opinions of the authors expressed herein do not necessarily state or reflect those of the United States Government or any agency thereof.

\section{Printed in the United States of America \\ Prepared For U.S. Department of Energy}

The Savannah River National Laboratory is operated for the U.S. Department of Energy by Washington Savannah River Company. 
Keywords: high level waste, glass, cold crucible induction melter

Retention: permanent

\section{DATA PACKET FOR THE FRIT 202-A11 - SB3 GLASS SYSTEM: A Candidate for the Cold Crucible Induction Melter (CCIM) Demonstration}

D.K. Peeler

K.M. Fox

T.B. Edwards

D.R. Best

I.A. Reamer

R.J. Workman

June 2007

Process Science and Engineering Section Savannah River National Laboratory Aiken, SC 29808 
WSRC-STI-2007-00302

Revision 0

\section{REVIEWS AND APPROVALS}

\section{AUTHORS:}

D.K. Peeler, Process Science and Engineering Section Date

K.M. Fox, Materials Science and Technology Section Date

T.B. Edwards, Statistical Consulting Section Date

D.R. Best, Process Science and Engineering Section Date

I.A. Reamer, Process Science and Engineering Section Date

R.J. Workman, Process Science and Engineering Section Date

\section{TECHNICAL REVIEWER:}

M.E. Smith, Process Science and Engineering Section Date

\section{APPROVERS:}

R.E. Edwards, Manager, Process Science and Engineering Section Date

C.C. Herman, Manager, Process Engineering Technology Group Date 
WSRC-STI-2007-00302

Revision 0

\section{EXECUTIVE SUMMARY}

A demonstration of the Cold Crucible Induction Melter (CCIM) technology is currently planned for the fall of 2007 to assess the potential for attaining higher waste throughputs as compared to joule heated melter technology. The CCIM demonstrations will be based on a Defense Waste Processing Facility (DWPF) waste slurry feed surrogate with a nominal operating temperature of approximately $1250^{\circ} \mathrm{C}$ (higher temperatures may be used). The waste slurry feed (nominally 45 50 weight percent solids) surrogate will be representative of Sludge Batch 3 (SB3) in order to allow a direct comparison to the DWPF joule heated melter performance during processing of this sludge waste. This pilot scale demonstration is being conducted to evaluate performance and to identify potential processing issues with the existing CCIM technology, and it will include characterization of the resultant glass product to ensure current product performance (durability) specifications are met.

The information presented in this data packet provides a technical basis from which decisions regarding the melter demonstration can be made. More specifically, the results presented in this report provide technical data on the impact of waste loading (WL) on critical properties of interest - in particular, durability, liquidus temperature, and viscosity.

All of the glasses of this study, regardless of heat treatment, were acceptable when their durabilities were compared to those of the Environmental Assessment (EA) glass. In general, as WL increases, the durabilities for the quenched versions of the glasses tend to decrease due to the changing composition of the glass. For the glasses subjected to the canister centerline cooling (ссc) regime, the durability response appears to be more non-linear as WL increases. At WLs less than 50\%, X-ray diffraction (XRD) analysis indicates the potential for the presence of aegirine and/or nepheline crystalline phases, and when these phases are present, there is a decrease in the durability of the glass. As WL is increased above $50 \%$, there is a transition from the aegirine and/or nepheline phases to a spinel phase field leading to more durable glasses.

The results for durability suggest that WLs of $50 \%$ or greater should be targeted for the CCIM demonstration, thus, avoiding the potential for the formation of aegirine and/or nepheline. However, if decisions to target WLs of $50 \%$ or greater are made, liquidus temperature $\left(T_{L}\right)$ measurements indicate that there could be some degree of crystallization within the melter if a nominal $1250^{\circ} \mathrm{C}$ temperature is used. It is also anticipated that increasing WLs will lead to higher $\mathrm{T}_{\mathrm{L}}$ 's. Specifically, the $\mathrm{T}_{\mathrm{L}}$ of the $50 \% \mathrm{WL}$ glass (HTLG-21) was measured to be slightly above $1250^{\circ} \mathrm{C}$. To minimize the potential of crystallization during processing, higher melt temperatures could be targeted which not only could allow for higher WLs to be obtained but will also result in a reduction in viscosity, which in itself could pose certain processing issues (the ability to control the pour and the possibility of increased volatility). The viscosity of the $50 \% \mathrm{WL}$ glass at $1250^{\circ}$ and $1300^{\circ} \mathrm{C}$ was measured to be 20 and 13 Poise, respectively. Thus, a balance between processing and product performance issues may be required for the initial CCIM demonstrations since the frit development efforts to date were not necessarily intended to optimize this glass system nor have these efforts accounted for the variation from the intended target that is likely to occur in the composition of the waste slurry feed surrogate that is being used in the study. 


\section{Table of Contents}

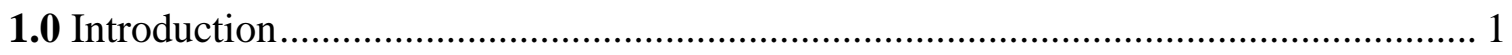

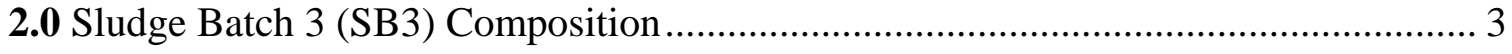

3.0 Candidate Frit Compositions and Various Predicted Properties..................................... 4

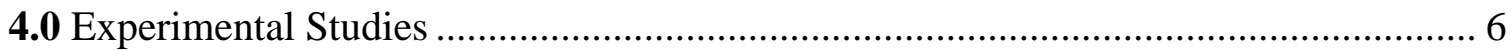

4.1 Target Compositions and Glass Fabrication .......................................................... 6

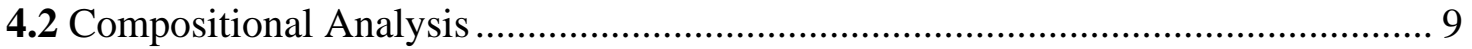

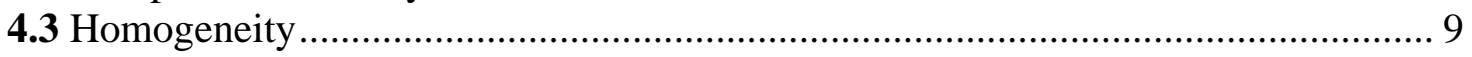

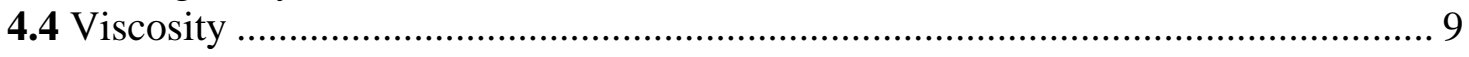

4.5 Liquidus Temperature................................................................................... 10

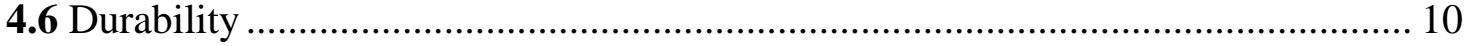

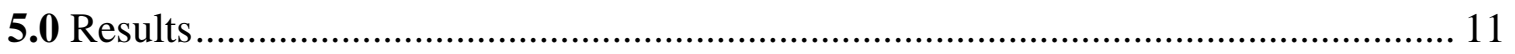

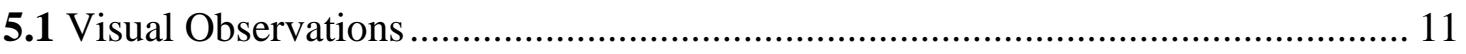

5.1.1 Quenched Glasses ...................................................................................... 11

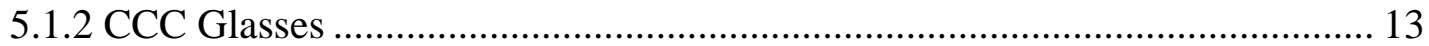

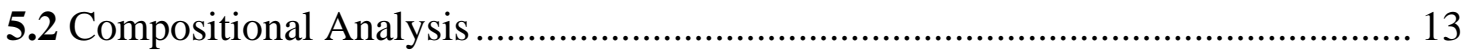

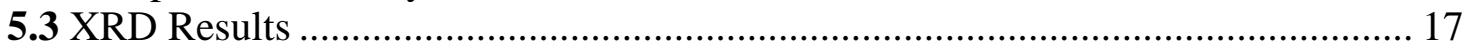

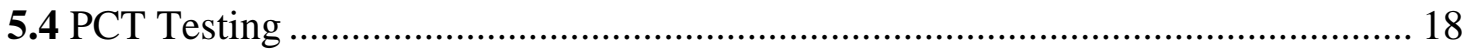

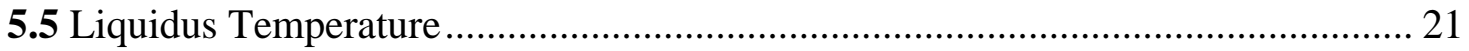

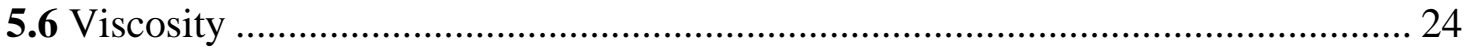

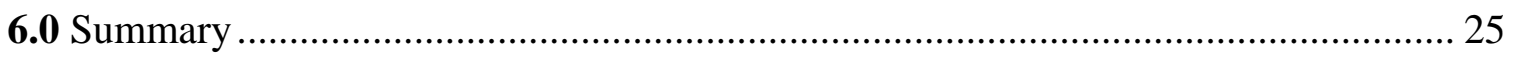

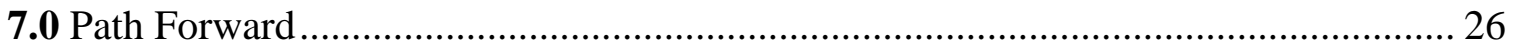

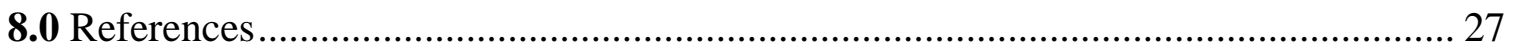

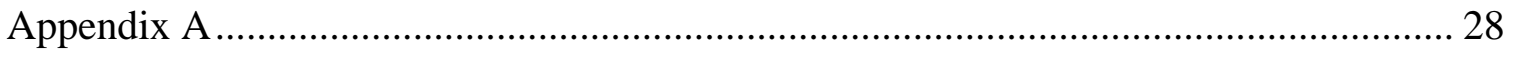

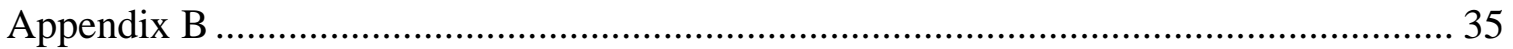

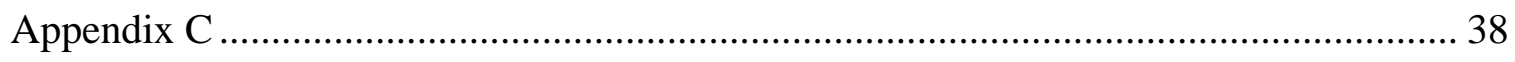




\section{List of Tables}

Table 1. Nominal SB3 Simulant Composition. 3

Table 2. Nominal Composition (wt\%) of Frit 202-A11. 4

Table 3. Target Compositions for Initial Series of 202-A11 Based Glasses

Targeting 45, 50, and 55\% Waste Loading. 7

Table 4. Target Compositions of the Second Series ("WL Series") of Frit 202-A11 Based Glasses.

Table 5. Visual Observations of 202-A11 Based HTLG Quenched and CCC Glasses.

Table 6. Target Versus Measured Compositions for the Initial Series of 202-A11 Based Glasses.

Table 7. Target Versus Measured Compositions for WL Series of 202-A11 Based Glasses.

Table 8. XRD Results for 202-A11 Based Glasses.

Table 9. PCT Results of Quenched and CCC Glasses. 19

Table 10. Measured Viscosity Data as a Function of Temperature for HTLG-21. 24

\section{List of Figures}

Figure 1. PCT Response (NL [B]) as a Function of WL for the Quenched HTLG Glasses.

Figure 2. PCT Response (NL [B]) as a Function of WL for the CCC HTLG Glasses.

Figure 3. Optical Micrograph of the 202-A11 at 50\% WL (HTLG-21) after a 24 hour, $1150^{\circ} \mathrm{C}$ Heat Treatment. Photo taken near the crucible bottom at $100 x$.

Figure 4. Optical Micrograph of the 202-A11 at 50\% WL (HTLG-21) after a 24 hour, $1200^{\circ} \mathrm{C}$ Heat Treatment. Photo taken of bulk sample at 500x.

Figure 5. Optical Micrograph of the 202-A11 at 50\% WL (HTLG-21) after a 24 hour, $1250^{\circ} \mathrm{C}$ Heat Treatment. Photo taken of bulk sample (near crucible bottom) at $1000 \mathrm{x}$. 


\section{LIST OF ABBREVIATIONS}

$\begin{array}{ll}\text { AD } & \text { Analytical Development } \\ \text { ARM } & \text { Approved Reference Material } \\ \text { ASTM } & \text { American Society of Testing and Materials } \\ \text { cCC } & \text { Canister Centerline Cooling } \\ \text { CCIM } & \text { Cold Crucible Induction Melter } \\ \text { DOE } & \text { Department of Energy } \\ \text { DWPF } & \text { Defense Waste Processing Facility } \\ \text { EA } & \text { Environmental Assessment } \\ \text { EDS } & \text { Energy dispersive spectroscopy } \\ \text { HTLG } & \text { High temperature liquidus glasses } \\ \text { ICP-AES } & \text { Inductively Coupled Plasma-Atomic Emission } \\ \text { JHM } & \text { Spectroscopy } \\ \text { LM } & \text { Joule heated melter } \\ \text { PCT } & \text { Lithium metaborate } \\ \text { PF } & \text { Product Consistency Test } \\ \text { PSAL } & \text { Peroxide fusion } \\ \text { SB3 } & \text { Process Science Analytical Laboratory } \\ \text { SEM } & \text { Sludge Batch 3 } \\ \text { SRNL } & \text { Scanning Electron Microscopy } \\ \text { SRS } & \text { Savannah River National Laboratory } \\ T_{L} & \text { Savannah River Site } \\ \eta & \text { Liquidus temperature } \\ \text { WAPS } & \text { viscosity } \\ \text { WL } & \text { Waste Acceptance Product Specifications } \\ \text { XRD } & \text { waste loading } \\ & \text { X-ray diffraction } \\ & \end{array}$


WSRC-STI-2007-00302

Revision 0

\subsection{Introduction}

Initial operations at the Defense Waste Processing Facility (DWPF) targeted a nominal waste loading of $28 \%$ (on a calcined oxide basis). Based on strategic glass formulation approaches and physical improvements to the Joule Heated Melter (JHM) system, recent operations with Sludge Batch 3 (SB3) have transitioned to a nominal waste loading of 38\%. Although this has lead to a significant increase in the waste throughput for the site, additional increases are possible by coupling advanced melter technologies with glass formulation efforts. More specifically, advancements in melter technology have the potential to produce glass faster and at higher waste loadings relative to current operations - primary parameters in the waste throughput equation. One of these technologies is the Cold Crucible Induction Melter (CCIM) with bubbler and/or mechanical agitation. Additional improvements in waste loading and/or melt rate relative to current operations will have a dramatic, positive impact on the life-cycle costs for the Department of Energy (DOE) at the Savannah River Site (SRS).

A demonstration of the CCIM technology is currently planned for the fall of 2007 to assess the potential for attaining higher waste throughputs. The CCIM demonstrations will be based on a DWPF waste slurry feed surrogate with a nominal operating temperature of approximately $1250^{\circ} \mathrm{C}$ (higher temperatures may be used). The waste slurry feed (nominally 45 - 50 weight percent solids) surrogate will be representative of SB3 in order to allow a direct comparison to the DWPF joule heated melter performance during processing of this sludge waste. This pilot scale demonstration is being conducted to evaluate performance and identify potential processing issues with the existing CCIM technology and will include characterization of the resultant glass product to ensure current product performance (durability) specifications are met.

The glass product will be a high waste loading (about 50\%, based on a calcined oxide basis) borosilicate glass and must meet current requirements for disposal at a Federal Repository. Specifically, the Waste Acceptance Product Specifications (WAPS Specification 1.3) define acceptance through the use of the American Society of Testing Materials (ASTM) Product Consistency Test (PCT) as the measure of waste form performance or durability (ASTM 2002). Acceptance relies upon the mean leachate concentrations of lithium, sodium and boron (after normalization for the glass composition) being less than those of the Environmental Assessment (EA) benchmark glass (Janzten et al. 1993).

In addition to the glass or waste form acceptance criteria, process criteria through CCIM are also important from a glass formulation perspective. Criteria associated with the liquidus temperature $\left(T_{L}\right)$, viscosity $(\eta)$, and electrical conductivity (or its inverse, resistivity) are critical parameters to ensure acceptable processing of the glass through the melter. It should be noted that the specifications associated with product performance (WAPS Specification 1.3) are clearly defined and can be addressed through standard testing protocols (i.e., the PCT). Although DWPF does have specific processing constraints (e.g., viscosity $(\eta)$ at $1150^{\circ} \mathrm{C}$ is between $20-110$ Poise and liquidus temperature $\left(\mathrm{T}_{\mathrm{L}}\right)$ is less than $1050^{\circ} \mathrm{C}$ not accounting for uncertainties) for the current $\mathrm{JHM}$, the processing constraints of the CCIM are not as clearly defined or understood by Savannah River National Laboratory (SRNL).

Historically, glass formulation efforts have balanced processing and product performance criteria to ensure a successful melter demonstration or to meet programmatic objectives. To support the CCIM pilot scale demonstration, the SRNL performed a series of preliminary assessments and scoping tests which led to the identification of a candidate glass forming system (Peeler 2007). 
The preliminary glass formulation work included a series of paper study assessments in which the current DWPF process control models were used to guide glass formulation efforts - specifically the identification of candidate glass forming systems that may allow programmatic objectives to be met. Through this study, candidate frits were identified which led to acceptable predicted properties based on certain process criteria established for the CCIM technology. Based on that assessment, glasses were fabricated, characterized, and tested to compare model predictions with actual, measured properties. The resulting glass data were summarized by Peeler (2007) from which a primary candidate frit was identified for further characterization. The primary frit is referred to as Frit 202-A11.

Given the identification of Frit 202-A11 as the preferred frit, supplemental information has been developed to provide a technical basis from which a decision regarding the melter demonstration can be made. More specifically, the results presented in this report provide technical data on the impact of waste loading (WL) on critical properties of interest. This report documents the compositional and physical property information associated with a series of Frit 202-A11 based SB3 glasses. The results of two specific series of glasses will be discussed. First, three glasses targeting 45, 50, and 55\% WL were fabricated and characterized as part of a frit down-select process. In the second series (referred to as the "waste loading series"), eight Frit 202-A11 based glasses were produced and characterized targeting WLs from $44-58 \%$ in $2 \%$ increments. The primary intent of this second series was to provide a finer WL grid from which trends of critical properties could be assessed and decisions regarding the targeted WL could be made. Although the two series are discussed independently, obviously there is overlap between the two which will provide a measure of reproducibility or sensitivity of the glass forming system to critical processing and performance properties of interest.

The information is presented to serve as a technical database from which future data needs can be determined to support the CCIM demonstration as well as to ensure that the properties associated with the glasses are acceptable from the CCIM processing perspective. It should be noted that the frit development activities associated with this program should not be considered optimized. This latter statement is based on the fact that the formulation efforts were performed over a limited time interval to support the programmatic schedule. In addition, applying the current DWPF process control models to the compositional region of interest may lead to the determination of general trends but may not provide as accurate of information that would be required to adequately lower risk for the demonstration. The intent of the glass formulation effort is to provide a technical basis from which the programmatic objectives can be met, that is, demonstrating that the CCIM technology has the potential to increase waste loading and/or melt rate for DWPF-type sludges - not an optimized system. 


\subsection{Sludge Batch 3 (SB3) Composition}

Table 1 summarizes the nominal SB3 simulant (non-radioactive) composition being used to support the glass formulation studies. This composition is based on the analytical data reported by the DWPF during processing of SB3 and represents a "running average" (renormalized after removing $\mathrm{U}_{3} \mathrm{O}_{8}$ and $\mathrm{ThO}_{2}$ ). ${ }^{1}$ It is recognized that the removal of $\mathrm{U}_{3} \mathrm{O}_{8}$ from the composition and the renormalization do increase the concentration of the other components. That being said, the primary concern with this renormalization process is the relative increase in the $\mathrm{Fe}_{2} \mathrm{O}_{3}, \mathrm{NiO}$, and $\mathrm{Cr}_{2} \mathrm{O}_{3}$ values as these components are spinel formers, and it is anticipated that spinel formation (or liquidus temperature) will be a significant technical issue for processing of SB3 at WLs of $50 \%$ or greater. The artificial increase in these components and the targeting of higher WLs should increase the propensity of spinel formation. It should be noted that the $\mathrm{SO}_{4}$ concentration was fixed at $0.719 \mathrm{wt} \%$ (not renormalized).

Table 1. Nominal SB3 Simulant Composition.

\begin{tabular}{||l|c||}
\hline Oxide & $\begin{array}{c}\mathrm{Wt} \% \\
\text { (calcined } \\
\text { oxide basis) }\end{array}$ \\
\hline $\mathrm{Al}_{2} \mathrm{O}_{3}$ & 16.898 \\
\hline $\mathrm{CaO}$ & 3.305 \\
\hline $\mathrm{Cr}_{2} \mathrm{O}_{3}$ & 0.192 \\
\hline $\mathrm{CuO}$ & 0.075 \\
\hline $\mathrm{Fe}_{2} \mathrm{O}_{3}$ & 37.302 \\
\hline $\mathrm{K}_{2} \mathrm{O}$ & 0.339 \\
\hline $\mathrm{MgO}$ & 3.813 \\
\hline $\mathrm{MnO}$ & 7.085 \\
\hline $\mathrm{Na}_{2} \mathrm{O}$ & 24.174 \\
\hline $\mathrm{NiO}$ & 1.921 \\
\hline $\mathrm{SiO}_{2}$ & 3.940 \\
\hline $\mathrm{TiO}_{2}$ & 0.057 \\
\hline $\mathrm{SO}_{4}$ & 0.719 \\
\hline $\mathrm{ZrO}_{2}$ & 0.184 \\
\hline & 100.000 \\
\hline
\end{tabular}

\footnotetext{
${ }^{1}$ The $\mathrm{U}_{3} \mathrm{O}_{8}$ concentration in SB3 was approximately $9 \mathrm{wt} \%$ (on a calcined oxide basis). $\mathrm{ThO}_{2}$ was less than $0.5 \mathrm{wt} \%$.
} 
WSRC-STI-2007-00302

Revision 0

\subsection{Candidate Frit Compositions and Various Predicted Properties}

Based on preliminary model assessments as well as initial scoping tests which generated select physical property data, Frit 202-A11 was identified as the primary candidate for processing SB3 through the CCIM technology at an $\sim 50 \% \mathrm{WL}$. Table 2 summarizes the nominal composition of Frit 202-A11 (wt\%, calcined oxide basis).

Table 2. Nominal Composition (wt\%) of Frit 202-A11.

\begin{tabular}{||c|c|c|c|c||}
\hline Frit ID & $\mathrm{B}_{2} \mathrm{O}_{3}$ & $\mathrm{Li}_{2} \mathrm{O}$ & $\mathrm{Na}_{2} \mathrm{O}$ & $\mathrm{SiO}_{2}$ \\
\hline 202-A11 & 9 & 6 & 3 & 82 \\
\hline
\end{tabular}

For the nominal 50\% WL target, current DWPF process control model predictions for viscosity $(\eta)$ and liquidus temperature $\left(T_{L}\right)$ for the $202-A 11$ based glass are $1135^{\circ} \mathrm{C}$ and 33 Poise (at $1150^{\circ} \mathrm{C}$ ), respectively. It is noted that the use of the current DWPF process control models provided guidance in terms of selecting or identifying candidate frits but were used with some caution given the potential for extrapolation - especially for liquidus temperature predictions. ${ }^{2}$ Consider the compositional range for $\mathrm{Fe}_{2} \mathrm{O}_{3}$ and $\mathrm{MnO}$ over which the $\mathrm{T}_{\mathrm{L}}$ model was developed: $\sim 3.5$ to $\sim 17 \mathrm{wt} \%$ in glass for $\mathrm{Fe}_{2} \mathrm{O}_{3}$ and $\sim 0.7$ to $3.25 \mathrm{wt} \%$ in glass for $\mathrm{MnO}$. With the renormalization of the SB3 composition once uranium and thorium were removed, the nominal $\mathrm{Fe}_{2} \mathrm{O}_{3}$ and $\mathrm{MnO}$ concentrations in sludge are 37.3 and $7.1 \mathrm{wt} \%$, respectively. At 50\% WL, the projected $\mathrm{Fe}_{2} \mathrm{O}_{3}$ and $\mathrm{MnO}$ concentrations in glass would be approximately 18.7 and $3.6 \mathrm{wt} \%$ exceeding the upper limits for which the $\mathrm{T}_{\mathrm{L}}$ model was developed. This may lead to biased $\mathrm{T}_{\mathrm{L}}$ predictions (as will be shown). The current DWPF $\mathrm{T}_{\mathrm{L}}$ model provided insight into the relative differences among various frit compositions but the actual predicted values were found to be less than conservative and hence should be used with caution in future formulation work.

It is also noted that certain DWPF model predictions are not in-line with the nominal operating conditions proposed by the current CCIM task. More specifically, the nominal melt temperature for the CCIM is anticipated to be $\sim 1250^{\circ} \mathrm{C}$ compared to the nominal DWPF melt temperature of $1150^{\circ} \mathrm{C}$. The DWPF model predictions for viscosity are based on, or predicted at, $1150^{\circ} \mathrm{C}-$ not $1250^{\circ} \mathrm{C}^{3}$

Consider the impact of these two properties on potential processing considerations or WL decisions for the CCIM demonstrations. If the $T_{L}$ of the glass system is found to be greater than the projected nominal operating temperature $\left(\sim 1250^{\circ} \mathrm{C}\right)$, then there is a potential compromise in the nominal operating conditions of the CCIM. Assume the $\mathrm{T}_{\mathrm{L}}$ of a 50\% WL Frit 202-A11 based glass system is $1275^{\circ} \mathrm{C}$. If the CCIM criteria for processing dictate that the nominal operating temperature be maintained above the $\mathrm{T}_{\mathrm{L}}$, then nominal melt temperatures greater than $1275^{\circ} \mathrm{C}$ may be required. This could lead to either enhanced volatilization or to a glass viscosity that is unacceptable (too low) for processing and/or pouring. If the CCIM technology is tolerant or

\footnotetext{
${ }^{2}$ Preliminary models developed for higher WL glasses have since been developed and were subsequently used to predict various properties. The results of these predictions will be reported in Section 5.0. Although utilized in this report, the models are based on limited data covering an extremely large compositional region and therefore applicability may be questioned. To support implementation of these higher WL systems within DWPF, a specific programmatic effort is required to ensure model applicability to the compositional region of interest.

${ }^{3}$ The DWPF viscosity model does have a temperature term but it is currently defined or set for predictions at $1150^{\circ} \mathrm{C}-$ the nominal temperature for DWPF. The temperature term could be set to $1250^{\circ} \mathrm{C}$ but SRNL would have to validate the range of model validity in terms of sufficient data being taken at $1250^{\circ} \mathrm{C}$.
} 
robust to a certain vol\% of crystalline material in the melt pool, then the nominal melt temperature could be lower (i.e., the nominal melt temperature would be less than $T_{L}$ ) which could minimize potential volatility as well as provide a higher glass viscosity. The viability of this potential compromise of operating parameters are aspects of the CCIM technology that must be addressed by its providers given the use of Frit 202-A11. It is noted that subsequent glass formulation efforts could potentially address this issue as warranted. 
WSRC-STI-2007-00302

Revision 0

\subsection{Experimental Studies}

\subsection{Target Compositions and Glass Fabrication}

Based on the identification of Frit 202-A11 as the primary candidate frit, two series of glasses have been fabricated using the nominal SB3 composition (see Table 1). The initial series of tests used the nominal SB3 composition and targeted WLs of 45, 50, and 55\% to identify trends in critical properties as a function of WL. Based on the trends observed in the initial test series, a more finely tuned grid of WLs was targeted in the second series of glasses. More specifically, a series of 8 glasses based on the nominal SB3 composition and Frit 202-A11 targeting WLs of 44 $-58 \%$ in $2 \%$ increments was fabricated and characterized. The intent of this second set of glasses was to provide technical data at intermediate WLs to ensure that the key physical properties were known over a wider WL interval as well as to assess possible non-linear effects as one transitions from 44 to $58 \%$ WL. Coupling the results of these two series of tests provides a database from which the impacts of WL on various properties of interest could be used as a decision tool or a guide regarding the targeted WL for the CCIM demonstration to avoid unacceptable property regions (if they exist). It is noted that $\mathrm{T}_{\mathrm{L}}$ and viscosity measurements were not obtained on all study glasses.

It should be noted that all of the results presented in this data packet assume a nominal SB3 composition with no compositional variation applied. It is recommended that specific properties of interest (such as durability) be assessed to account for possible variation in the sludge composition to be produced by a vendor. More specifically, in support of the actual CCIM demonstration a sludge simulant is being produced by an off-site vendor. Although the vendor will be targeting the nominal SB3 composition as shown in Table 1, some variation from the target should be anticipated. Coupling the compositional uncertainty of the sludge simulant with potential uncertainties in the targeted WL may lead to a compositional region beyond that covered by technical data to date. That being the case, the authors recommend the fabrication and testing of a series of glasses that are intended to bound the compositional variation of the sludge simulant over a WL interval of interest.

Target compositions of the 202-A11 glasses are summarized in Table 3 (initial series) and Table 4 (second series). The glasses are referred to as the "HTLG" glasses indicating that these are high $T_{L}$ glasses. Each HTLG glass was prepared from the proper proportions of reagent-grade metal oxides, carbonates, $\mathrm{H}_{3} \mathrm{BO}_{3}$, and salts in $150 \mathrm{~g}$ batches. The raw materials were thoroughly mixed and placed into a $90 \%$ platinum / $10 \%$ rhodium, $250 \mathrm{~mL}$ crucible. The batch was placed in a high-temperature furnace at the target melt temperature of $1250^{\circ} \mathrm{C}$. The crucible was removed from the furnace after an isothermal hold at $1250^{\circ} \mathrm{C}$ for 1 hour. The glass was poured onto a clean, stainless steel plate and allowed to air cool (quench). The glass pour patty was used as a sampling stock for the various property measurements, including chemical composition and durability testing.

It is noted that HTLG-48 has the same targeted composition as HTLG-34 - both 50\% WL glasses. These two glasses will provide insight into the reproducibility of the measurements of various properties assuming target compositions are met. 
Table 3. Target Compositions for Initial Series of 202-A11 Based Glasses Targeting 45, 50, and 55\% Waste Loading.

\begin{tabular}{||c|c|c|c||}
\hline \hline & HTLG-47 & HTLG-48 & HTLG-49 \\
\hline Oxide & $\begin{array}{c}\text { 202-A11, } \\
\text { 45\% WL }\end{array}$ & $\begin{array}{c}\text { 202-A11, } \\
\text { 50\% WL }\end{array}$ & $\begin{array}{c}\text { 202-A11, } \\
\text { 55\% WL }\end{array}$ \\
\hline $\mathrm{Al}_{2} \mathrm{O}_{3}$ & 7.60 & 8.45 & 9.29 \\
\hline $\mathrm{B}_{2} \mathrm{O}_{3}$ & 4.95 & 4.50 & 4.05 \\
\hline $\mathrm{CaO}$ & 1.49 & 1.65 & 1.82 \\
\hline $\mathrm{Cr}_{2} \mathrm{O}_{3}$ & 0.09 & 0.10 & 0.11 \\
\hline $\mathrm{CuO}$ & 0.03 & 0.04 & 0.04 \\
\hline $\mathrm{Fe}_{2} \mathrm{O}_{3}$ & 16.80 & 18.65 & 20.52 \\
\hline $\mathrm{K}_{2} \mathrm{O}$ & 0.15 & 0.17 & 0.19 \\
\hline $\mathrm{Li}_{2} \mathrm{O}$ & 3.30 & 3.00 & 2.70 \\
\hline $\mathrm{MgO}$ & 1.72 & 1.91 & 2.10 \\
\hline $\mathrm{MnO}$ & 3.19 & 3.54 & 3.90 \\
\hline $\mathrm{Na}_{2} \mathrm{O}$ & 12.50 & 13.59 & 14.65 \\
\hline $\mathrm{NiO}_{\mathrm{SO}}$ & 0.86 & 0.96 & 1.06 \\
\hline $\mathrm{SO}_{4}$ & 0.32 & 0.36 & 0.40 \\
\hline $\mathrm{SiO}_{2}$ & 46.90 & 42.97 & 39.07 \\
\hline $\mathrm{TiO}_{2}$ & 0.03 & 0.03 & 0.03 \\
\hline $\mathrm{ZrO}_{2}$ & 0.08 & 0.09 & 0.10 \\
\hline $\mathrm{Total}^{2}$ & 100.0 & 100.0 & 100.0 \\
\hline \hline
\end{tabular}


Table 4. Target Compositions of the Second Series ("WL Series") of Frit 202-A11 Based Glasses.

\begin{tabular}{|c|c|c|c|c|c|c|c|c|}
\hline & HTLG-31 & HTLG-32 & HTLG-33 & HTLG-34 & HTLG-35 & HTLG-36 & HTLG-37 & HTLG-38 \\
\hline & $\begin{array}{l}\text { 202-A11, } \\
44 \% \text { WL }\end{array}$ & $\begin{array}{l}\text { 202-A11, } \\
46 \% \text { WL }\end{array}$ & $\begin{array}{l}\text { 202-A11, } \\
48 \% \text { WL }\end{array}$ & $\begin{array}{l}\text { 202-A11, } \\
50 \% \text { WL }\end{array}$ & $\begin{array}{l}\text { 202-A11, } \\
52 \% \text { WL }\end{array}$ & $\begin{array}{l}\text { 202-A11, } \\
54 \% \text { WL }\end{array}$ & $\begin{array}{l}\text { 202-A11, } \\
56 \% \text { WL }\end{array}$ & $\begin{array}{l}\text { 202-A11, } \\
58 \% \text { WL }\end{array}$ \\
\hline $\mathrm{Al}_{2} \mathrm{O}_{3}$ & 7.44 & 7.77 & 8.11 & 8.45 & 8.79 & 9.12 & 9.46 & 9.80 \\
\hline $\mathrm{B}_{2} \mathrm{O}_{3}$ & 5.04 & 4.86 & 4.68 & 4.50 & 4.32 & 4.14 & 3.96 & 3.78 \\
\hline $\mathrm{CaO}$ & 1.45 & 1.52 & 1.59 & 1.65 & 1.72 & 1.78 & 1.85 & 1.92 \\
\hline $\mathrm{Cr}_{2} \mathrm{O}_{3}$ & 0.08 & 0.09 & 0.09 & 0.10 & 0.10 & 0.10 & 0.11 & 0.11 \\
\hline $\mathrm{CuO}$ & 0.03 & 0.03 & 0.04 & 0.04 & 0.04 & 0.04 & 0.04 & 0.04 \\
\hline $\mathrm{Fe}_{2} \mathrm{O}_{3}$ & 16.41 & 17.16 & 17.90 & 18.65 & 19.40 & 20.14 & 20.89 & 21.64 \\
\hline $\mathrm{K}_{2} \mathrm{O}$ & 0.15 & 0.16 & 0.16 & 0.17 & 0.18 & 0.18 & 0.19 & 0.20 \\
\hline $\mathrm{Li}_{2} \mathrm{O}$ & 3.36 & 3.24 & 3.12 & 3.00 & 2.88 & 2.76 & 2.64 & 2.52 \\
\hline $\mathrm{MgO}$ & 1.68 & 1.75 & 1.83 & 1.91 & 1.98 & 2.06 & 2.14 & 2.21 \\
\hline $\mathrm{MnO}$ & 3.12 & 3.26 & 3.40 & 3.54 & 3.68 & 3.83 & 3.97 & 4.11 \\
\hline $\mathrm{Na}_{2} \mathrm{O}$ & 12.32 & 12.74 & 13.16 & 13.59 & 14.01 & 14.43 & 14.86 & 15.28 \\
\hline $\mathrm{NiO}$ & 0.85 & 0.88 & 0.92 & 0.96 & 1.00 & 1.04 & 1.08 & 1.11 \\
\hline $\mathrm{SO}_{4}$ & 0.32 & 0.33 & 0.35 & 0.36 & 0.37 & 0.39 & 0.40 & 0.42 \\
\hline $\mathrm{SiO}_{2}$ & 47.65 & 46.09 & 44.53 & 42.97 & 41.41 & 39.85 & 38.29 & 36.73 \\
\hline $\mathrm{TiO}_{2}$ & 0.03 & 0.03 & 0.03 & 0.03 & 0.03 & 0.03 & 0.03 & 0.03 \\
\hline $\mathrm{ZrO}_{2}$ & 0.08 & 0.08 & 0.09 & 0.09 & 0.10 & 0.10 & 0.10 & 0.11 \\
\hline Total & 100.0 & 100.0 & 100.0 & 100.0 & 100.0 & 100.0 & 100.0 & 100.0 \\
\hline
\end{tabular}


Approximately $25 \mathrm{~g}$ of each HTLG glass was heat-treated to simulate cooling along the centerline of a DWPF-type canister to gauge the effects of thermal history on product performance. This cooling schedule is referred to as the ccc (canister centerline cooling) curve. It should be noted that the ccc schedule was altered to capture the increased nominal CCIM melt temperature of $1250^{\circ} \mathrm{C}$. That is, the nominal DWPF ccc schedule begins at $1150^{\circ} \mathrm{C}$ and initially ramps down at $8^{\circ} \mathrm{C} / \mathrm{min}$ into the $900^{\circ} \mathrm{C}$ range. The adjusted cooling schedule was initiated at $1250^{\circ} \mathrm{C}$ and was ramped down at $10^{\circ} \mathrm{C} / \mathrm{min}$ to $1150^{\circ} \mathrm{C}$ at which point the normal DWPF ccc schedule was followed. Also note that there was no isothermal hold at $1150^{\circ} \mathrm{C}$.

\subsection{Compositional Analysis}

To confirm that the as-fabricated glasses corresponded to the defined target compositions, a representative sample from each glass was submitted to the SRNL Process Science Analytical Laboratory (PSAL) for chemical analysis using two dissolution techniques (i.e., sodium peroxide fusion $[\mathrm{PF}]$ and lithium-metaborate $[\mathrm{LM}]$ ). Each glass was prepared in duplicate for each cation dissolution technique (PF and LM). All of the prepared samples were analyzed (twice for each element of interest) by Inductively Coupled Plasma - Atomic Emission Spectroscopy (ICP-AES).

\subsection{Homogeneity}

Homogeneity in this report refers to the presence of crystallization in the glass samples. Initially, visual observations of the quenched and ccc glasses were recorded. Although visual observations for crystallization were performed and documented, representative samples of all HTLG glasses were submitted to Analytical Development (AD) for X-ray diffraction (XRD) analysis. Samples were run under conditions providing a detection limit of approximately $0.5 \mathrm{vol} \%$. That is, if crystals (or undissolved solids) were present at $0.5 \mathrm{vol} \%$ or greater, the diffractometer was not only capable of detecting the crystals but also allowed for a qualitative determination of the type of crystal(s) present. Otherwise, a characteristically high background devoid of crystalline peaks indicated that the glass product was amorphous, suggesting either a completely amorphous product or that the degree of crystallization was below the detection limit.

For specific glasses, additional characterization of the glass surface or cross-section was performed using Scanning Electron Microscopy (SEM) with Energy Dispersive Spectroscopy (EDS). The XRD and SEM/EDS results are complementary in nature and will serve as a sound technical basis for assessing the impacts of crystallization on properties of interest.

\subsection{Viscosity}

High temperature viscosity $(\eta)$ was measured as a function of temperature using a spindle viscometer for a 50\% WL based sample (HTLG-21) ${ }^{4}$. The measurements were obtained using standard procedures which are compliant with ASTM C 965-81.

In general, the glass was heated to $\sim 1250^{\circ} \mathrm{C}$ in a platinum alloy crucible and maintained until thermal equilibrium was reached. An initial torque reading (at a constant spindle speed) was taken at $\sim 1250^{\circ} \mathrm{C}$ with subsequent measurements at both higher and lower temperatures ranging from $\sim 1150^{\circ} \mathrm{C}$ to $1300^{\circ} \mathrm{C}$ using a hysteresis approach (to the extent possible). Note that the temperature range over which viscosity readings were taken is rather limited. This is a result of an upper temperature limit of the viscometer being used $\left(\sim 1300^{\circ} \mathrm{C}\right.$, maximum furnace temperature) and the possible impacts of crystallization (see Section 9.0) at lower temperatures on

\footnotetext{
${ }^{4}$ Note: HTLG-21 was a glass produced during the scoping study phase of this program. The target composition is identical to both HTLG-48 and HTLG-34 as listed in Tables 3 and 4, respectively.
} 
the accuracy and/or stability of the viscosity readings. A viscosity standard glass was used to verify calibration during this process.

\subsection{Liquidus Temperature}

To gain insight into the liquidus temperature for this glass system, isothermal heat treatments were performed on a 202-A11 based glass at 50\% WL (HTLG-21 specifically). Isothermal heat treatments were performed at $1150^{\circ}, 1200^{\circ}$, and $1250^{\circ} \mathrm{C}$ for 24 hours. Thin sections of the heat treated samples were produced and examined via optical microscopy for the presence of crystalline phases.

\subsection{Durability}

The ASTM PCT was used as the measure of waste form performance or durability. The PCT was performed in triplicate on each HTLG quenched and ccc glass. The experimental test matrix also included the EA glass, the Approved Reference Material (ARM) glass, and blanks from the sample cleaning batch. Samples were ground, washed, and prepared according to the standard procedure. Fifteen milliliters of Type I ASTM water were added to $1.5 \mathrm{~g}$ of glass in stainless steel vessels. The vessels were closed, sealed, and placed in an oven at $90 \pm 2{ }^{\circ} \mathrm{C}$ where the samples were maintained for 7 days. Once cooled, the resulting solutions were sampled (filtered and acidified) and then analyzed by PSAL. Normalized release rates were calculated based on both target and measured compositions. 
WSRC-STI-2007-00302

Revision 0

\subsection{Results}

\subsection{Visual Observations}

\subsubsection{Quenched Glasses}

Prior to discussing the visual observations, a few words regarding the terminology used to describe the appearance of the glasses are warranted. The use of "homogeneous" indicates that the sample was classified as a single-phase system (i.e., no evidence of crystallization either on the surface or within the bulk). The term "surface crystals" implies that the surface of the glass was characterized by the presence of crystallization while the cross-section of bulk glass appeared homogeneous (i.e., single-phase, black and shiny). Surface crystallization in the HTLG glasses was apparent through the presence of a "textured" surface that ranged in appearance from "dull" to "metallic". The metallic sheen or surfaces appeared almost mirror-like in some cases (in particular at the higher WLs). 
WSRC-STI-2007-00302

Revision 0

Table 5. Visual Observations of 202-A11 Based HTLG Quenched and CCC Glasses.

\begin{tabular}{|c|c|c|c|}
\hline Glass & WL & Quenched & CCC \\
\hline HTLG-47 & 45 & Homogeneous & $\begin{array}{c}\text { Surface: dull, brown coating } \\
\text { Bulk: dull, coal-like color }\end{array}$ \\
\hline HTLG-48 & 50 & $\begin{array}{c}\text { Surface: crystallization, metallic sheen; } \\
\text { Bulk: visually homogeneous }\end{array}$ & $\begin{array}{l}\text { Surface and bulk appear dull and black, no } \\
\text { specific brown coating on surface noted. }\end{array}$ \\
\hline HTLG-49 & 55 & $\begin{array}{l}\text { Surface: crystallization, metallic sheen; } \\
\text { Bulk: visually homogeneous } \\
\end{array}$ & $\begin{array}{l}\text { Surface and bulk appear dull and black, no } \\
\text { specific brown coating on surface noted. }\end{array}$ \\
\hline HTLG-31 & 44 & Homogeneous & $\begin{array}{l}\text { Surface: dull, dark brown coating } \\
\text { Bulk: two distinct brown layers }\end{array}$ \\
\hline HTLG-32 & 46 & Homogeneous & $\begin{array}{l}\text { Surface: dull, dark brown coating } \\
\text { Bulk: dull, coal-like color }\end{array}$ \\
\hline HTLG-33 & 48 & $\begin{array}{l}\text { Surface: crystallization, slight metallic sheen; } \\
\text { Bulk: visually homogeneous }\end{array}$ & $\begin{array}{l}\text { Surface: dull, dark brown coating } \\
\text { Bulk: dull, coal-like color }\end{array}$ \\
\hline HTLG-34 & 50 & $\begin{array}{c}\text { Surface: crystallization, metallic sheen; } \\
\text { Bulk: visually homogeneous }\end{array}$ & $\begin{array}{l}\text { Surface and bulk appear dull and black, no } \\
\text { specific brown coating on surface noted. }\end{array}$ \\
\hline HTLG-35 & 52 & $\begin{array}{l}\text { Surface: crystallization, metallic sheen; } \\
\text { Bulk: visually homogeneous }\end{array}$ & $\begin{array}{l}\text { Surface and bulk appear dull and black, no } \\
\text { specific brown coating on surface noted. }\end{array}$ \\
\hline HTLG-36 & 54 & $\begin{array}{l}\text { Surface: crystallization, metallic sheen; } \\
\text { Bulk: glass is slightly dull near center of } \\
\text { patty, majority of glass still reflective }\end{array}$ & $\begin{array}{l}\text { Surface and bulk appear dull and black, no } \\
\text { specific brown coating on surface noted. }\end{array}$ \\
\hline HTLG-37 & 56 & $\begin{array}{c}\text { Surface: crystallization, metallic sheen; } \\
\text { Bulk: glass is duller in appearance relative to } \\
54 \% \text { WL glass }\end{array}$ & $\begin{array}{l}\text { Surface: slight metallic sheen or pattern } \\
\text { Bulk: dull black }\end{array}$ \\
\hline HTLG-38 & 58 & $\begin{array}{c}\text { Surface: crystallization, metallic sheen; } \\
\text { Bulk: glass is duller in appearance relative to } \\
56 \% \text { WL glass }\end{array}$ & $\begin{array}{l}\text { Surface: metallic coating or pattern } \\
\text { Bulk: dull black }\end{array}$ \\
\hline
\end{tabular}

Appendix A provides digital photos of the as-fabricated, quenched HTLG glasses. In general, the visual observations of the as-fabricated, quenched glasses change as a function of WL. The lower WL (44, 45\%, and 46\%) glasses appeared visually homogeneous - void of crystallization on both the surface and the cross-section (or bulk) of the pour patty. As the WLs transition to $48 \%$ and higher, the slight metallic surface haze transitions to a very reflective, metallic coating for the asfabricated, quenched samples. The metallic surface layer has been observed in other high WL DWPF or Hanford type glasses and, based on XRD analyses, was related to the formation of spinels (e.g., magnetite) (Peeler et al. 2002). This will be confirmed for the HTLG glasses as noted later in Section 5.3. Note that the visual observations for HTLG-34 and HTLG-48 (both targeting 50\% WL) are consistent.

The bulk (or cross-sections) of the intermediate to higher WL, quenched glasses also transition from visually homogeneous (black and reflective glass) to a dull appearance indicative of bulk crystallization. The trends in visual observations are consistent with expectations that the propensity for spinel formation increases with increased WL (i.e., higher concentrations of the spinel-formers: $\mathrm{Cr}, \mathrm{Fe}$, and $\mathrm{Ni}$ ). 


\subsubsection{Glasses}

Visual observations of the ccc glasses indicate a high degree of devitrification in all 202-A11 based HTLG glasses. From 44 to 54\% WL, all of the sample surfaces were characterized as dull or having a dark coating. The cross-section of HTLG-31ccc (44\% WL) had two distinct brown layers - this was not observed in any other HTLG ccc samples. At 56 and 58\% WL, the surfaces became more metallic in nature while the bulk glass remained dull. Appendix B contains digital photos of the initial set of HTLG glasses (-47, -48, and -50) after the altered ccc heat treatment. Although the "WL series" of ccc glasses are not shown, all of the samples were highly devitrified as described in Table 5.

It should be noted that the extensive devitrification (type and extent to be discussed in Section 5.3) occurs upon slow cooling (i.e., ccc adjusted for the higher melt temperature). Although visually unappealing, the primary concern to address is the possible impact of the devitrification on durability (i.e., Does the slow cooling promote the formation of a crystalline phase which results in a negative impact on the durability response relative to the equivalent quenched glass?). If there is no impact or the impact does not result in an unacceptable PCT response (as defined by the EA benchmark), the glasses would meet DWPF acceptance criteria. Although the glass is visually unappealing, it is an acceptable waste form. It is known that the formation of spinels has very little if any practical impact on the PCT response of DWPF-type glasses. However, nepheline formation in these glasses is possible and could lead to a practical and/or significant reduction in durability as measured by the PCT.

\subsection{Compositional Analysis}

Table 6 and Table 7 summarize the target versus measured compositions of the initial HTLG glasses (45, 50, and 55\% WL) and the HTLG WL series, respectively. A percent relative difference to the target for each oxide is also provided to support the assessment. The measured compositions of both series of glasses indicate that there were no significant batching errors or volatility issues during fabrication. With the exception of select $\mathrm{MgO}$ and $\mathrm{NiO}$ values, those major components projected to be greater than $0.5 \mathrm{wt} \%$ in glass are within $\pm 10 \%$ of their targeted values. This is considered to be within the uncertainty of the batching and analytical processes associated with the ICP-AES. In general, the measured MgO values appear to be higher than their targeted values for most HTLG glasses while measured $\mathrm{NiO}$ values appear to be on the low side. 
Table 6. Target Versus Measured Compositions for the Initial Series of 202-A11 Based Glasses.

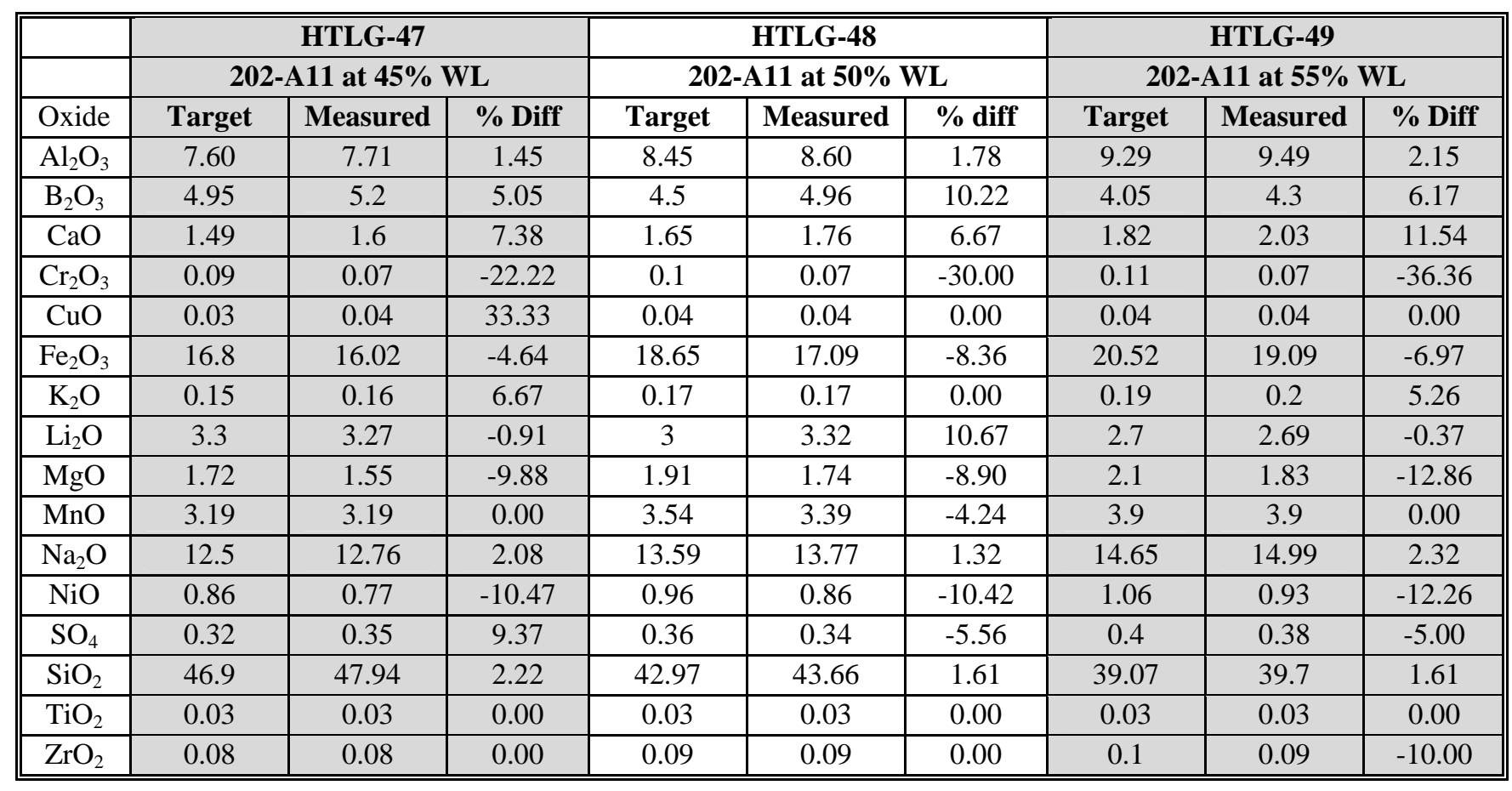


Table 7. Target Versus Measured Compositions for WL Series of 202-A11 Based Glasses.

\begin{tabular}{|c|c|c|c|c|c|c|c|c|c|c|c|c|}
\hline & \multicolumn{3}{|c|}{ "HTLG-31 } & \multicolumn{3}{|c|}{ "HTLG-32 } & \multicolumn{3}{|c|}{ "HTLG-33 } & \multicolumn{3}{|c|}{ HTLG-34 } \\
\hline & \multicolumn{3}{|c|}{ 202-A11, 44\% WL } & \multicolumn{3}{|c|}{ 202-A11, 46\% WL } & \multicolumn{3}{|c|}{ 202-A11, 48\% WL } & \multicolumn{3}{|c|}{ 202-A11, 50\% WL } \\
\hline & Target & Measured & $\%$ Diff & Target & Measured & \% Diff & Target & Measured & \% Diff & Target & Measured & \% Diff \\
\hline $\mathrm{Al}_{2} \mathrm{O}_{3}$ & 7.44 & 7.68 & 3.23 & 7.77 & 8.04 & 3.47 & 8.11 & 8.37 & 3.21 & 8.45 & 8.78 & 3.91 \\
\hline $\mathrm{B}_{2} \mathrm{O}_{3}$ & 5.04 & 5.28 & 4.76 & 4.86 & 4.96 & 2.06 & 4.68 & 4.7 & 0.43 & 4.5 & 4.51 & 0.22 \\
\hline $\mathrm{CaO}$ & 1.45 & 1.47 & 1.38 & 1.52 & 1.52 & 0.00 & 1.59 & 1.59 & 0.00 & 1.65 & 1.66 & 0.61 \\
\hline $\mathrm{Cr}_{2} \mathrm{O}_{3}$ & 0.08 & 0.08 & 0.00 & 0.09 & 0.07 & -22.22 & 0.09 & 0.08 & -11.11 & 0.1 & 0.08 & -20.00 \\
\hline $\mathrm{CuO}$ & 0.03 & 0.04 & 33.33 & 0.03 & 0.04 & 33.33 & 0.04 & 0.04 & 0.00 & 0.04 & 0.04 & 0.00 \\
\hline $\mathrm{Fe}_{2} \mathrm{O}_{3}$ & 16.41 & 16.73 & 1.95 & 17.16 & 17.37 & 1.22 & 17.9 & 18.23 & 1.84 & 18.65 & 18.88 & 1.23 \\
\hline $\mathrm{K}_{2} \mathrm{O}$ & 0.15 & 0.25 & 66.67 & 0.16 & 0.17 & 6.25 & 0.16 & 0.17 & 6.25 & 0.17 & 0.18 & 5.88 \\
\hline $\mathrm{Li}_{2} \mathrm{O}$ & 3.36 & 3.36 & 0.00 & 3.24 & 3.25 & 0.31 & 3.12 & 3.06 & -1.92 & 3 & 2.99 & -0.33 \\
\hline $\mathrm{MgO}$ & 1.68 & 1.77 & 5.36 & 1.75 & 1.94 & 10.86 & 1.83 & 2.11 & 15.30 & 1.91 & 2.23 & 16.75 \\
\hline $\mathrm{MnO}$ & 3.12 & 3.21 & 2.88 & 3.26 & 3.34 & 2.45 & 3.4 & 3.52 & 3.53 & 3.54 & 3.66 & 3.39 \\
\hline $\mathrm{Na}_{2} \mathrm{O}$ & 12.32 & 12.76 & 3.57 & 12.74 & 13.07 & 2.59 & 13.16 & 13.41 & 1.90 & 13.59 & 13.99 & 2.94 \\
\hline $\mathrm{NiO}$ & 0.85 & 0.78 & -8.24 & 0.88 & 0.76 & -13.64 & 0.92 & 0.83 & -9.78 & 0.96 & 0.86 & -10.42 \\
\hline $\mathrm{SO}_{4}$ & 0.32 & 0.29 & -9.38 & 0.33 & 0.33 & 0.00 & 0.35 & 0.35 & 0.00 & 0.36 & 0.36 & 0.00 \\
\hline $\mathrm{SiO}_{2}$ & 47.65 & 48.15 & 1.05 & 46.09 & 47.51 & 3.08 & 44.53 & 45.58 & 2.36 & 42.97 & 44.08 & 2.58 \\
\hline $\mathrm{TiO}_{2}$ & 0.03 & 0.03 & 0.00 & 0.03 & 0.03 & 0.00 & 0.03 & 0.03 & 0.00 & 0.03 & 0.03 & 0.00 \\
\hline $\mathrm{ZrO}_{2}$ & 0.08 & 0.07 & -12.50 & 0.08 & 0.08 & 0.00 & 0.09 & 0.08 & -11.11 & 0.09 & 0.08 & -11.11 \\
\hline
\end{tabular}


Table 7. Target Versus Measured Compositions for WL Series of 202-A11 Based Glasses (continued).

\begin{tabular}{|c|c|c|c|c|c|c|c|c|c|c|c|c|}
\hline & \multicolumn{3}{|c|}{ HTLG-35 } & \multicolumn{3}{|c|}{ HTLG-36 } & \multicolumn{3}{|c|}{ HTLG-37 } & \multicolumn{3}{|c|}{ HTLG-38 } \\
\hline & \multicolumn{3}{|c|}{ 202-A11, 52\% WL } & \multicolumn{3}{|c|}{ 202-A11, 54\% WL } & \multicolumn{3}{|c|}{ 202-A11, 56\% WL } & \multicolumn{3}{|c|}{ 202-A11, 58\% WL } \\
\hline & Target & Measured & $\%$ Diff & Target & Measured & \% Diff & Target & Measured & \% Diff & Target & Measured & \% Diff \\
\hline $\mathrm{Al}_{2} \mathrm{O}_{3}$ & 8.79 & 9.1 & 3.53 & 9.12 & 9.6 & 5.26 & 9.46 & 10.03 & 6.03 & 9.8 & 10.23 & 4.39 \\
\hline $\mathrm{B}_{2} \mathrm{O}_{3}$ & 4.32 & 4.31 & -0.23 & 4.14 & 4.3 & 3.86 & 3.96 & 3.91 & -1.26 & 3.78 & 3.72 & -1.59 \\
\hline $\mathrm{CaO}$ & 1.72 & 1.75 & 1.74 & 1.78 & 1.87 & 5.06 & 1.85 & 1.94 & 4.86 & 1.92 & 1.99 & 3.65 \\
\hline $\mathrm{Cr}_{2} \mathrm{O}_{3}$ & 0.1 & 0.08 & -20.00 & 0.1 & 0.08 & -20.00 & 0.11 & 0.09 & -18.18 & 0.11 & 0.09 & -18.18 \\
\hline $\mathrm{CuO}$ & 0.04 & 0.05 & 25.00 & 0.04 & 0.05 & 25.00 & 0.04 & 0.05 & 25.00 & 0.04 & 0.05 & 25.00 \\
\hline $\mathrm{Fe}_{2} \mathrm{O}_{3}$ & 19.4 & 19.59 & 0.98 & 20.14 & 19.45 & -3.43 & 20.89 & 21.02 & 0.62 & 21.64 & 21.81 & 0.79 \\
\hline $\mathrm{K}_{2} \mathrm{O}$ & 0.18 & 0.21 & 16.67 & 0.18 & 0.2 & 11.11 & 0.19 & 0.21 & 10.53 & 0.2 & 0.21 & 5.00 \\
\hline $\mathrm{Li}_{2} \mathrm{O}$ & 2.88 & 2.88 & 0.00 & 2.76 & 2.76 & 0.00 & 2.64 & 2.63 & -0.38 & 2.52 & 2.54 & 0.79 \\
\hline $\mathrm{MgO}$ & 1.98 & 2.23 & 12.63 & 2.06 & 2.35 & 14.08 & 2.14 & 2.47 & 15.42 & 2.21 & 2.55 & 15.38 \\
\hline $\mathrm{MnO}$ & 3.68 & 3.78 & 2.72 & 3.83 & 3.77 & -1.57 & 3.97 & 4.07 & 2.52 & 4.11 & 4.22 & 2.68 \\
\hline $\mathrm{Na}_{2} \mathrm{O}$ & 14.01 & 14.47 & 3.28 & 14.43 & 15.13 & 4.85 & 14.86 & 15.72 & 5.79 & 15.28 & 16.01 & 4.78 \\
\hline $\mathrm{NiO}$ & 1.0 & 0.84 & -16.00 & 1.04 & 0.84 & -19.23 & 1.08 & 0.92 & -14.81 & 1.11 & 0.97 & -12.61 \\
\hline $\mathrm{SO}_{4}$ & 0.37 & 0.36 & -2.70 & 0.39 & 0.33 & -15.38 & 0.4 & 0.35 & -12.50 & 0.42 & 0.36 & -14.29 \\
\hline $\mathrm{SiO}_{2}$ & 41.41 & 42.59 & 2.85 & 39.85 & 40.66 & 2.03 & 38.29 & 39.59 & 3.40 & 36.73 & 38.09 & 3.70 \\
\hline $\mathrm{TiO}_{2}$ & 0.03 & 0.03 & 0.00 & 0.03 & 0.03 & 0.00 & 0.03 & 0.03 & 0.00 & 0.03 & 0.03 & 0.00 \\
\hline $\mathrm{ZrO}_{2}$ & 0.1 & 0.08 & -20.00 & 0.1 & 0.09 & -10.00 & 0.1 & 0.09 & -10.00 & 0.11 & 0.1 & -9.09 \\
\hline
\end{tabular}




\subsection{XRD Results}

Representative samples of both quenched and ccc HTLG glasses were submitted for XRD analysis. Table 8 summarizes the XRD results (see Appendix $C$ for the actual XRD patterns). For the quenched glasses targeting $48 \% \mathrm{WL}$ or less, the results suggest that the glasses are homogeneous, which is consistent with visual observations. ${ }^{5}$ Visual observations (as noted in Section 5.1) of the 50\% WL glasses (HTLG-48 and HTLG-34) indicated that the surfaces were characterized by some degree of crystallization. It is noted that the samples were run under XRD conditions that provide a detection limit of approximately $0.5 \mathrm{vol} \%$. That is, if crystals (or undissolved solids) were present at $0.5 \mathrm{vol} \%$ or greater, the diffractometer would not only be capable of detecting the crystals but would also allow a qualitative determination of the type of crystal(s) present. Otherwise, a characteristically high background devoid of crystalline peaks would indicate that the glass product was amorphous, suggesting either a completely amorphous product or that the degree of crystallization was below the detection limit. The XRD data suggest that the vol\% crystallization in the $50 \%$ WL glasses was borderline at the approximate 0.5 vol\% detection limit with HTLG-48 (Figure C2 in Appendix C) being X-ray amorphous while HTLG34 (Figure C7 in Appendix C) was characterized by magnetite.

$\mathrm{XRD}$ results for the glasses targeting greater than $50 \% \mathrm{WL}$ indicate the presence of magnetite $\left(\mathrm{Fe}^{+2} \mathrm{Fe}_{2}{ }^{+3} \mathrm{O}_{4}\right.$ or spinel). As noted in Section 5.1, visual observations of these glasses indicated an increased degree of surface crystallization as well as the potential for an increase in bulk crystallization as WL increases. Given magnetite is the only phase detected in the quenched glasses over the $44-58 \%$ WL range, there should be no practical (or measurable) impact of crystallization on durability. However, the durability of the glasses over this WL range may show a decreasing or increasing trend based strictly on the overall glass composition.

Table 8. XRD Results for 202-A11 Based Glasses.

\begin{tabular}{||c|c|c|c||}
\hline Glass ID & WL & Quenched & CCC \\
\hline HTLG-47 & 45 & Homogeneous & $\begin{array}{c}\text { Magnetite, Aegirine, } \\
\text { Nepheline }\end{array}$ \\
\hline HTLG-48 & 50 & Homogeneous & Magnetite \\
\hline HTLG-49 & 55 & Magnetite & Magnetite \\
\hline & & Homogeneous & Aegirine, Magnetite \\
\hline HTLG-31 & 44 & Homogeneous & $\begin{array}{c}\text { Magnetite, Aegirine, } \\
\text { Hematite }\end{array}$ \\
\hline HTLG-32 & 46 & Homogeneous & $\begin{array}{c}\text { Magnetite, Aegirine, } \\
\text { Hematite, Nepheline }\end{array}$ \\
\hline HTLG-33 & 48 & Magnetite & Magnetite, Aegirine \\
\hline HTLG-34 & 50 & Magnetite & Magnetite \\
\hline HTLG-35 & 52 & Magnetite & Magnetite \\
\hline HTLG-36 & 54 & Magnetite & Magnetite \\
\hline HTLG-37 & 56 & Magnetite & Magnetite \\
\hline HTLG-38 & 58 & &
\end{tabular}

${ }^{5}$ The XRD results provided for HTLG-31 quenched have an overlay of magnetite's signature pattern (see Figure C4 in Appendix C). Although the pattern is shown, the presence of magnetite is questioned based of the absence of any well defined peaks in the pattern.

${ }^{6}$ Note that the XRD pattern for HTLG-31ccc (see Figure C15) appears to include magnetite as well as aegirine although only aegirine is indicated in the figure. 
XRD results for the ccc glasses indicate crystallization in all eleven 202-A11 based glasses. It is interesting to note that at WLs of 50\% or higher (the exception being HTLG-34), the ccc glasses are only characterized by magnetite. The XRD results of the HTLG-34ccc glass indicate both magnetite and aegirine $\left(\mathrm{NaFe}\left(\mathrm{Si}_{2} \mathrm{O}_{6}\right)\right)$. At the lower WLs (44-50\%), XRD results indicate the formation of not only magnetite but aegirine and nepheline $\left(\mathrm{NaAlSiO}_{4}\right)$ in some of the glasses. Both of these phases could have a negative impact on the durability response given the removal of $\mathrm{Al}_{2} \mathrm{O}_{3}, \mathrm{Fe}_{2} \mathrm{O}_{3}$, and/or $\mathrm{SiO}_{2}$ from the residual glass matrix. Assuming the formation of nepheline and/or aegirine has a negative impact on durability, the question becomes how significant is the impact? The magnitude of the impact may depend not only on the type of crystallization but the volume percent (which was not determined). If the volume percentage is low, the impact to durability may be measurable, but could still result in very acceptable glasses relative to the EA glass benchmark.

From a CCIM demonstration perspective, and anticipating a measurable, negative impact of either aegirine and/or nepheline on the durability, one may consider targeting higher WLs (50\% or greater to avoid the possible formation of these two phases in slowly cooled glasses. It is noted that although the impact on the durability response is a critical factor for the demonstration, other processing considerations (such as $\mathrm{T}_{\mathrm{L}}$ ) may drive one to target lower WLs. As previously mentioned, there may be a need to balance processing and product performance issues for the initial demonstrations recognizing that frit development efforts are not optimized for this study.

\subsection{PCT Testing}

Table 9 summarizes the normalized boron release (NL [B]) based on measured compositions for both the quenched and ccc glasses as a function of WL. Three 202-A11 glasses (HTLG-27, -21, 28) targeting 45, 50, and 55\% WL were fabricated on 4-5-07. HTLG-47, -48, and -50 (202-A11 glasses targeting the same glass composition as $-27,-21$, and -28 , respectively) were fabricated at a later date and serve as a measure of reproducibility for this system. The PCT results of the initial 202-A11 glasses are shown in Table 9 as well as the latest results. 
WSRC-STI-2007-00302

Revision 0

Table 9. PCT Results of Quenched and CCC Glasses.

(NL [B], in $\mathrm{g} / \mathrm{L}$ based on measured compositions)

\begin{tabular}{|c|c|c|c||}
\hline Glass ID & WL & $\begin{array}{c}\text { Quenched } \\
\text { (NL [B]) }\end{array}$ & $\begin{array}{c}\text { CCC } \\
\text { (NL [B] })\end{array}$ \\
\hline HTLG-47 & 45 & 0.79 & 3.33 \\
\hline HTLG-48 & 50 & 0.97 & 0.75 \\
\hline HTLG-49 & 55 & 1.20 & 0.72 \\
\hline & & & \\
\hline HTLG-31 & 44 & 0.85 & 1.44 \\
\hline HTLG-32 & 46 & 0.85 & 6.50 \\
\hline HTLG-33 & 48 & 1.01 & 4.01 \\
\hline HTLG-34 & 50 & 1.10 & 1.70 \\
\hline HTLG-35 & 52 & 1.28 & 0.68 \\
\hline HTLG-36 & 54 & 1.21 & 0.70 \\
\hline HTLG-37 & 56 & 1.37 & 0.86 \\
\hline HTLG-38 & 58 & 1.35 & 1.11 \\
\hline & & & \\
\hline HTLG-27 (4-5-07) & 45 & 0.87 & 3.8 \\
\hline HTLG-21 (4-5-07) & 50 & 1.12 & 0.81 \\
\hline HTLG-28 (4-5-07) & 55 & 1.29 & 0.84 \\
\hline \multicolumn{2}{|l|}{} \\
\hline
\end{tabular}

Note: NL [B] (in g/L) for the EA glass is 16.695 .

A high-level review of the data suggests:

1. All Frit 202-A11 HTLG glasses (both quenched and ccc) are acceptable relative to the EA glass benchmark (they are at least an order of magnitude better than the EA glass). HTLG-47ccc is the least durable glass with a NL [B] of $3.33 \mathrm{~g} / \mathrm{L}$. The NL [B] for the EA glass is reported to be $16.695 \mathrm{~g} / \mathrm{L}$. Note that the XRD results indicated the presence of magnetite, aegirine, and nepheline in the HTLG-47ccc sample. The latter two phases are the probable cause of the reduced durability.

2. For the quenched glasses, the durability gradually decreases with increased WL (see Figure 1). This trend is consistent with a previous assessment of PCTs for Frit 202-A11 based glasses. As previously mentioned, given magnetite is the only phase detected in the quenched glasses over the $44-58 \%$ WL range, there should be no practical (or measurable) impact of crystallization on durability. Therefore, the gradual decrease in durability over this WL range is strictly based on the gradual change in glass composition. 
WSRC-STI-2007-00302

Revision 0

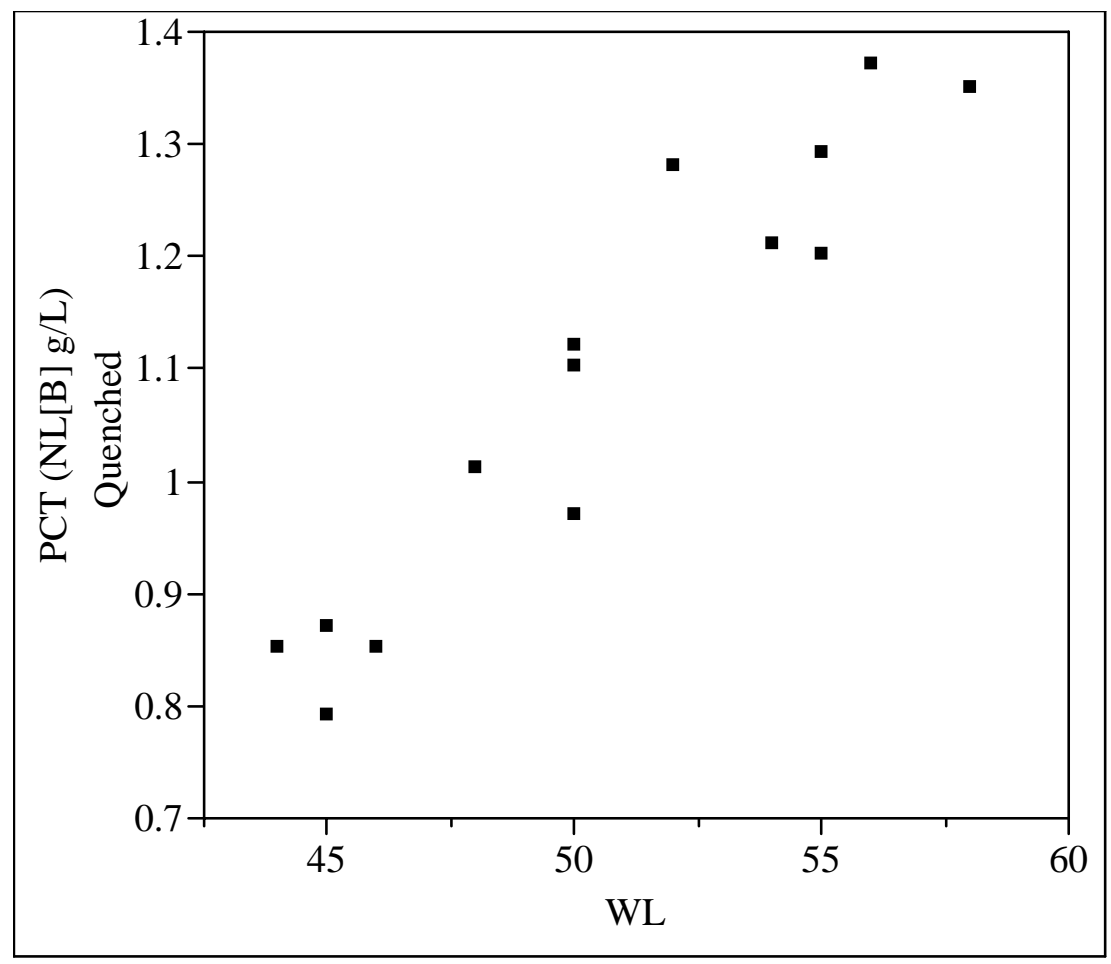

Figure 1. PCT Response (NL [B]) as a Function of WL for the Quenched HTLG Glasses.

3. For the ccc glasses, the durability appears to be a non-linear response as a function of WL (see Figure 2). In general, the intermediate to high WLs ( 50\% to 58\%) result in more durable HTLG ccc glasses. A closer look at these higher WL glasses suggest that there is a gradual decrease in durability with increased WL - which is consistent with their quenched counterparts and is a reflection of a changing glass composition. More specifically, the XRD results of these higher WL ccc glasses (50\% and greater) suggest only magnetite formation which should not have a significant (measurable) impact on durability. At the lower WLs ( $<50 \%$ ), the trend in the ccc PCT response is non-linear. This suggests a stronger impact on the durability response than just a changing composition - that impact being the formation of either aegirine and/or nepheline. When evaluating the PCT response of the HTLG ccC glasses from 44 to $50 \% \mathrm{WL}$, there is a gradual decrease in durability (i.e., increase in NL [B]) followed by an increase in durability. Comparing the PCT response to the XRD results, the impact of crystallization can be seen in the PCTs. Consider HTLG-31ccc (targeting 44\% WL). This glass has a measured PCT NL [B] response of $1.44 \mathrm{~g} / \mathrm{L}$ with XRD analysis indicating the presence of aegirine (no magnetite or nepheline). The formation of aegirine apparently has a small negative impact on the durability response given the quenched version of HTLG-31 has a measured NL [B] of $0.85 \mathrm{~g} / \mathrm{L}$. As WL increases to $45 \%$ (HTLG-47ccc), the formation of nepheline along with aegirine furthers the reduction in durability leading to a PCT response of $3.33 \mathrm{~g} / \mathrm{L}$. As WLs continue to increase up to $50 \% \mathrm{WL}$, the formation of aegirine and nepheline (including the potential increase in volume percentage of these two phases) combined with the changing glass composition to continue to decrease durability. The 46 and 48\% WL HTLG glasses are the two lowest durability glasses tested in this study although both are still acceptable relative to EA. It is noted that the XRD results for the HTLG-32ccc glass did not indicate nepheline formation although the 
45\% (HTLG-47ccc) and 48\% (HTLG-33ccc) glasses were characterized with nepheline. The non-linear PCT response over the $44-50 \%$ WL range in this glass forming system appears to be related to the formation of aegirine and nepheline and the concurrent effect of a changing glass composition.

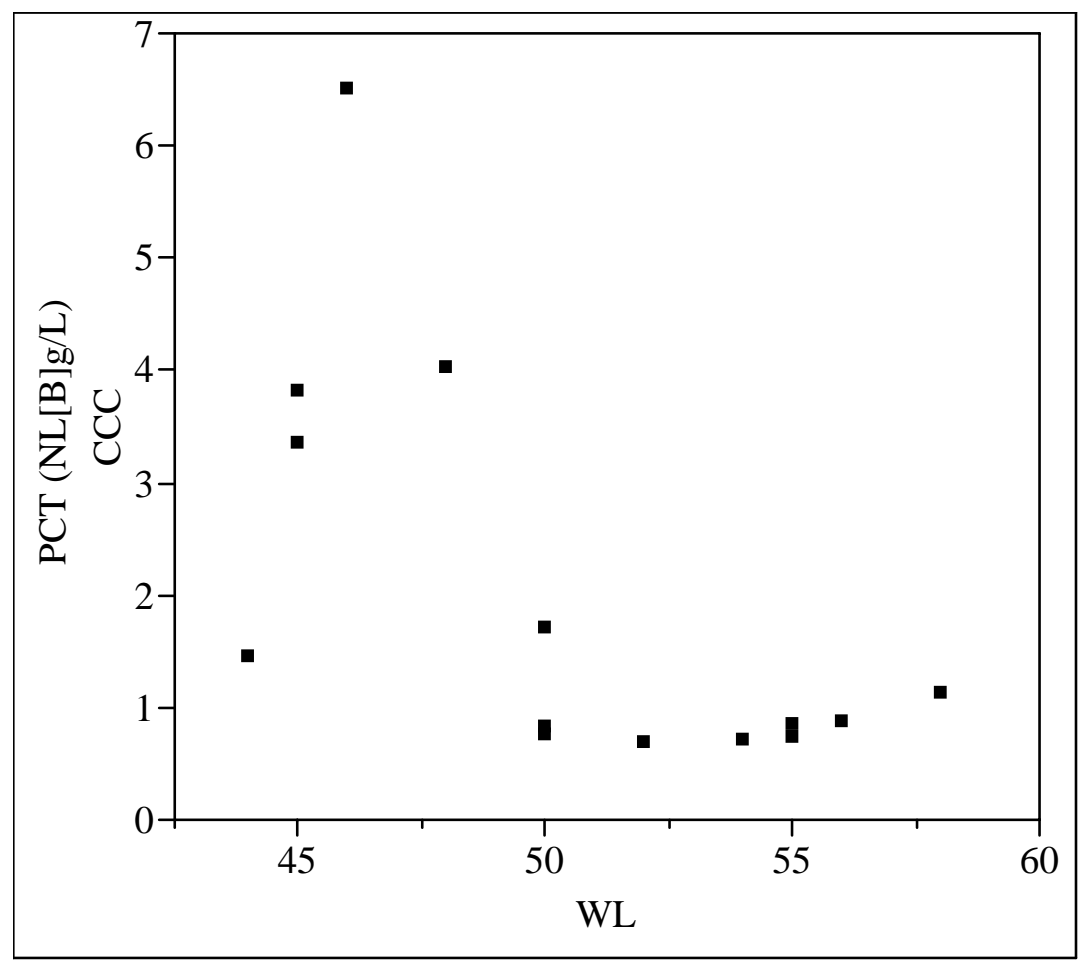

Figure 2. PCT Response (NL [B]) as a Function of WL for the CCC HTLG Glasses.

4. The PCT response for the 202-A11 glasses fabricated on 4-5-07 (HTLG-27, -21, -28) are consistent with those recently fabricated (HTLG-47, -48, and -50). This provides a measure of reproducibility.

From a CCIM demonstration perspective, the PCT results suggest that higher WLs should be targeted to avoid possible negative impacts of crystallization on durability. It is noted, however, that all of the HTLG glasses (both quenched and сcc) are acceptable relative to the EA glass. A concern with the non-linear response at the lower WLs is the fact that the PCT results are based on glasses targeting the nominal SB3 composition, and if sludge variation is introduced, there is an unknown response or behavior that exists. Other considerations such as $\mathrm{T}_{\mathrm{L}}$ (discussed in Section 5.5) also need to be evaluated and balanced with the PCT results.

\subsection{Liquidus Temperature}

Figures 3 - 5 show optical micrographs of HTLG-21 (50\% WL, fabricated on 04-05-07) after the 24 hour heat treatments at nominally $1150^{\circ}, 1200^{\circ}$, and $1250^{\circ} \mathrm{C}$, respectively. ${ }^{7}$ The sample heat treated at $1150^{\circ} \mathrm{C}$ contains significant quantities of crystallites (Figure 3). No formal

\footnotetext{
${ }^{7}$ HTLG-21 was a glass produced during the scoping study phase of this program. The target composition is identical to both HTLG-48 and HTLG-34 as listed in Tables 3 and 4, respectively.
} 
determination of the crystalline phase(s) was attempted, but based on morphology and XRD results of as-fabricated HTLG glasses (refer to Section 5.3), the crystalline phase appears to be spinel. At $1200^{\circ} \mathrm{C}$ (Figure 4), the quantity of spinels found in the bulk HTLG-21 sample decreases, but the volume fraction of crystallization observed indicates that the $T_{L}$ of the glass is greater than $1200^{\circ} \mathrm{C}$. Figure 5 shows a "cluster" of spinels located at the bottom of the crucible. Clustering at the bottom of the crucible may be indicative of settling as the viscosity of the glass system decreases with increased heat treatment temperature. Based on a comparison of the $1250^{\circ} \mathrm{C}$ heat treated sample with the as-received glass, the $T_{L}$ of this system appears to be approximately $1250^{\circ} \mathrm{C}-1275^{\circ} \mathrm{C}$.

It should be noted that models developed for another program have subsequently been used to predict various properties of select Frit 202-A11 based glasses. The predictions of an alternative $\mathrm{T}_{\mathrm{L}}$ model for the 45,50 , and $55 \% \mathrm{WL}$ glasses were $1188.2^{\circ}, 1250.6^{\circ}$, and $1297^{\circ} \mathrm{C}$, respectively. These predictions are more in-line with the measured $\mathrm{T}_{\mathrm{L}}$ response for the $50 \% \mathrm{WL}$, HTLG-21 glass. This information is not presented as a critique of the current DWPF $\mathrm{T}_{\mathrm{L}}$ model but to indicate that the glass compositional region of interest in this study may not overlap with that over which the current DWPF model was developed. It should be noted that the alternative models, although they appear to be more applicable, are not fully developed but could be used as a technical basis from which to revisit property models for this system.

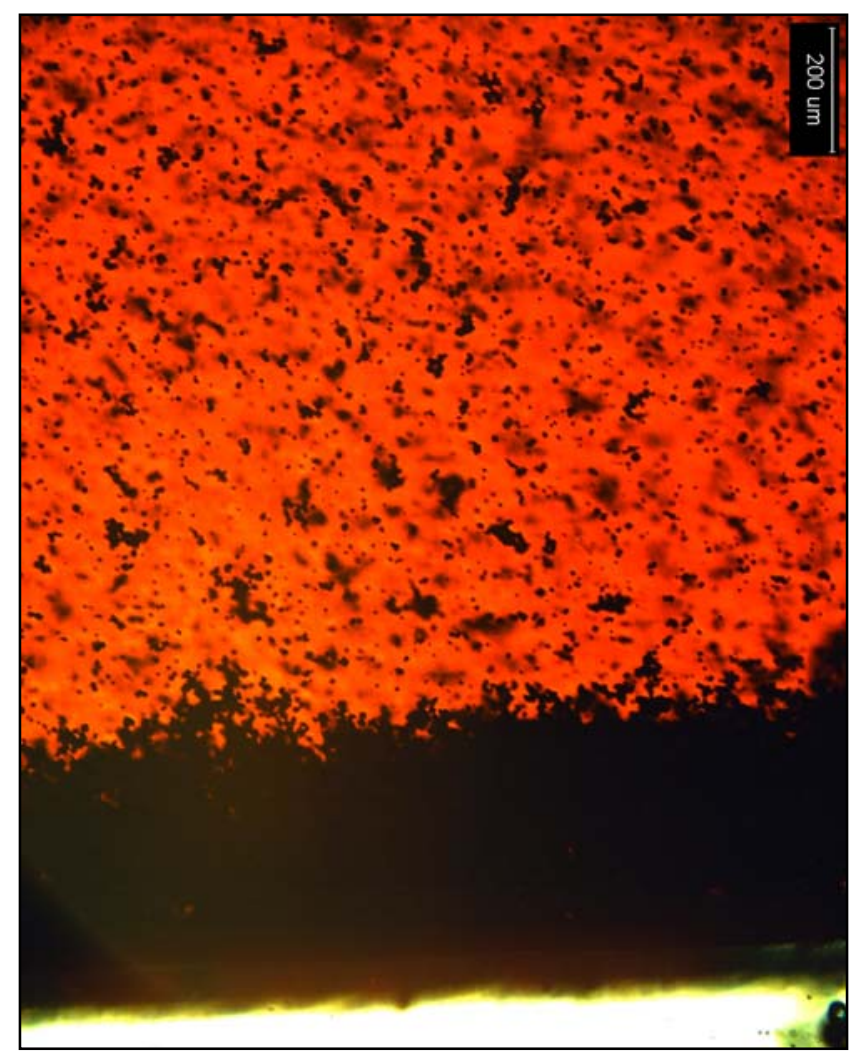

Figure 3. Optical Micrograph of the 202-A11 at 50\% WL (HTLG-21) after a 24 hour, $1150^{\circ} \mathrm{C}$ Heat Treatment. Photo taken near the crucible bottom at 100x. 


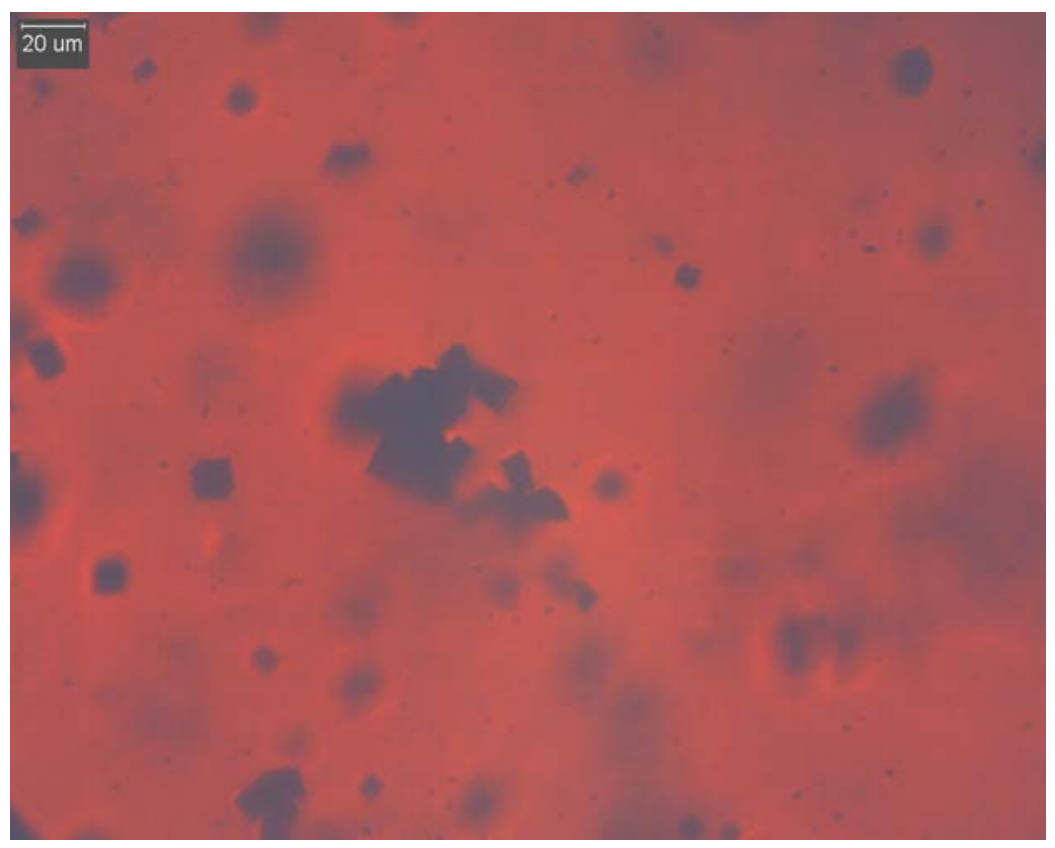

Figure 4. Optical Micrograph of the 202-A11 at 50\% WL (HTLG-21) after a 24 hour, $1200^{\circ} \mathrm{C}$ Heat Treatment. Photo taken of bulk sample at 500x.

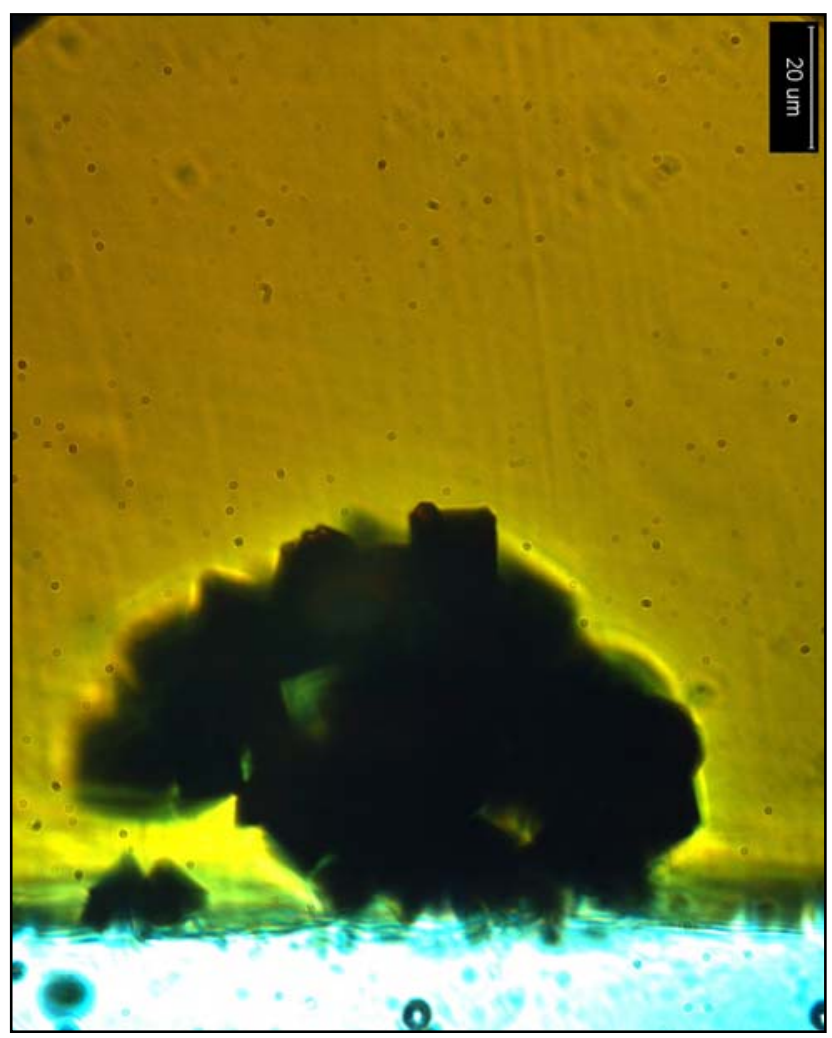

Figure 5. Optical Micrograph of the 202-A11 at 50\% WL (HTLG-21) after a 24 hour, $1250^{\circ} \mathrm{C}$ Heat Treatment. Photo taken of bulk sample (near crucible bottom) at 1000x. 


\subsection{Viscosity}

Viscosity $(\eta)$ as a function of temperature was measured by a rotating spindle technique for HTLG-21 (202-A11 at 50\% WL) ${ }^{8}$, and the results are provided in Table 10 . The measured viscosity of the HTLG-21 glass at $1250^{\circ} \mathrm{C}$ was approximately 20 Poise. Although the viscosity readings were relatively stable at $1250^{\circ} \mathrm{C}$, it is noted that the results may have been influenced by the presence of spinels given the isothermal heat treatments discussed in Section 5.5. The viscosity measurements were also relatively stable at $1200^{\circ} \mathrm{C}$; however, given the volume percent of spinels observed in the $1200^{\circ} \mathrm{C}$ isothermal heat treatment, this data point should be viewed and used with caution. The more reliable viscosity measurements are those at or above $1275^{\circ} \mathrm{C}$, temperatures above the estimated $\mathrm{T}_{\mathrm{L}}$ for this glass.

Table 10. Measured Viscosity Data as a Function of Temperature for HTLG-21.

\begin{tabular}{||c|c||}
\hline \multicolumn{2}{|c|}{ HTLG-21 } \\
\hline $\begin{array}{c}\text { Temperature } \\
\left({ }^{\circ} \mathrm{C}\right)\end{array}$ & $\begin{array}{c}\text { Viscosity } \\
\text { (Poise) }\end{array}$ \\
\hline 1300 & $\sim 13$ \\
\hline 1275 & $\sim 16$ \\
\hline 1250 & $\sim 20$ \\
\hline 1200 & $\sim 38$ \\
\hline$<1200$ & $\begin{array}{c}\text { Unstable } \\
\text { readings }\end{array}$ \\
\hline
\end{tabular}

\footnotetext{
${ }^{8}$ As previously mentioned, HTLG-21 was a glass produced during the scoping study phase of this program. The target composition is identical to both HTLG-48 and HTLG-34 as listed in Tables 3 and 4, respectively.
} 
WSRC-STI-2007-00302

Revision 0

\subsection{Summary}

A demonstration of the CCIM technology is currently planned for the fall of 2007 to assess the potential for attaining higher waste throughputs. The CCIM demonstrations will be based on a DWPF waste slurry feed surrogate with a nominal operating temperature of approximately $1250^{\circ} \mathrm{C}$ (higher temperatures may be used). The waste slurry feed (nominally 45 - 50 weight percent solids) surrogate will be representative of SB3 in order to allow a direct comparison to the DWPF joule heated melter performance during processing of this sludge waste. This pilot scale demonstration is being conducted to evaluate performance and to identify potential processing issues with the existing CCIM technology and will include characterization of the resultant glass product to ensure current product performance (durability) specifications are met.

The information presented in this data packet provides a technical basis from which decisions regarding the melter demonstration can be made. More specifically, the results presented in this report provide technical data on the impact of WL on critical properties of interest - in particular, durability, liquidus temperature, and viscosity.

All of the glasses of this study, regardless of heat treatment, were acceptable when their durabilities were compared to those of the EA glass. In general, as WL increases, the durabilities for the quenched versions of the glasses tend to decrease due to the changing composition of the glass. For the glasses subjected to the ccc regime, the durability response appears to be more non-linear as WL increases. At WLs less than 50\%, XRD analysis indicates the potential for the presence of aegirine and/or nepheline crystalline phases, and when these phases are present, there is a decrease in the durability of the glass. As WL is increased above $50 \%$, there is a transition from the aegirine and/or nepheline phases to a spinel phase field leading to more durable glasses.

The results for durability suggest that WLs of $50 \%$ or greater should be targeted for the CCIM demonstration, thus, avoiding the potential for the formation of aegirine and/or nepheline. However, if decisions to target WLs of $50 \%$ or greater are made, $\mathrm{T}_{\mathrm{L}}$ measurements indicate that there could be some degree of crystallization within the melter if a nominal $1250^{\circ} \mathrm{C}$ temperature is used. It is also anticipated that increasing WLs will lead to higher $\mathrm{T}_{\mathrm{L}}$ 's. Specifically, the $\mathrm{T}_{\mathrm{L}}$ of the $50 \%$ WL glass (HTLG-21) was measured to be slightly above $1250^{\circ} \mathrm{C}$. To minimize the potential of crystallization during processing, higher melt temperatures could be targeted which not only could allow for higher WLs to be obtained but will also result in a reduction in viscosity, which in itself could pose certain processing issues (the ability to control the pour and the possibility of increased volatility). The viscosity of the $50 \%$ WL glass at $1250^{\circ}$ and $1300^{\circ} \mathrm{C}$ was measured to be 20 and 13 Poise, respectively. Thus, a balance between processing and product performance issues may be required for the initial CCIM demonstrations since the frit development efforts to date were not necessarily intended to optimize this glass system nor have these efforts accounted for the variation from the intended target that is likely to occur in the composition of the waste slurry feed surrogate that is being used in the study. 


\subsection{Path Forward}

The following research activities are currently in progress or planned.

$>$ Perform electrical conductivity measurements on the HTLG-21 glass.

$>$ Perform a variability study to assess the potential impacts of compositional variation and/or WL on product performance. A test matrix has been developed and glasses are currently being fabricated based on the application of compositional uncertainty of the sludge. The primary objective of this study is to evaluate or identify possible sludge composition - frit combinations that may lead to an unacceptable glass (in terms of product performance). 
WSRC-STI-2007-00302

Revision 0

\subsection{References}

ASTM. 2002. "Standard Method for Determining Chemical Durability of Nuclear Waste Glasses: The Product Consistency Test (PCT),” ASTM C-1285-2002.

Jantzen, CM, NE Bibler, DC Beam, CL Crawford and MA Pickett. 1993. Characterization of the Defense Waste Processing Facility (DWPF) Environmental Assessment (EA) Glass Standard Reference Material, WSRC-TR-92-346, Revision 1, Westinghouse Savannah River Company, Aiken, South Carolina.

Peeler, DK, TB Edwards, CC Herman, IA Reamer, RJ Workman, JD Vienna, JV Crum, DE Smith, and DS Kim. 2002. Development of High Waste Loading Glasses for Advanced Melter Technologies, WSRC-TR-2002-00426, Revision 0, Westinghouse Savannah River Company, Aiken, South Carolina.

Peeler, DK. 2007. CCIM Testing: Status of Glass Formulation Activities, SRNL-PSE2007-00070, Washington Savannah River Company, Aiken, South Carolina. 


\section{Appendix A}

\section{Digital Photos of Quenched (As-Fabricated) Based HTLG Glasses}




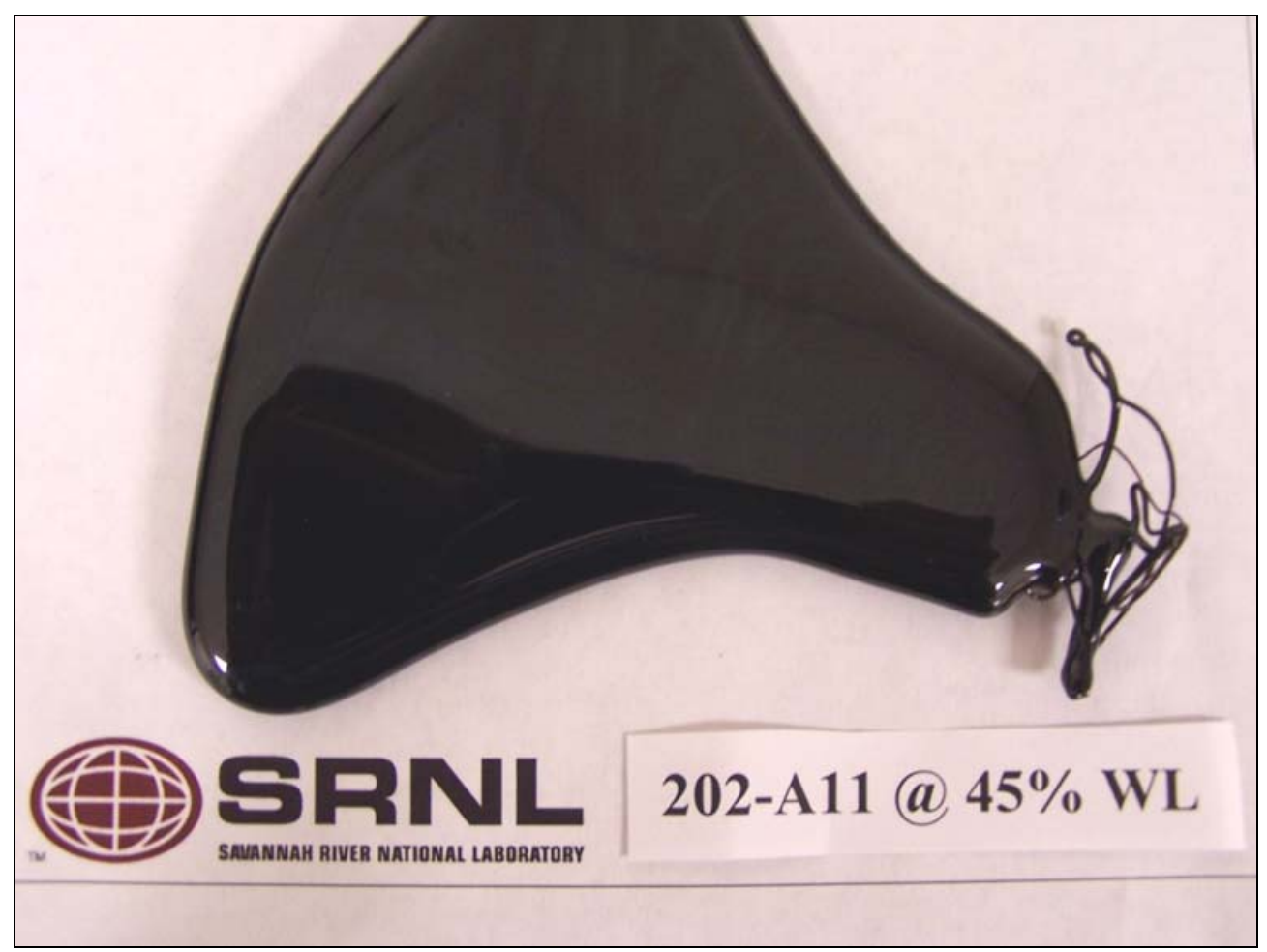

Figure A1. HTLG-47: 202-A11 @ 45\% WL

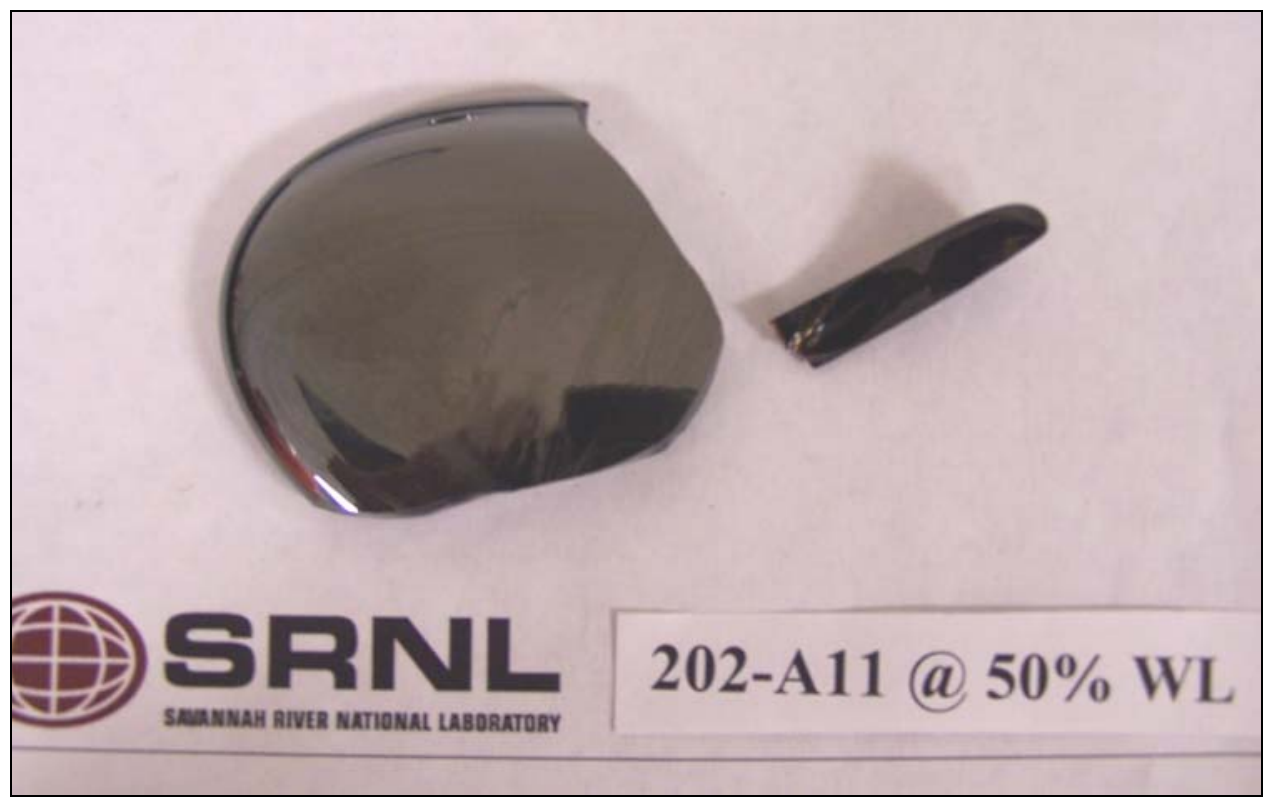

Figure A2. HTLG-48: 202-A11 @ 50\% WL 


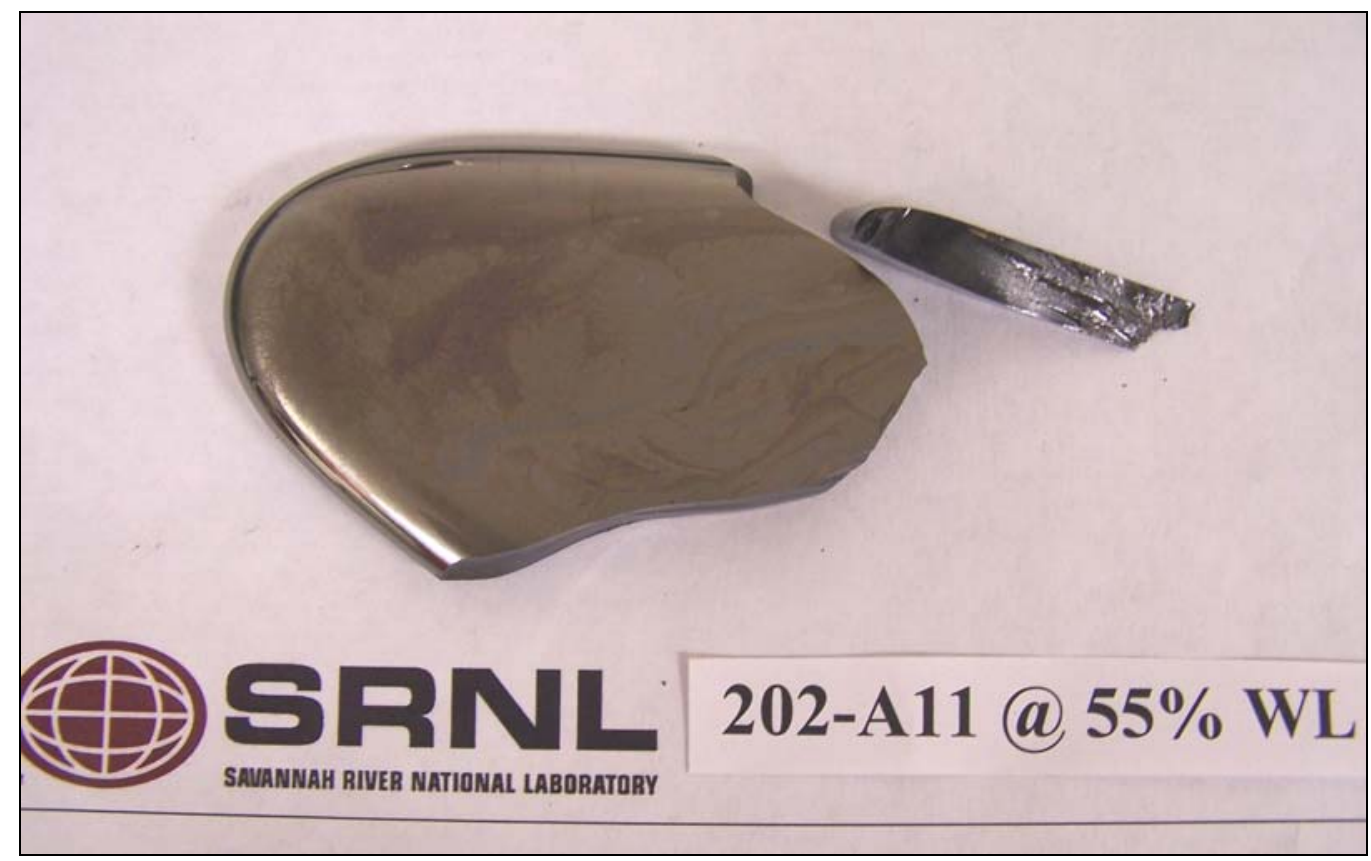

Figure A3. HTLG-49: 202-A11 @ 55\% WL 


\section{2-A11 Waste Loading Series}

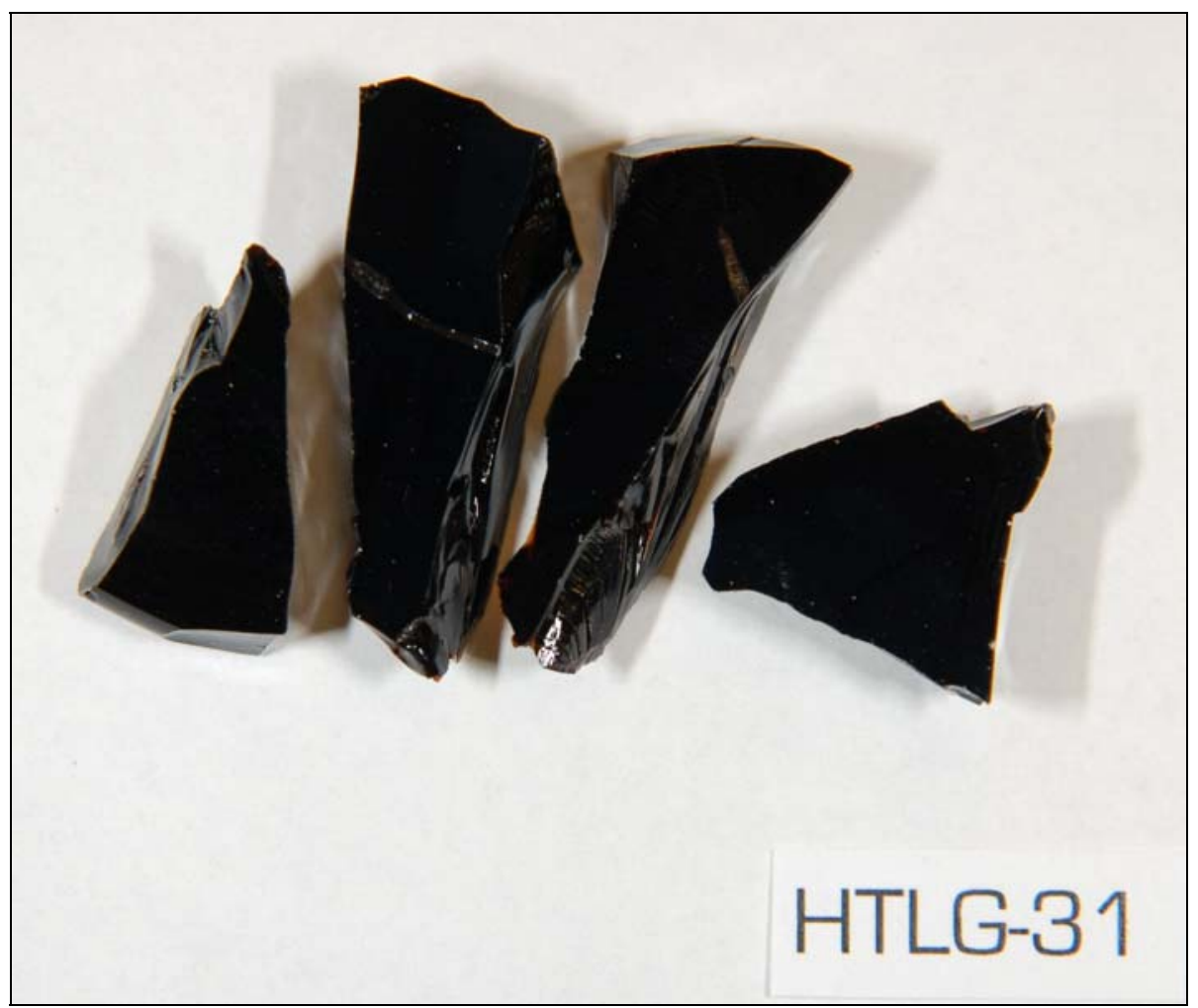

Figure A4. HTLG-31: 202-A11 @ 44\% WL

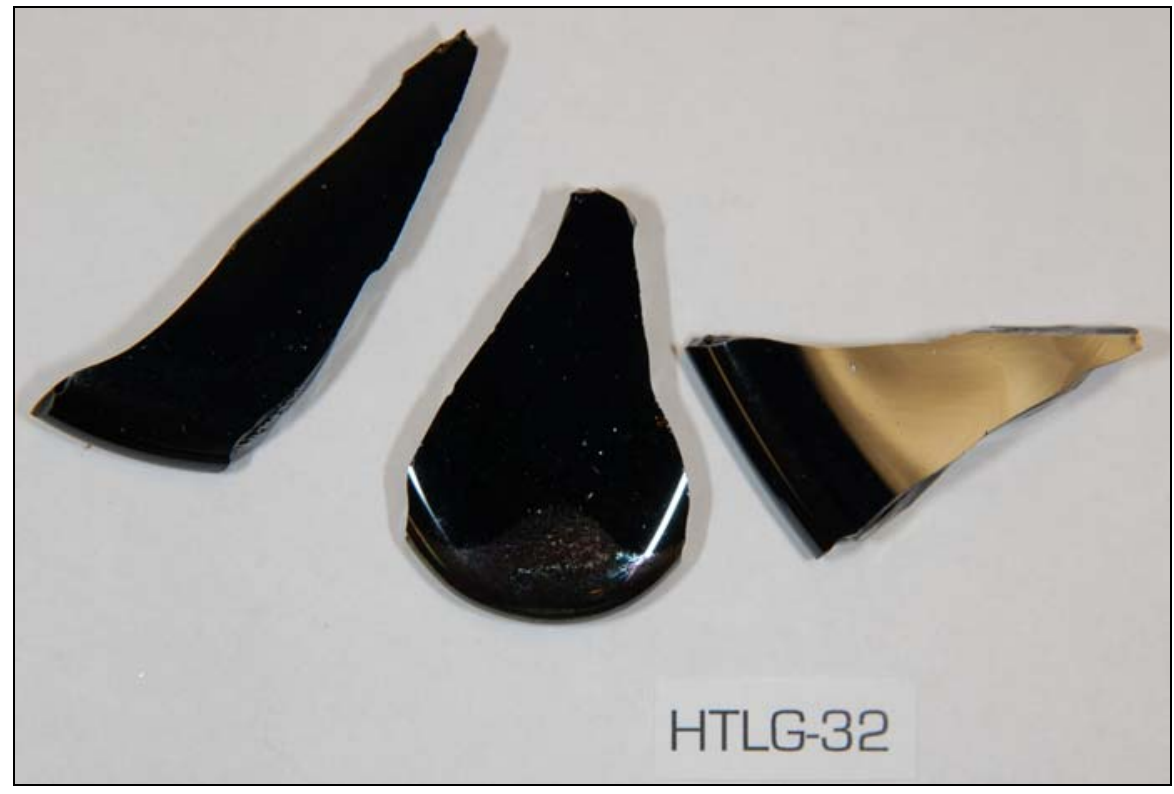

Figure A5. HTLG-32: 202-A11 @ 46\% WL 


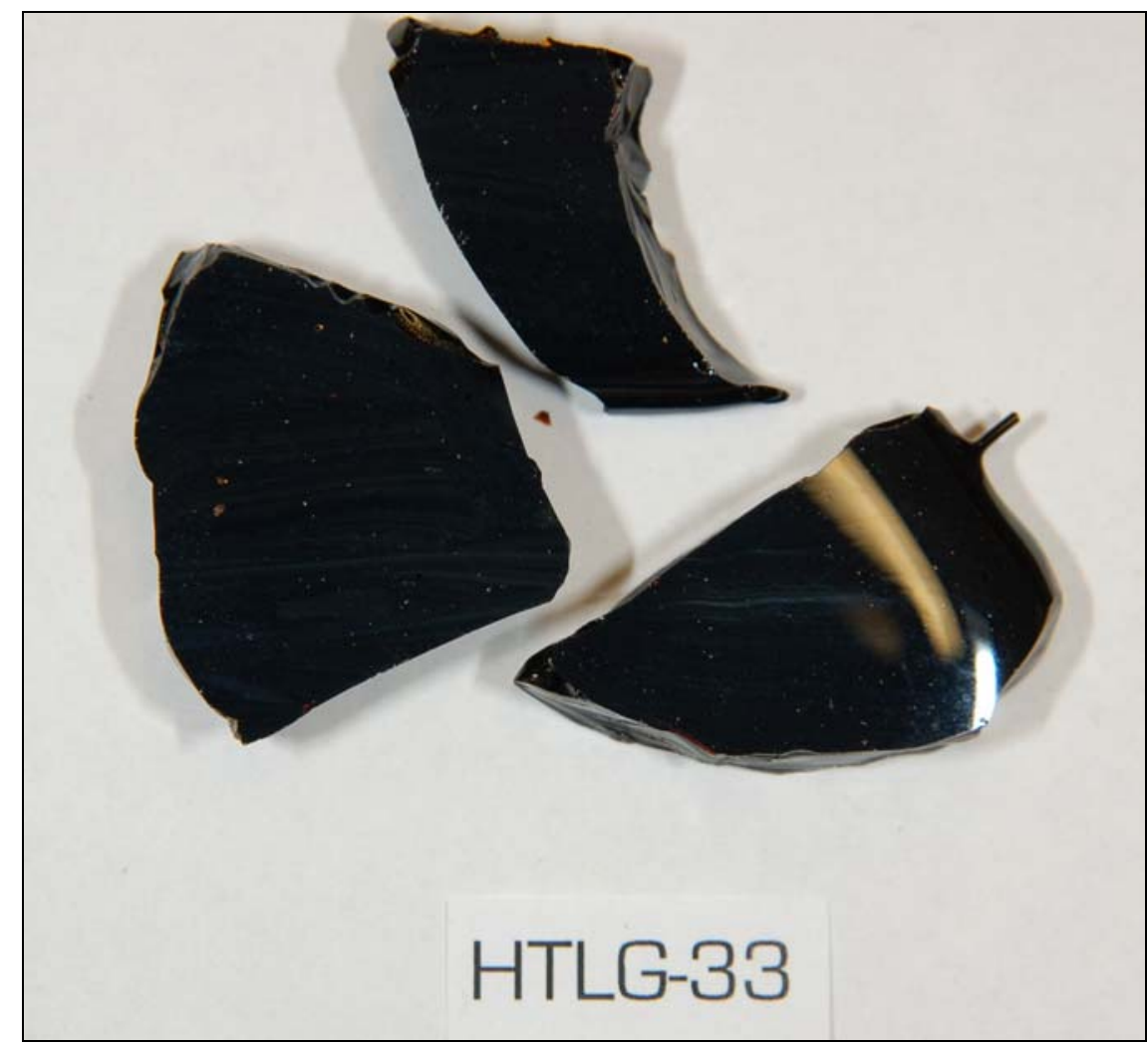

Figure A6. HTLG-33: 202-A11 @ 48\% WL

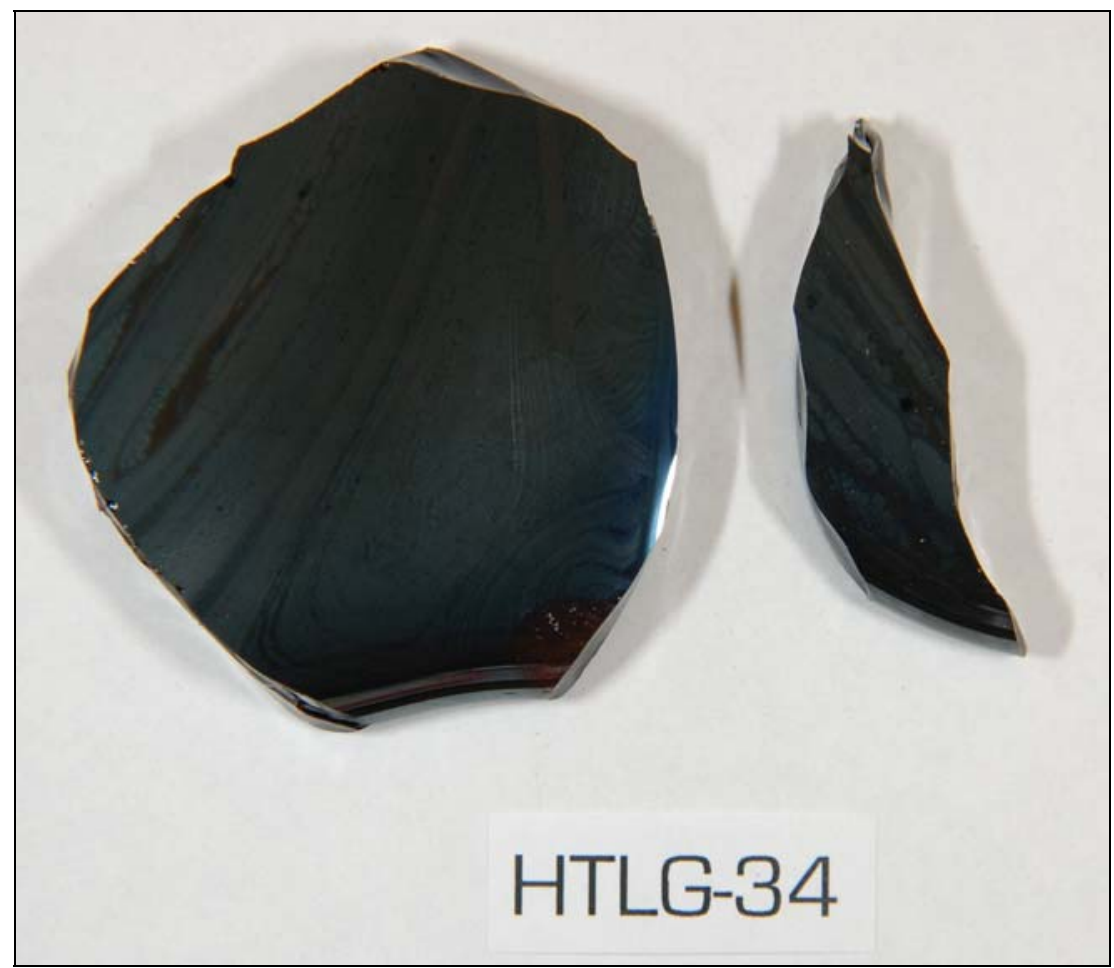

Figure A4. HTLG-34: 202-A11 @ 50\% WL 


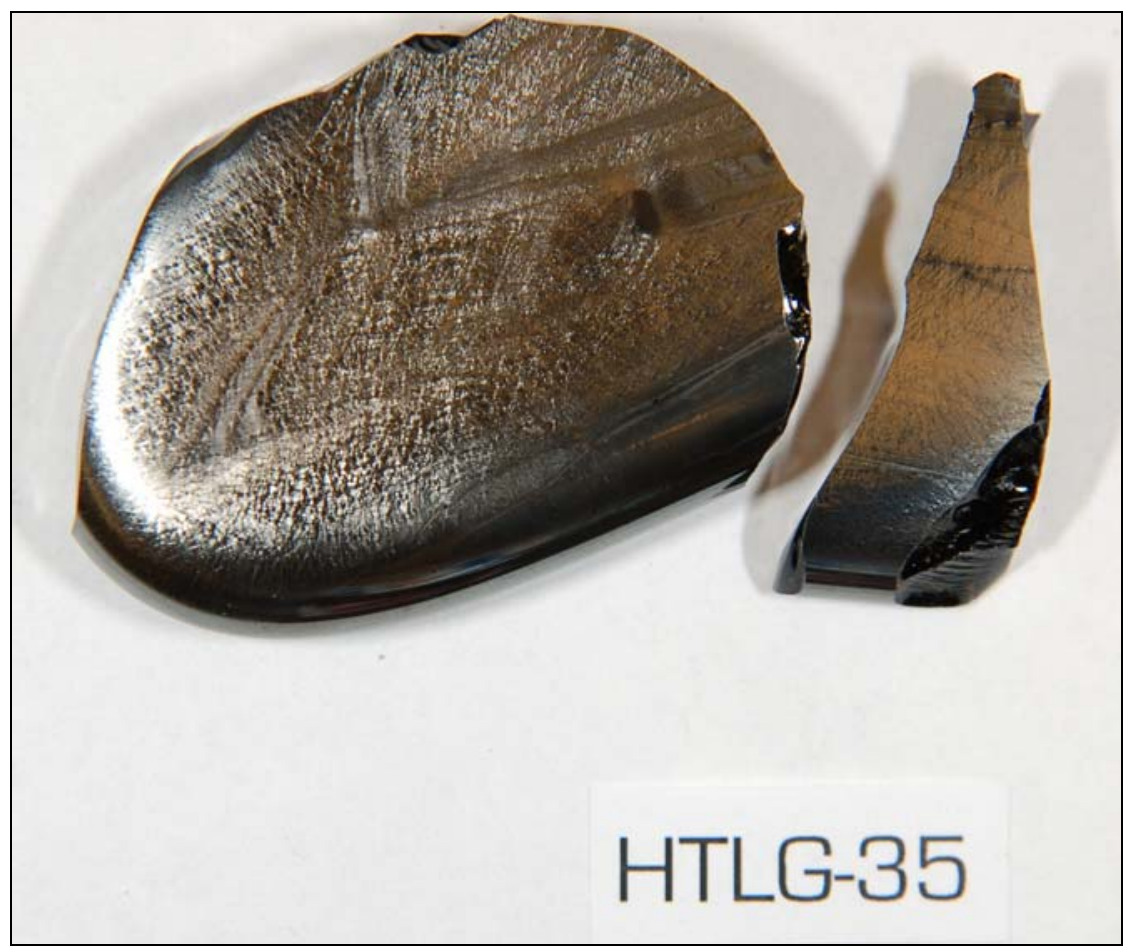

Figure A5. HTLG-35: 202-A11 @ 52\% WL

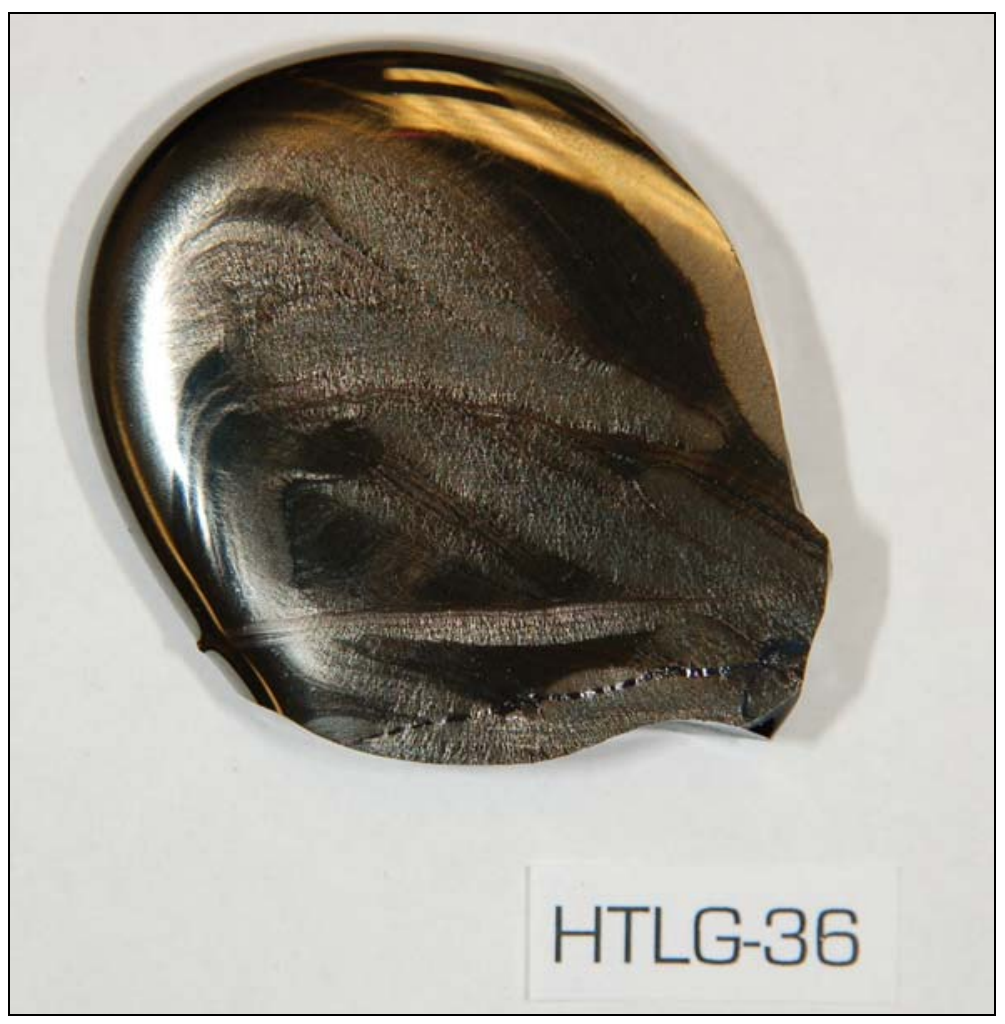

Figure A6. HTLG-36: 202-A11 @ 54\% WL 


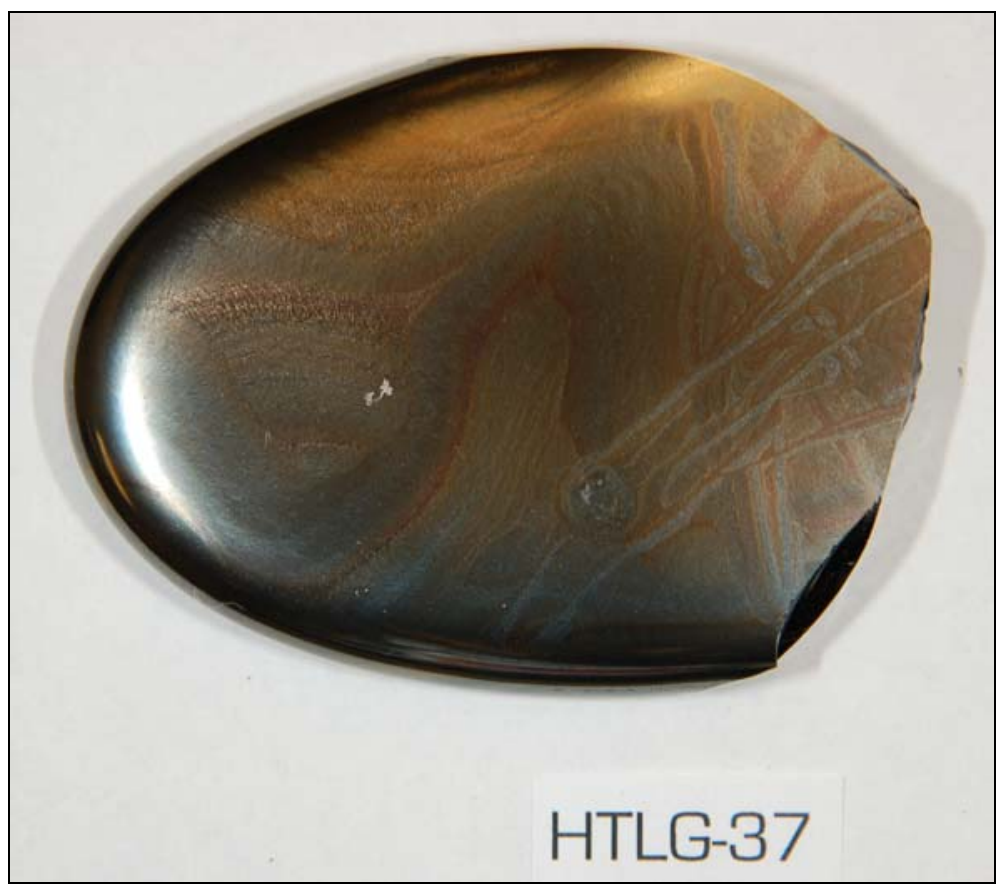

Figure A4. HTLG-37: 202-A11 @ 56\% WL

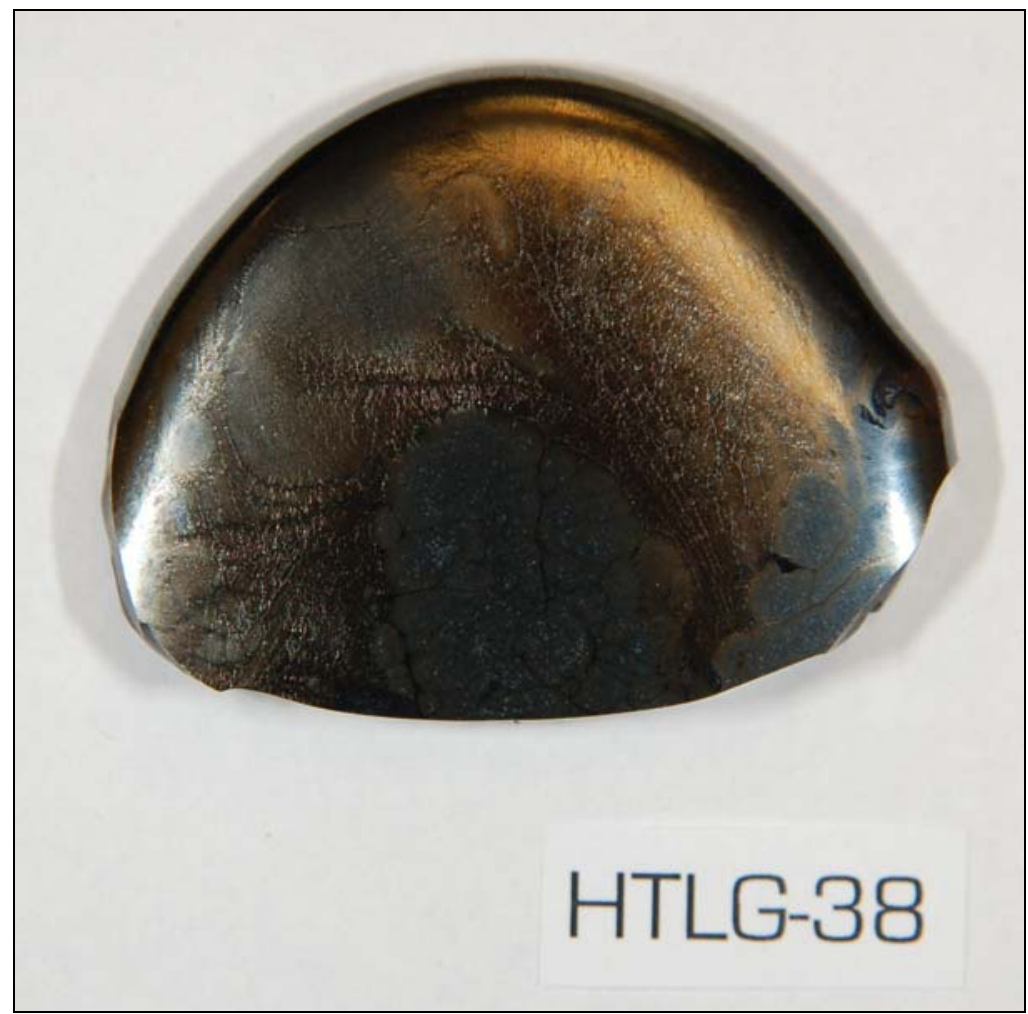

Figure A5. HTLG-38: 202-A11 @ 58\% WL 
WSRC-STI-2007-00302

Revision 0

\section{Appendix B}

\section{Digital Photos of CCC Based HTLG Glasses}




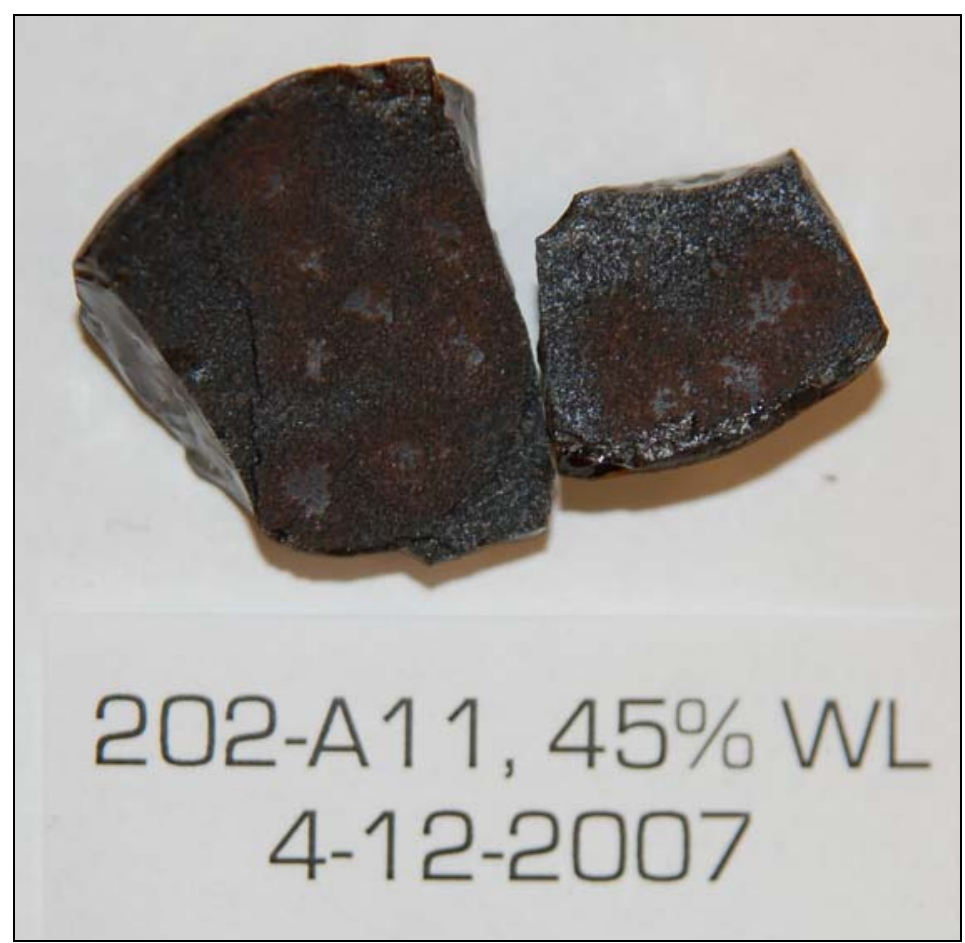

Figure B1. HTLG-47ccc: 202-A11 @ 45\% WL

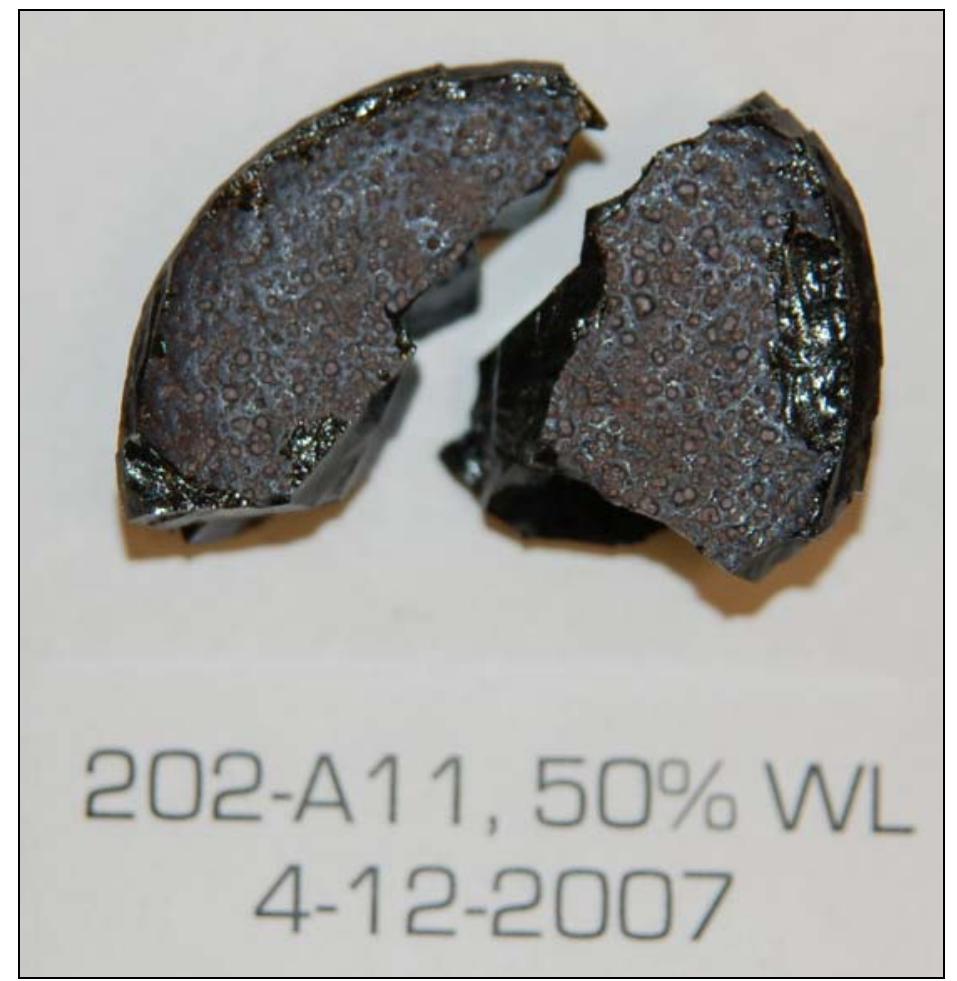

Figure B2. HTLG-48ccc: 202-A11 @ 50\% WL 


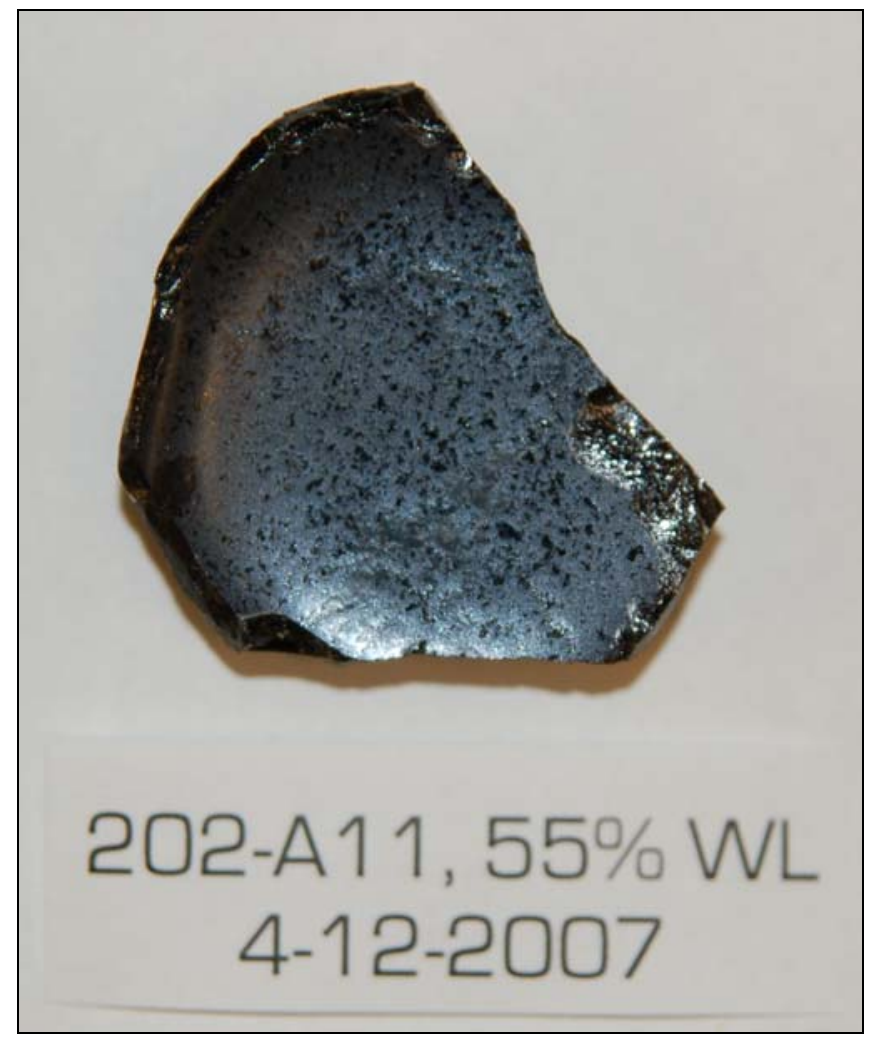

Figure B3. HTLG-49ccc: 202-A11 @ 55\% WL 
WSRC-STI-2007-00302

Revision 0

\section{Appendix C}

\section{X-Ray Diffraction Results}




\section{Quenched Glasses}

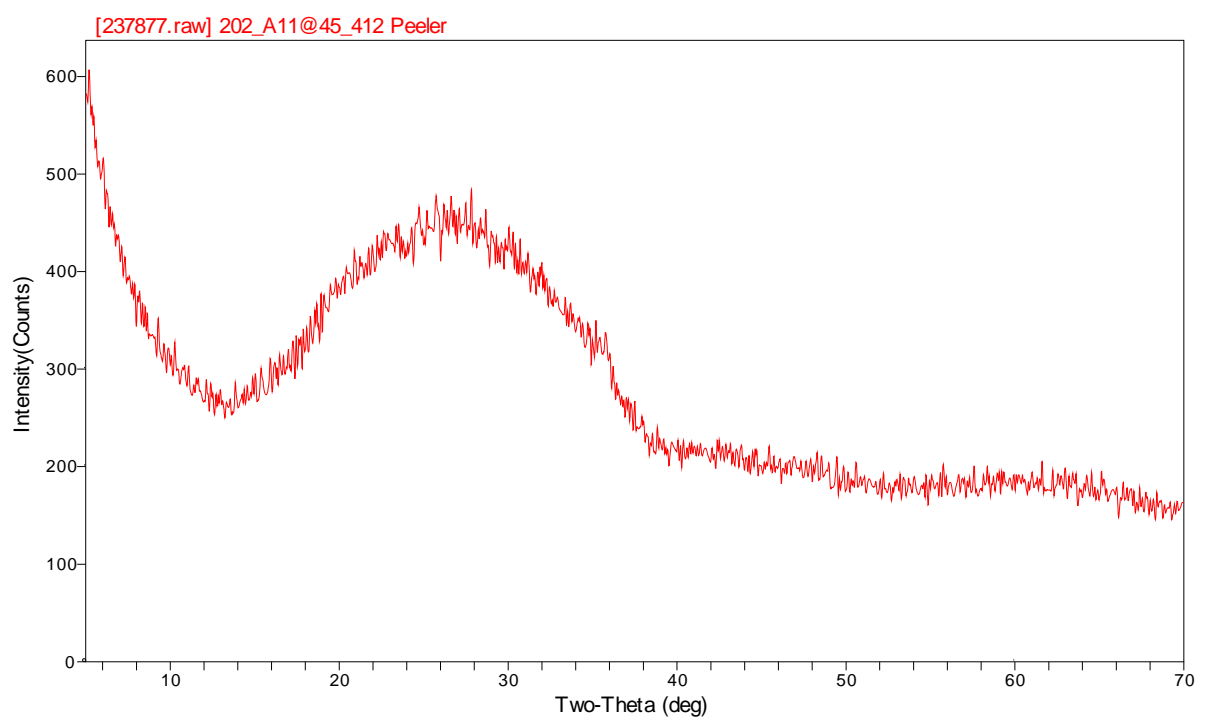

Figure C1. HTLG-47: 202-A11 @ 45\% WL

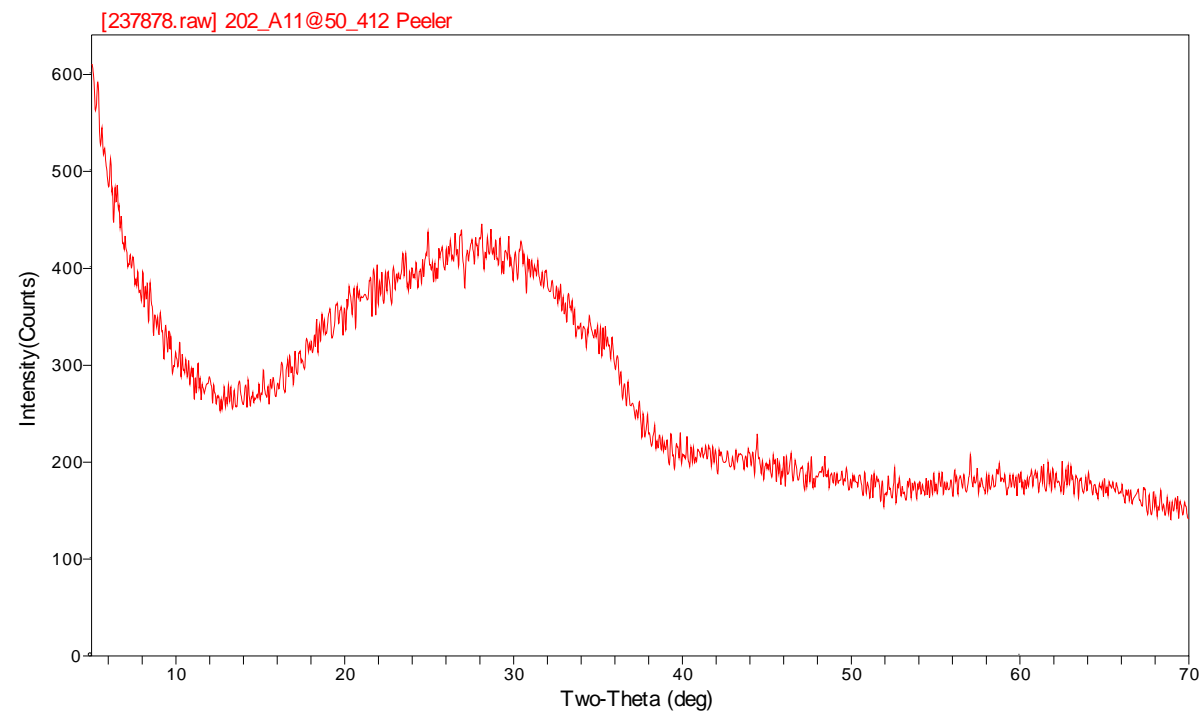

Figure C2. HTLG-48: 202-A11 @ 50\% WL 
WSRC-STI-2007-00302

Revision 0

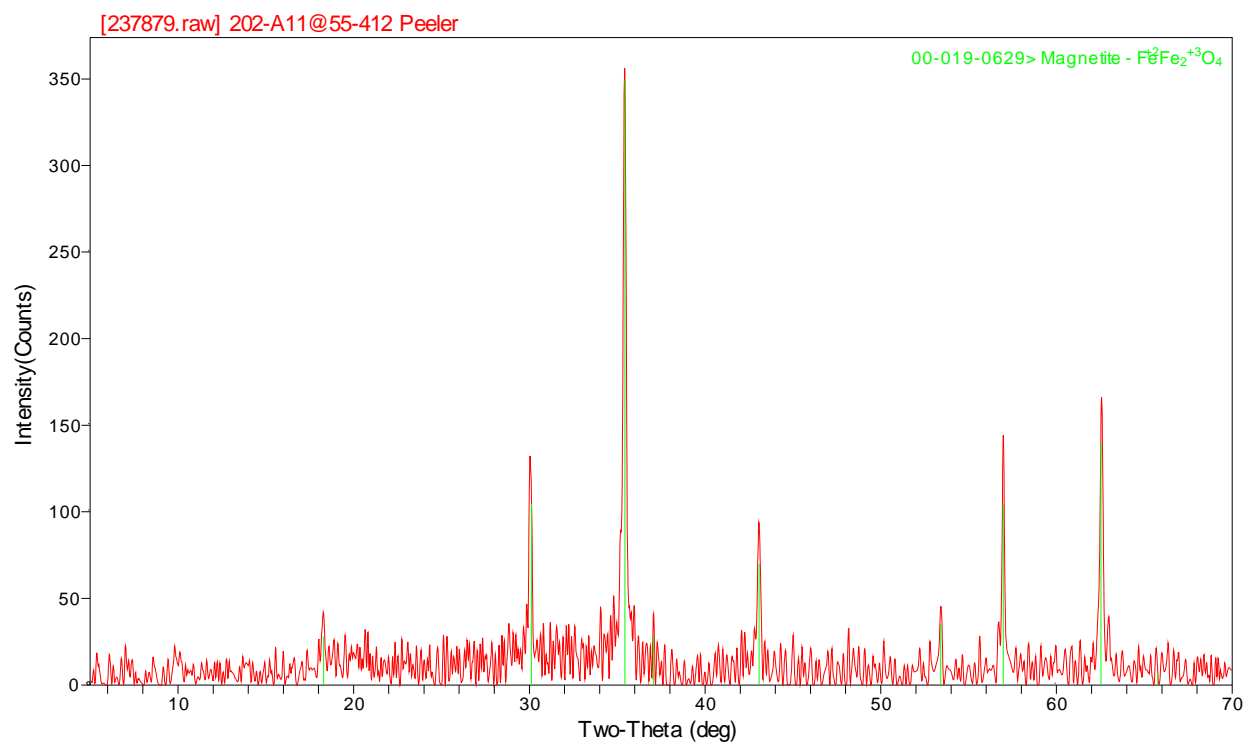

Figure C3. HTLG-49: 202-A11 @ 55\% WL 


\section{2-A11 Waste Loading Series}

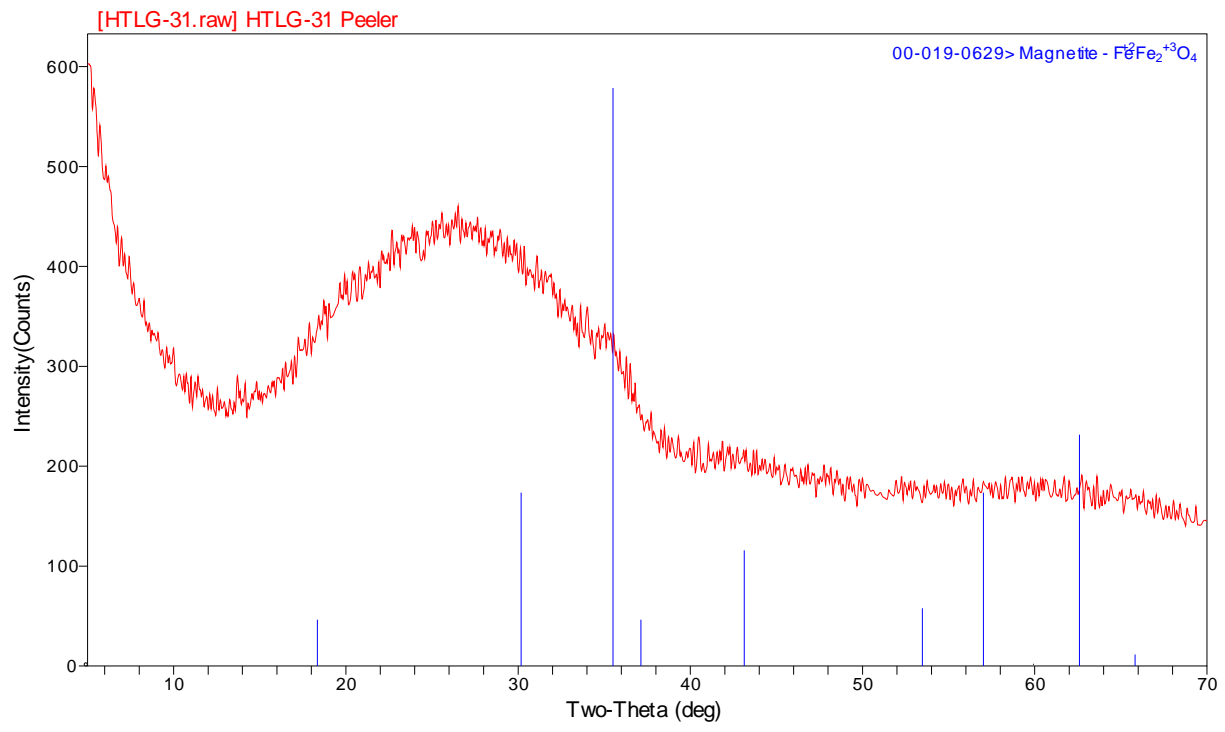

Figure C4. HTLG-31: 202-A11 @ 44\% WL

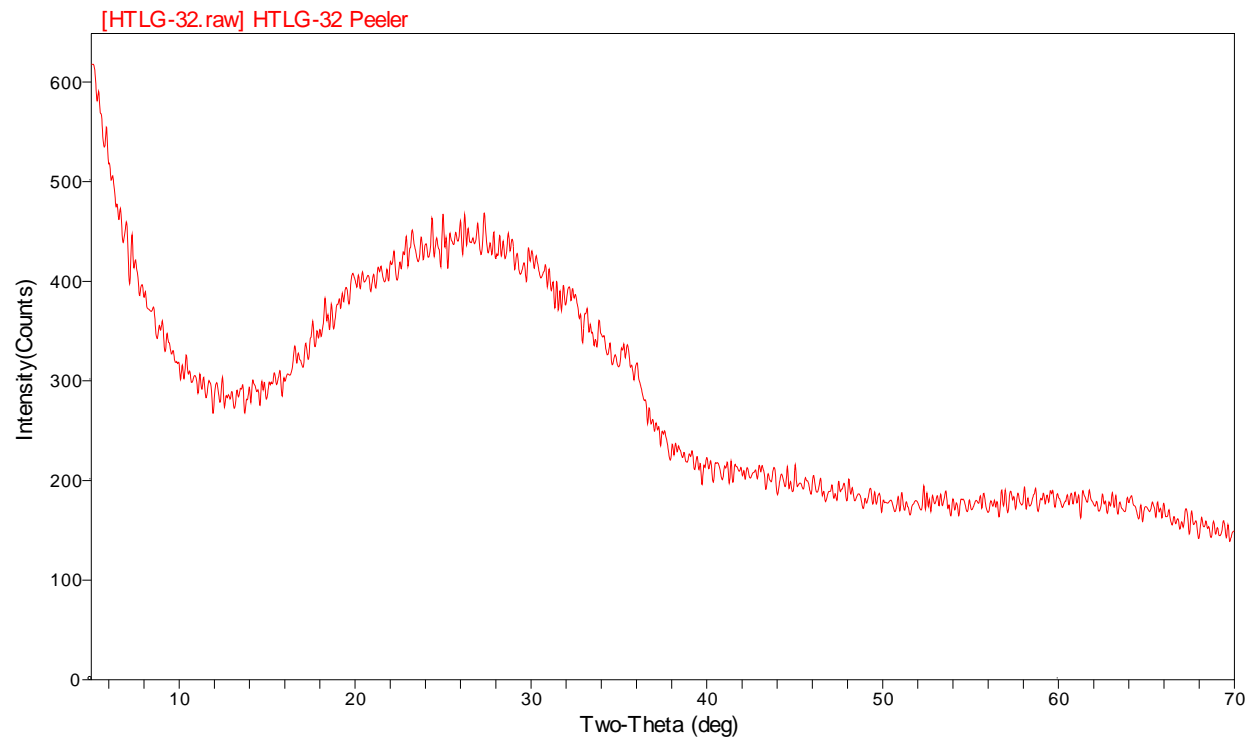

Figure C5. HTLG-32: 202-A11 @ 46\% WL 
WSRC-STI-2007-00302

Revision 0

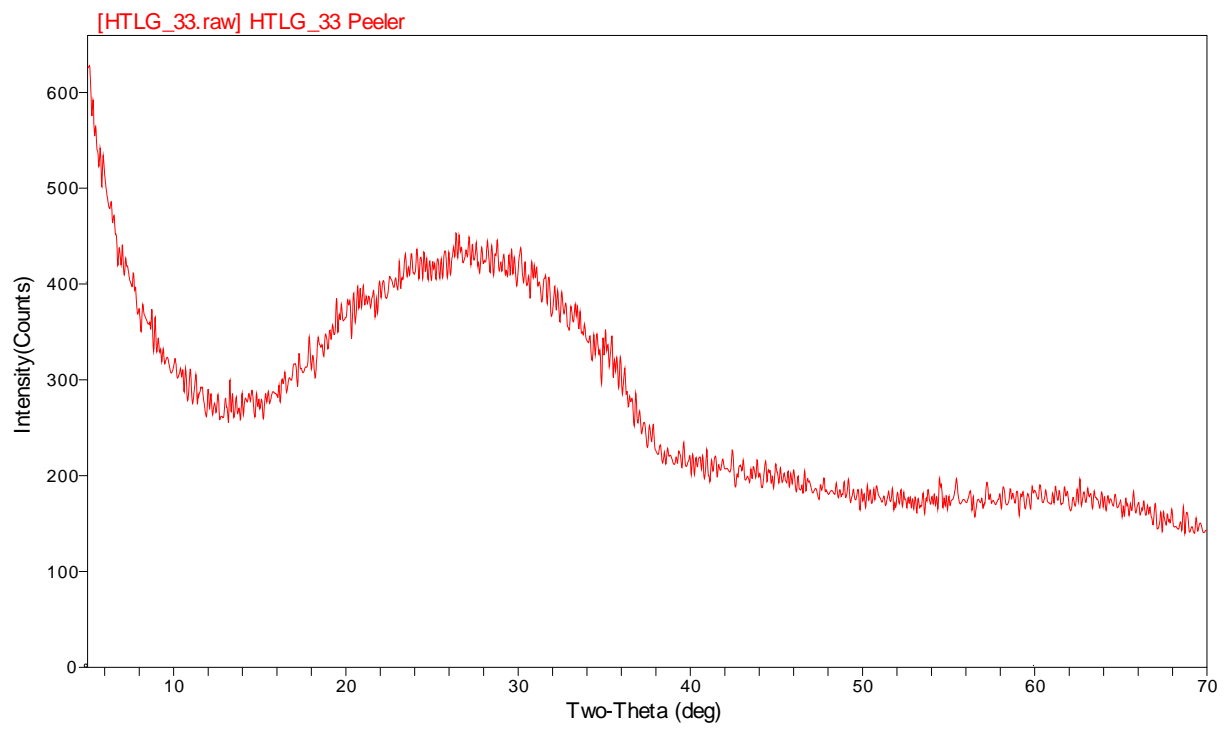

Figure C6. HTLG-33: 202-A11 @ 48\% WL

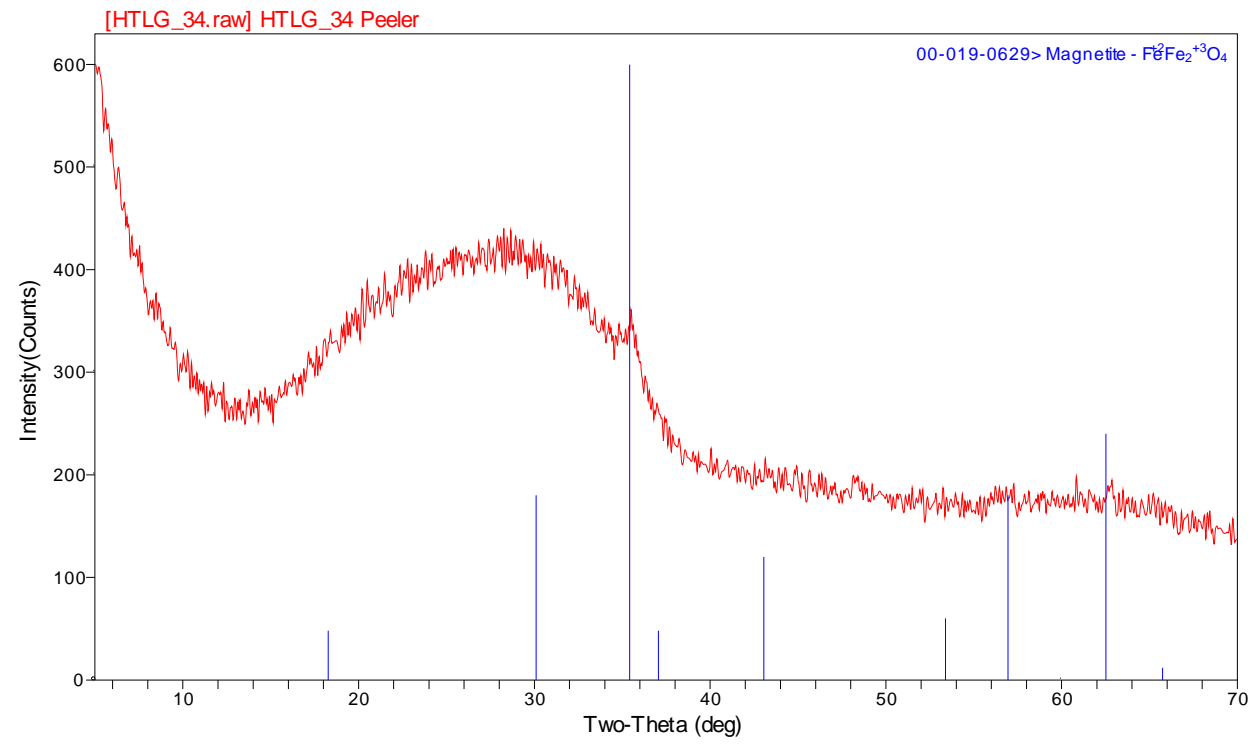

Figure C7. HTLG-34: 202-A11 @ 50\% WL 
WSRC-STI-2007-00302

Revision 0

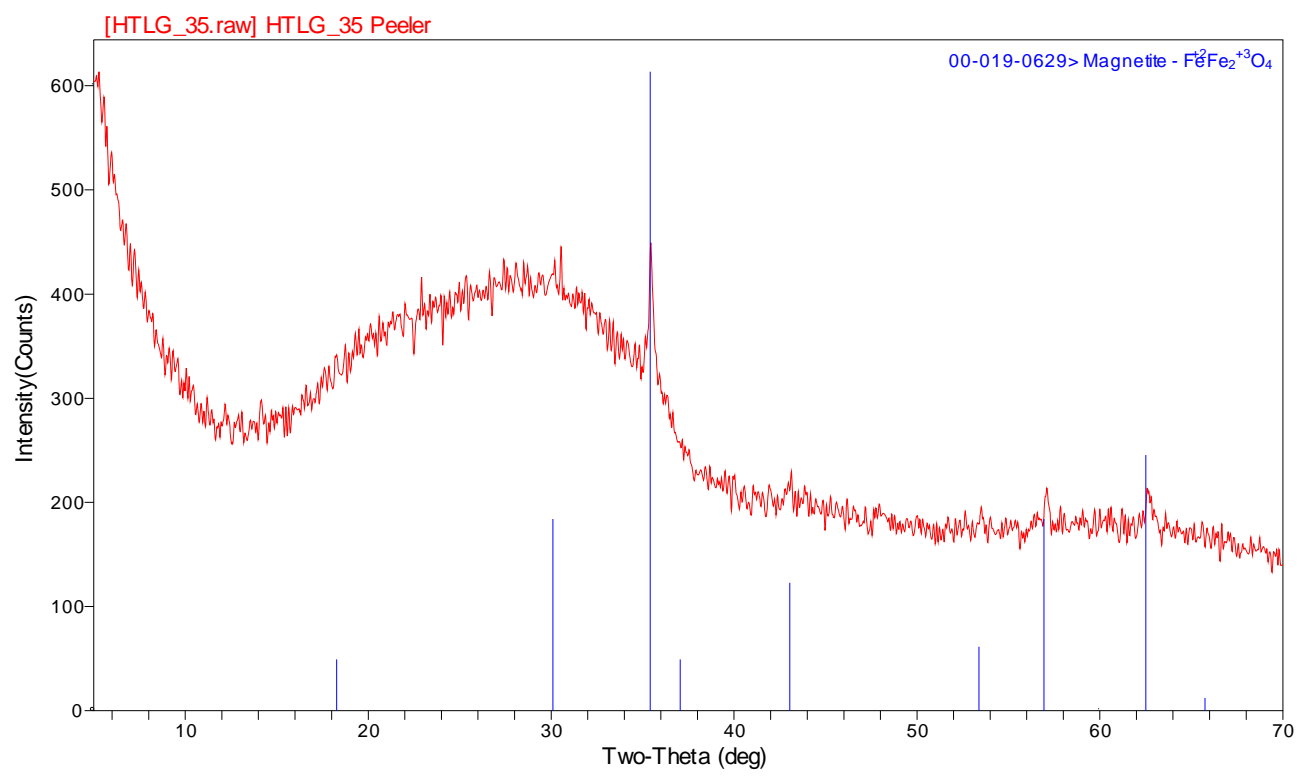

Figure C8. HTLG-35: 202-A11 @ 52\% WL

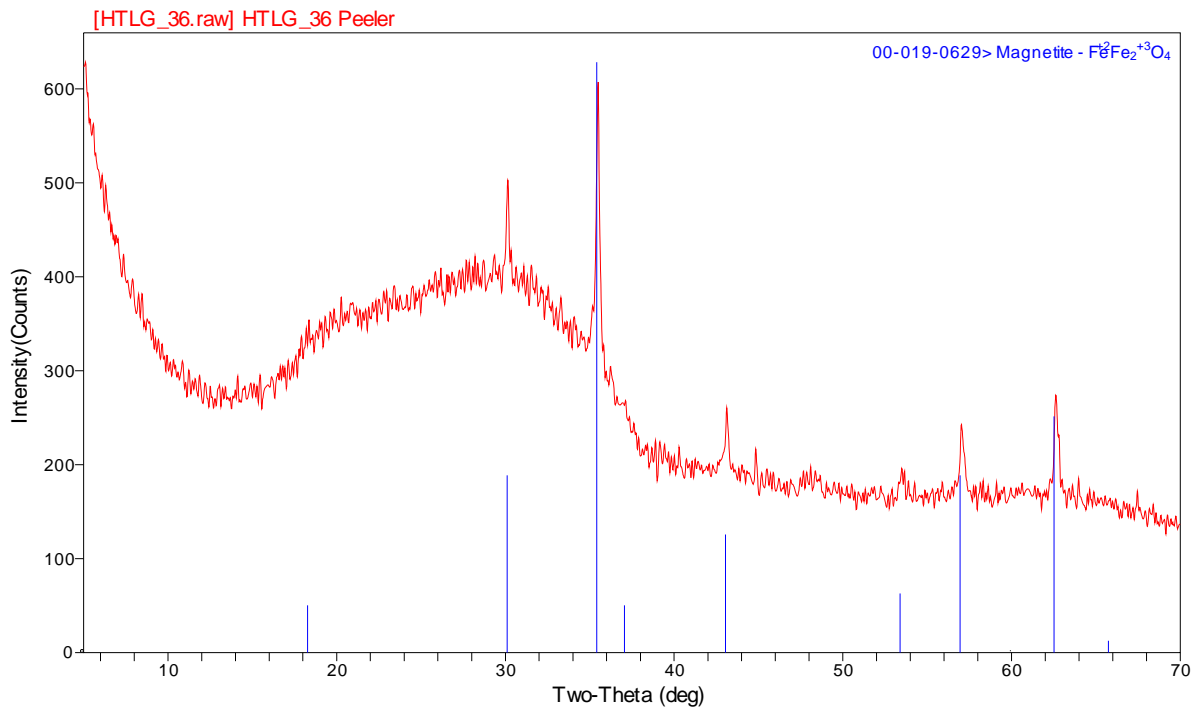

Figure C9. HTLG-36: 202-A11 @ 54\% WL 
WSRC-STI-2007-00302

Revision 0

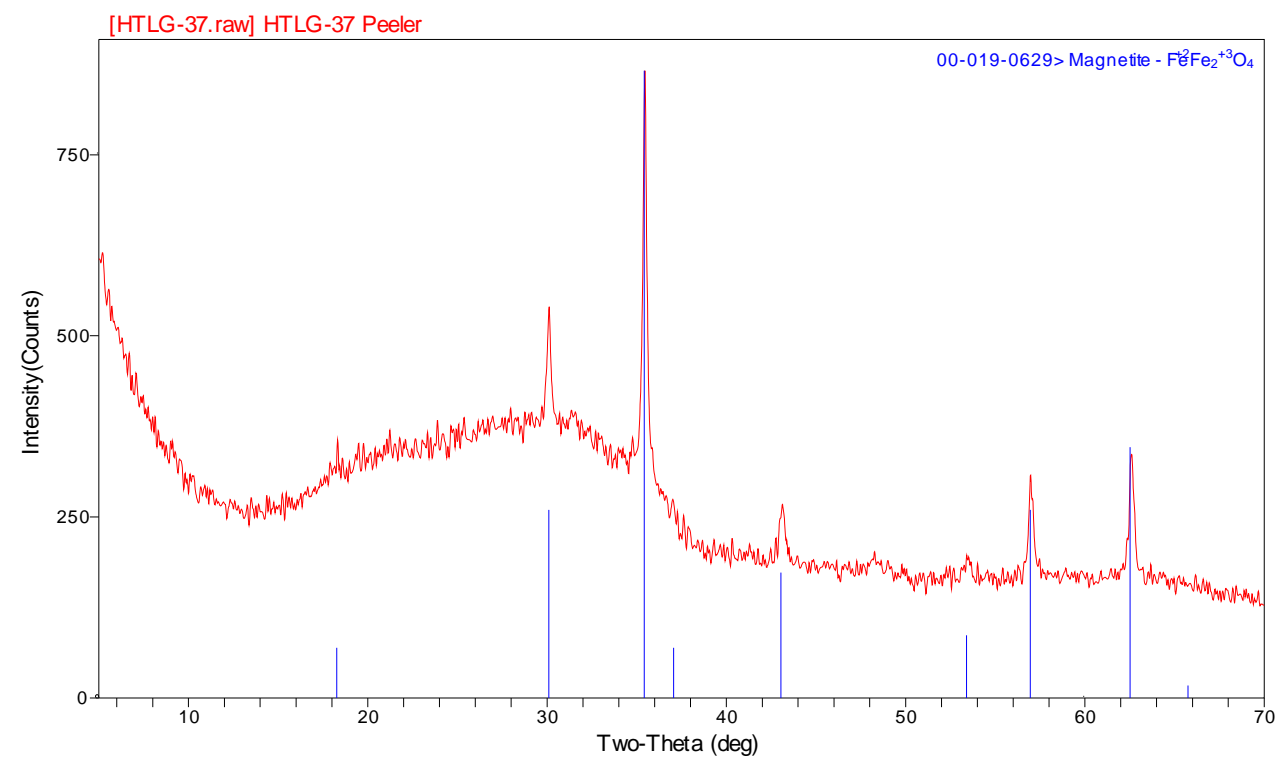

Figure C10. HTLG-37: 202-A11 @ 56\% WL

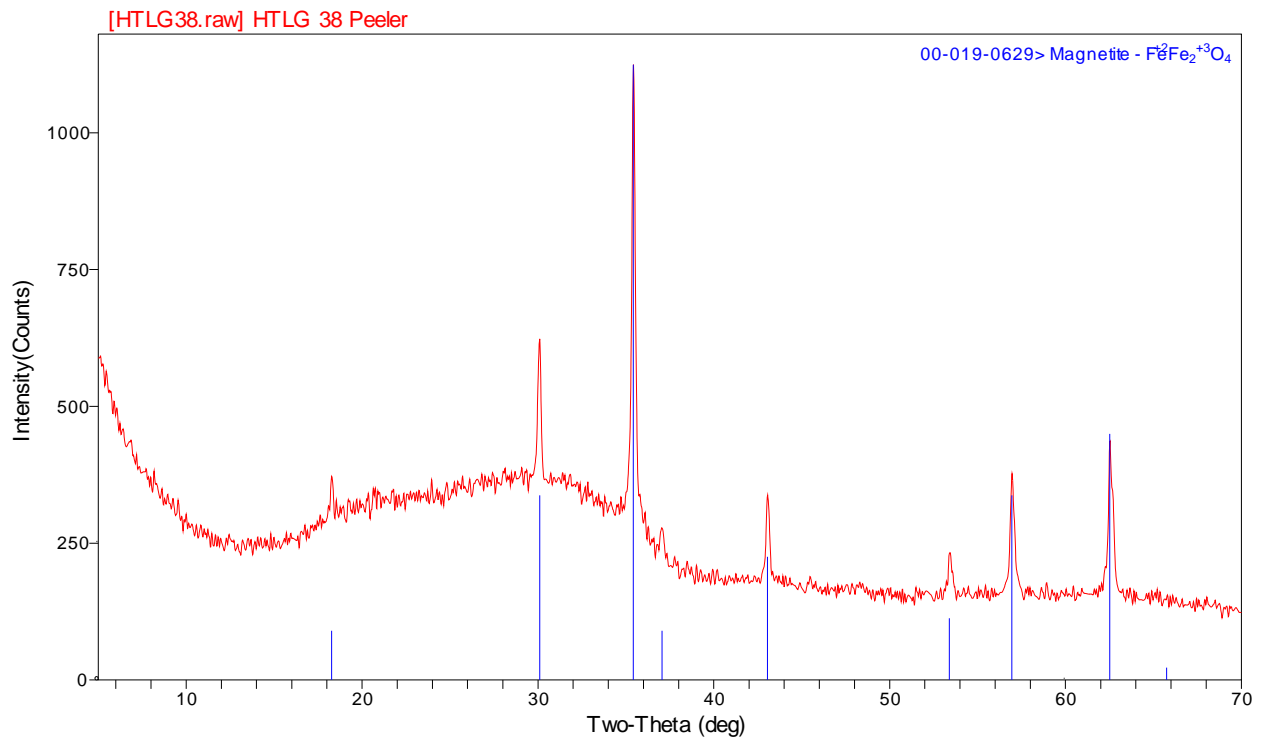

Figure C11. HTLG-38: 202-A11 @ 58\% WL 


\section{Glasses}

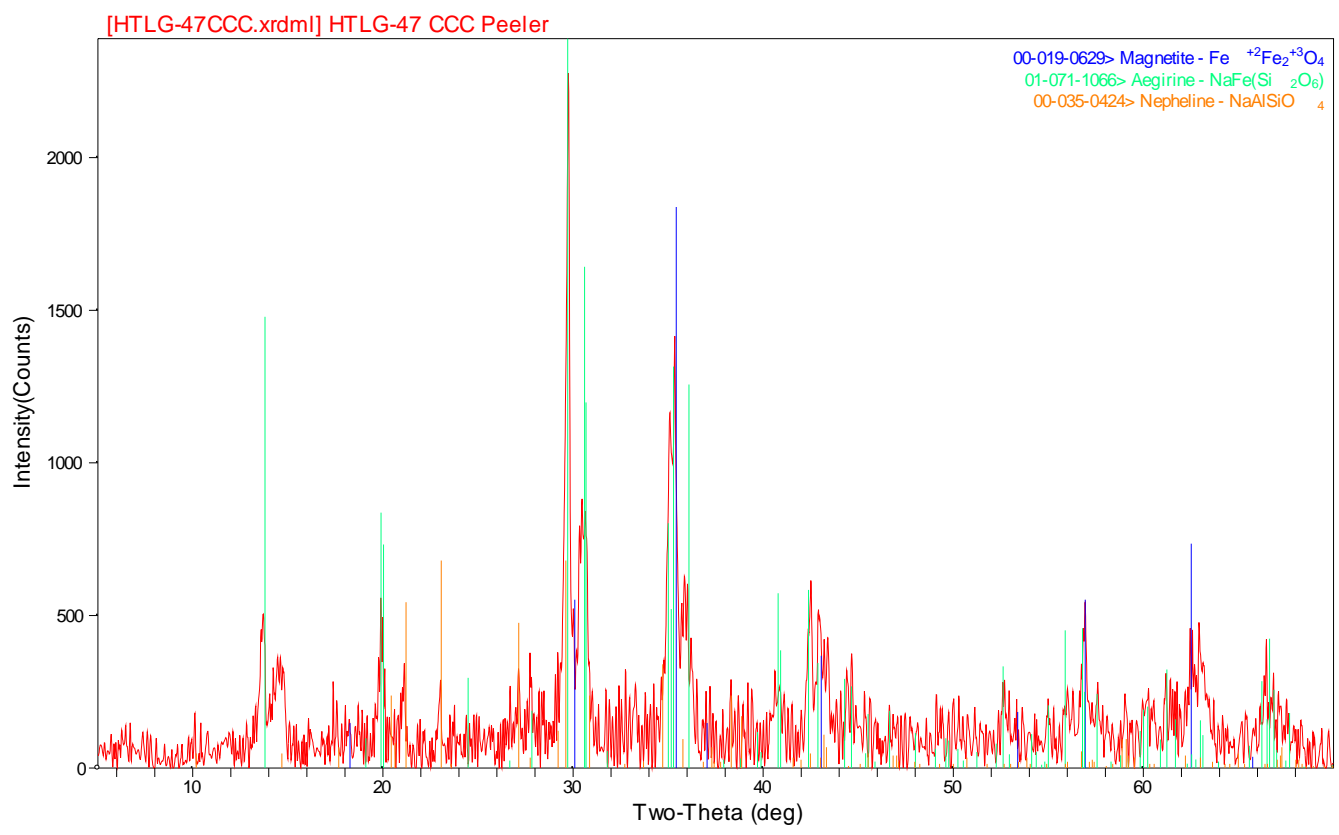

Figure C12. HTLG-47ccc: 202-A11 @ 45\% WL

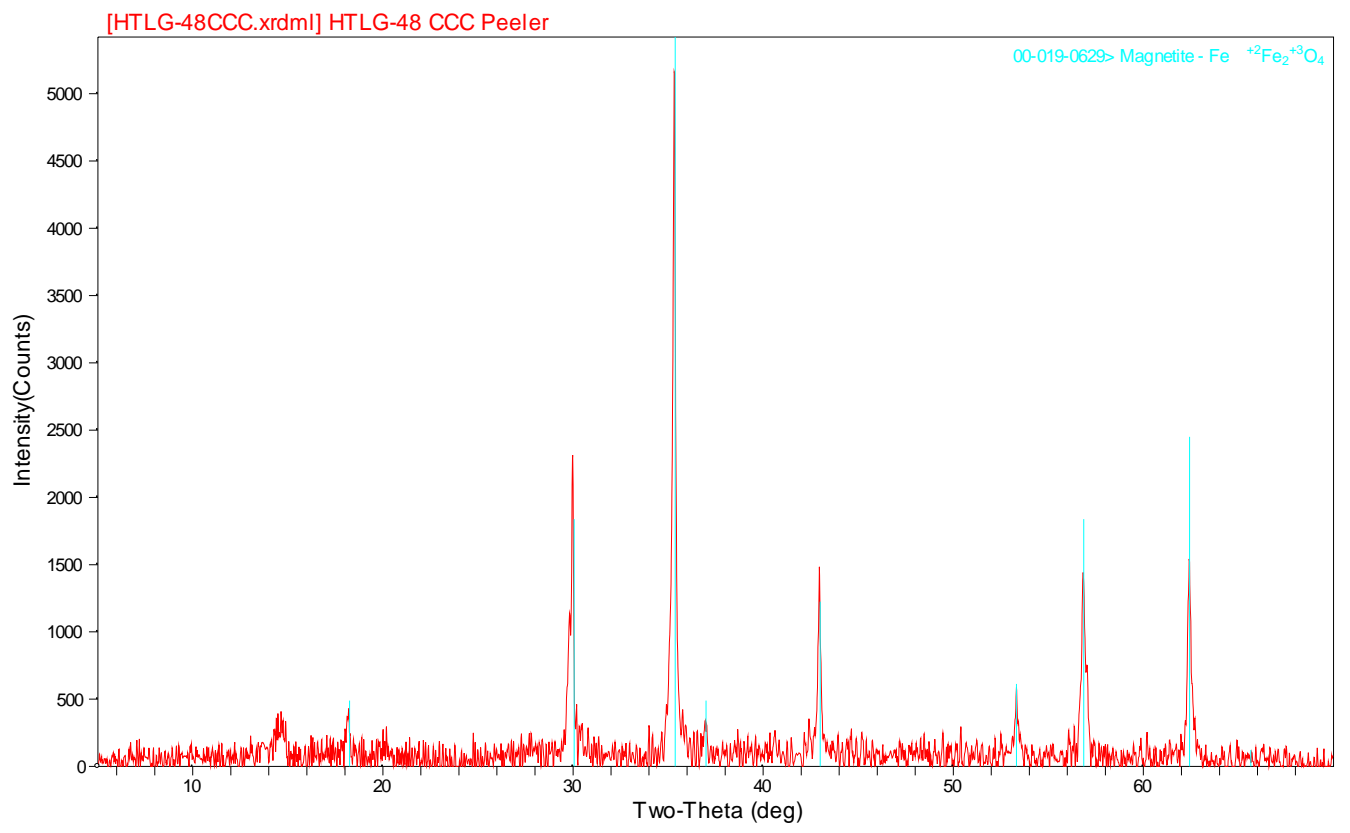

Figure C13. HTLG-48ccc: 202-A11 @ 50\% WL 


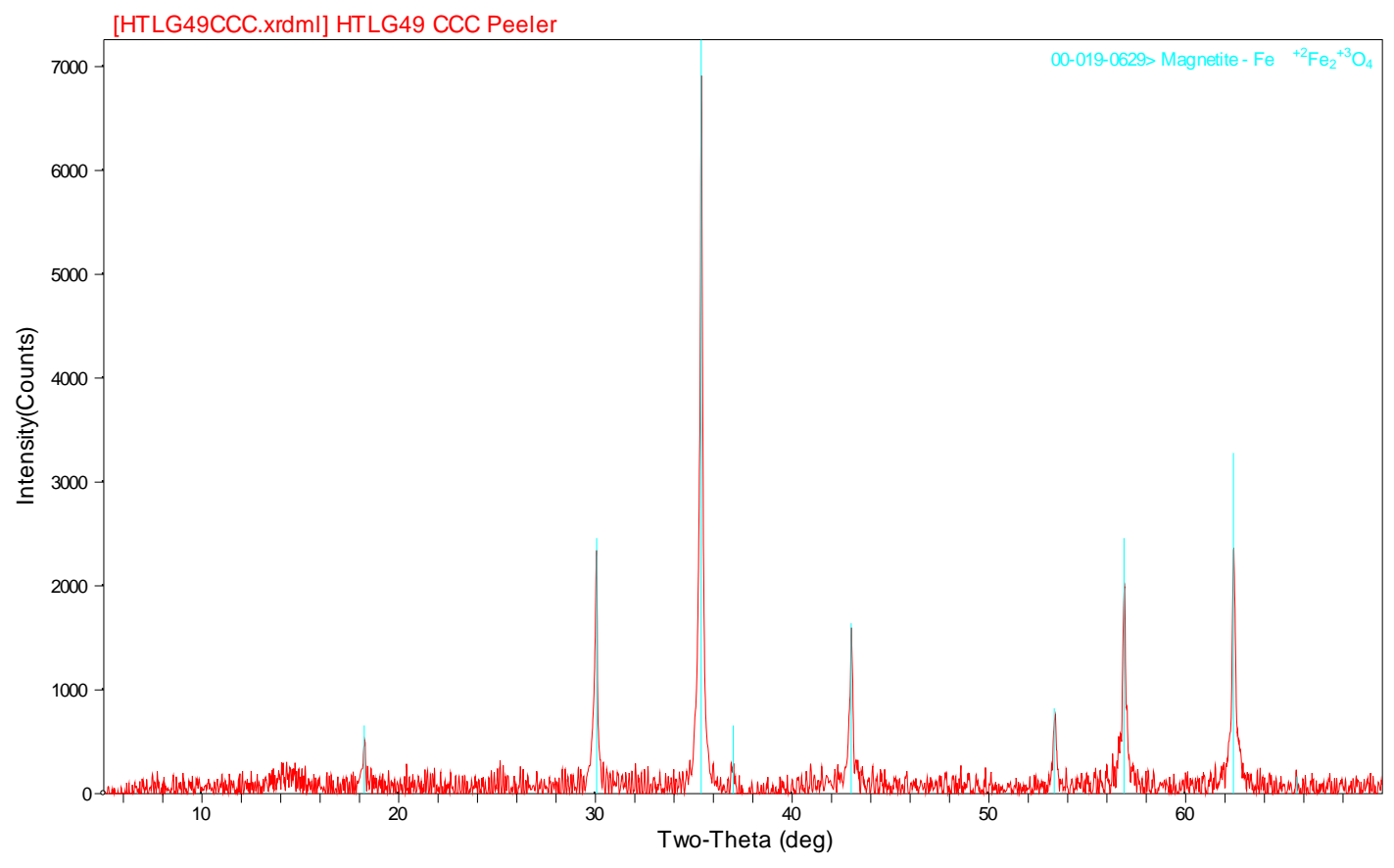

Figure C14. HTLG-49ccc: 202-A11 @ 55\% WL

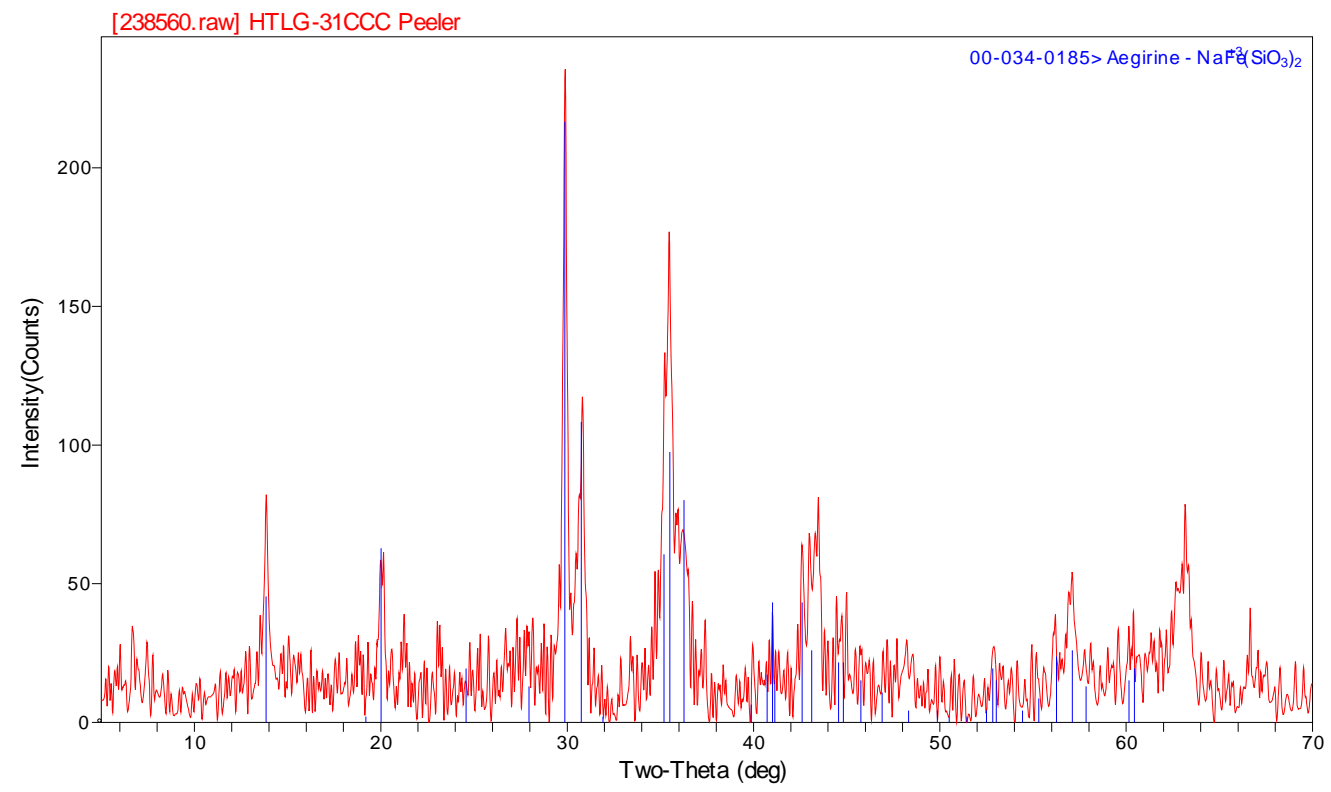

Figure C15. HTLG-31ccc: 202-A11 @ 44\% WL 
WSRC-STI-2007-00302

Revision 0

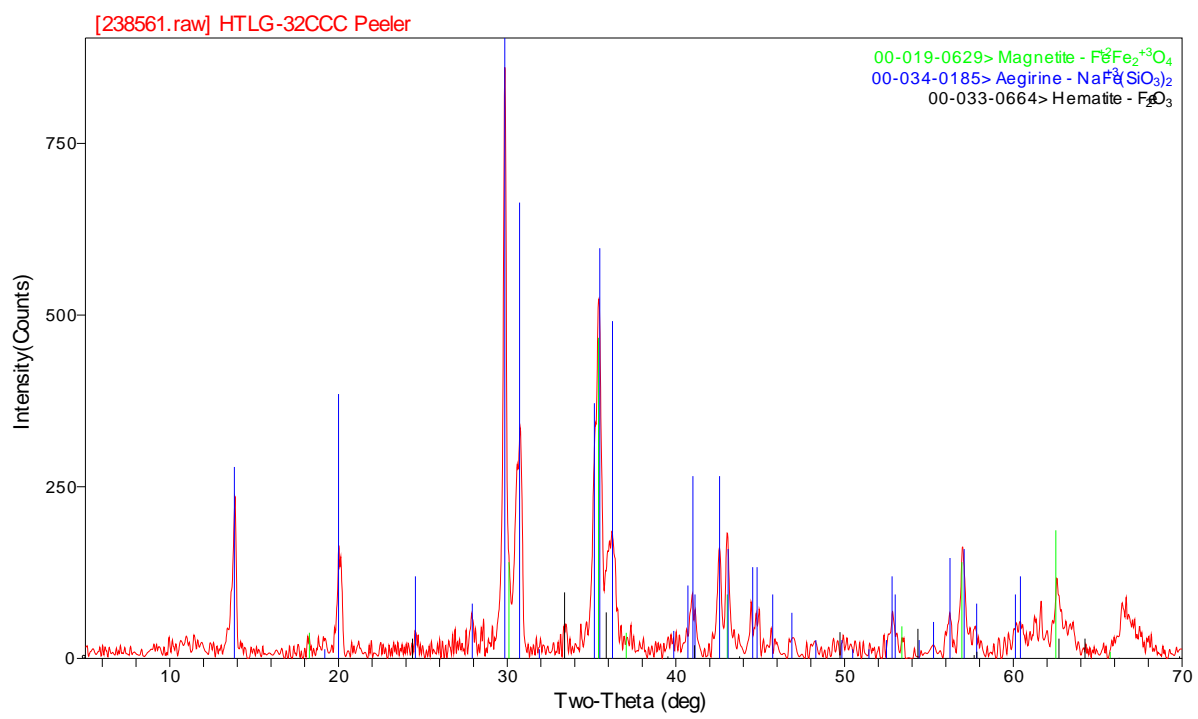

Figure C16. HTLG-32ccc: 202-A11 @ 46\% WL

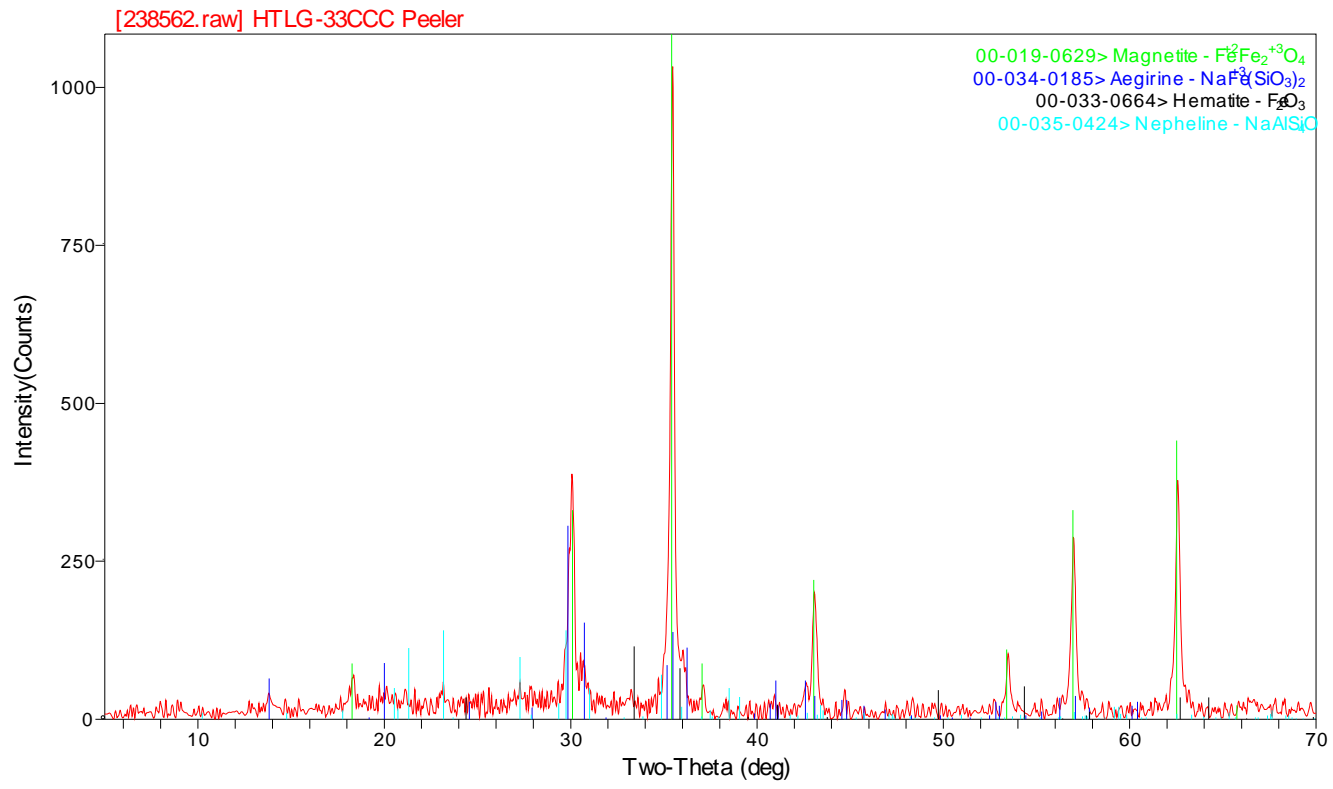

Figure C17. HTLG-33ccc: 202-A11 @ 48\% WL 
WSRC-STI-2007-00302

Revision 0

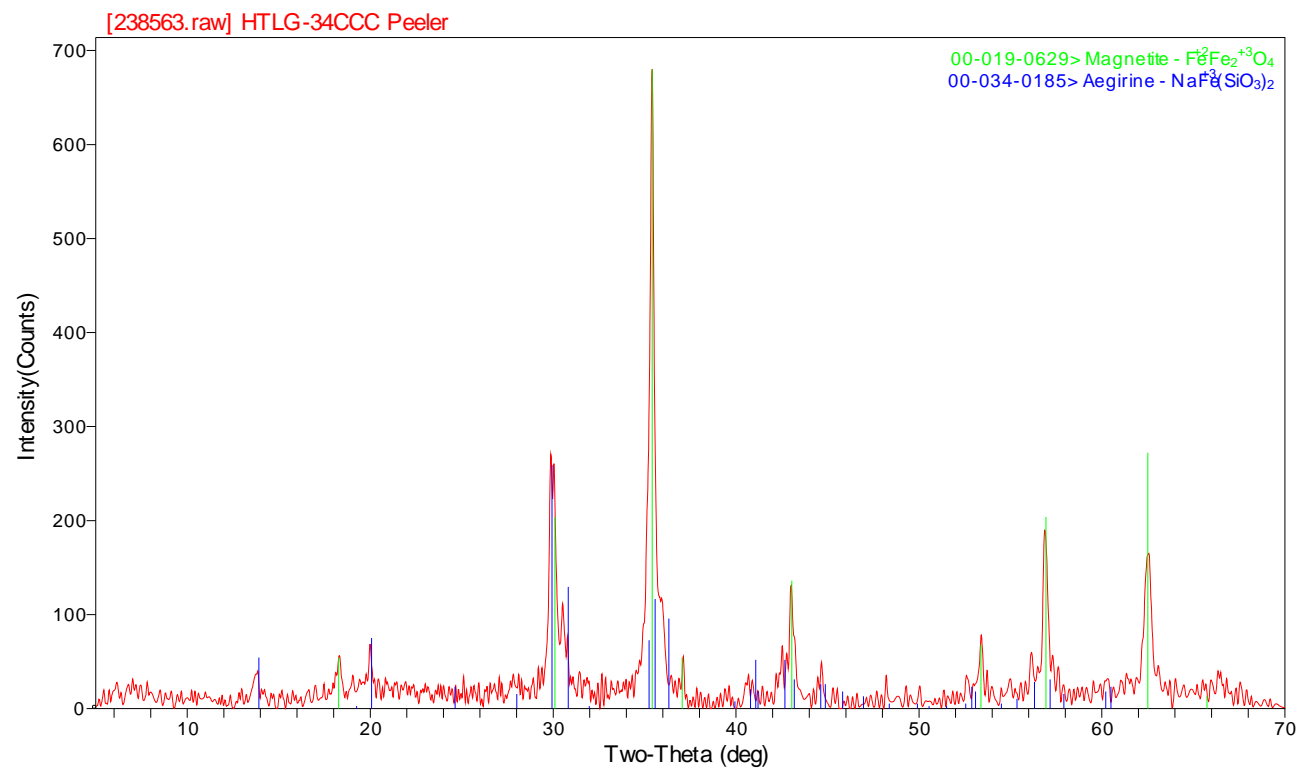

Figure C18. HTLG-34ccc: 202-A11 @ 50\% WL

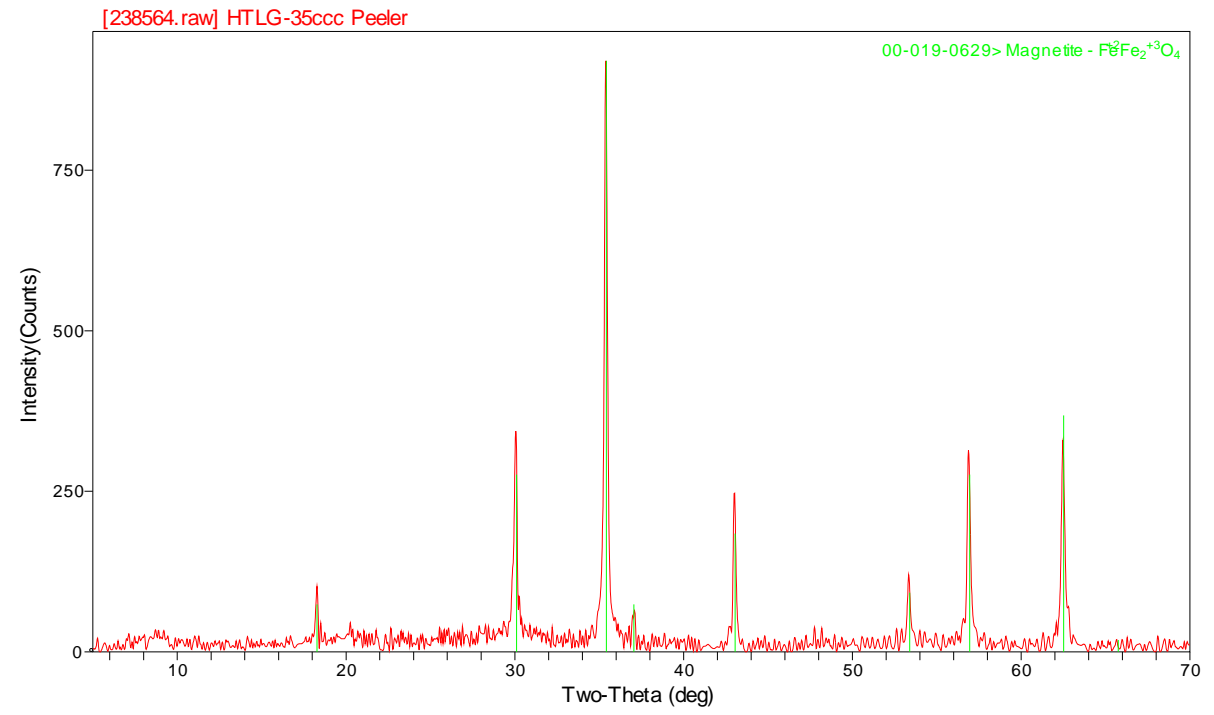

Figure C19. HTLG-35ccc: 202-A11 @ 52\% WL 
WSRC-STI-2007-00302

Revision 0

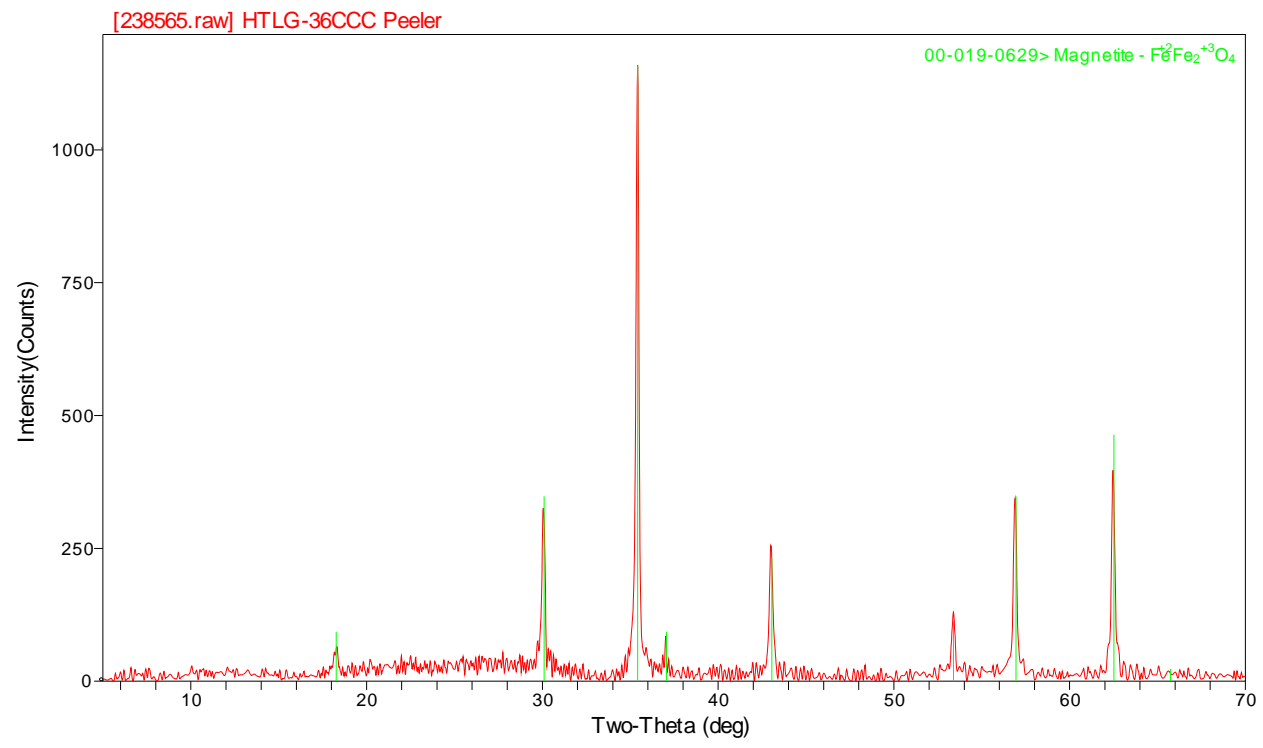

Figure C20. HTLG-36ccc: 202-A11 @ 54\% WL

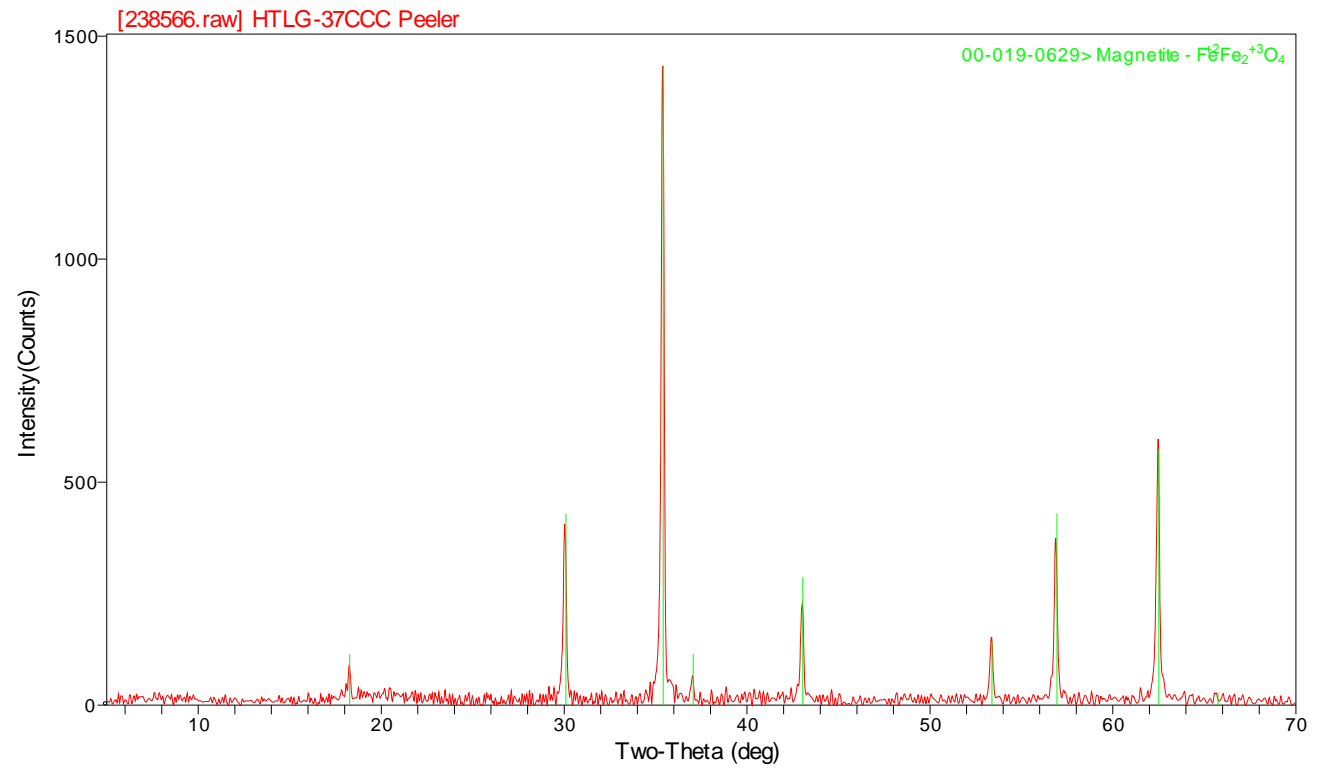

Figure C21. HTLG-37ccc: 202-A11 @ 56\% WL 
WSRC-STI-2007-00302

Revision 0

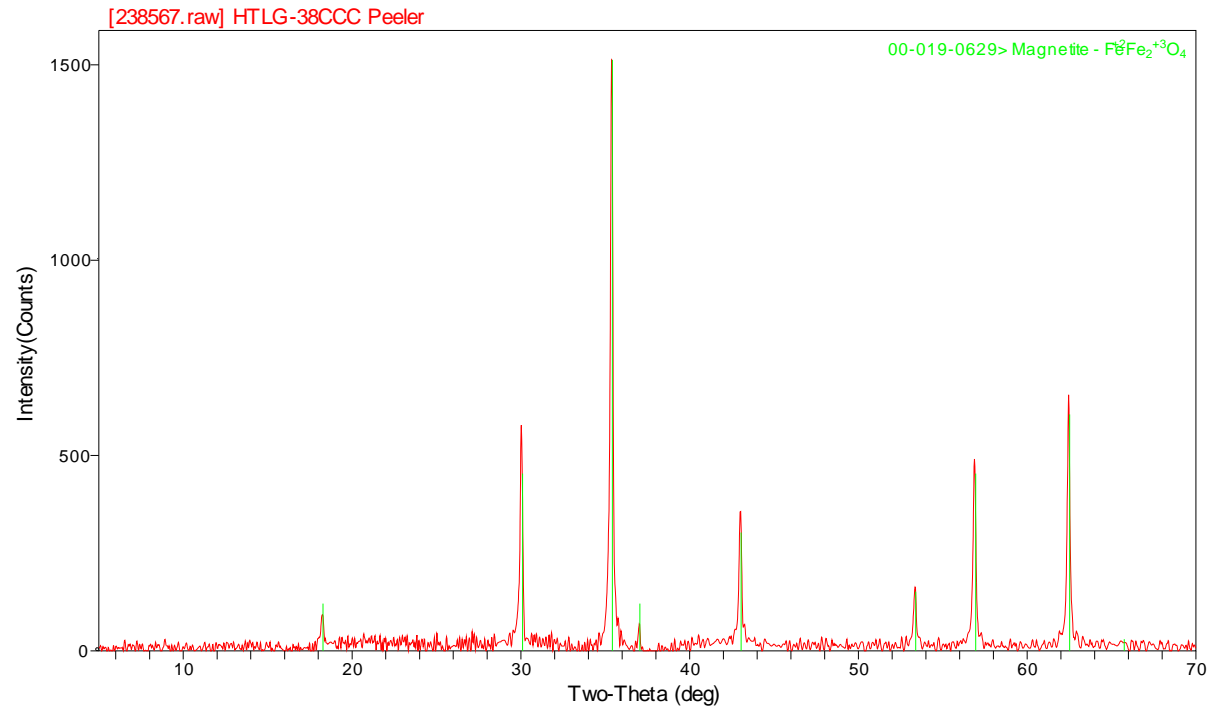

Figure C22. HTLG-38ccc: 202-A11 @ 58\% WL 
WSRC-STI-2007-00302

Revision 0

\section{Distribution:}

